SERVIÇO DE PÓS-GRADUAÇÃO DO ICMC-USP

Data de Depósito: $18.03 \cdot 2004$

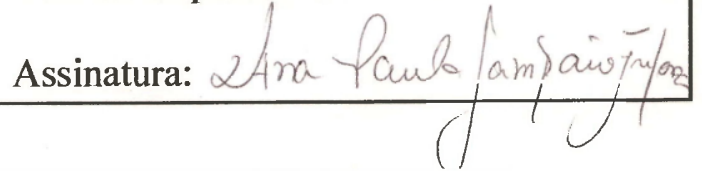

\title{
Uso de ontologia para classificação de vulnerabilidades em sistemas computacionais ${ }^{1}$
}

\author{
Antonio José dos Santos Brandão \\ Orientador: Prof. Dr. Edson dos Santos Moreira
}

Dissertação apresentada ao Instituto de Ciências Matemáticas e de Computação - ICMC-USP, como parte dos requisitos para obtenção do título de Mestre em Ciências da Computação e Matemática Computacional.

USP - São Carlos

$\mathrm{Março/2004}$

\footnotetext{
${ }^{1}$ Trabalho realizado com apoio financeiro da FAPESP. Processo $n^{\circ} .: 02 / 11307-5$
} 


\section{A Comissão Julgadora:}

Prof. Dr. Edson dos Santos Moreira

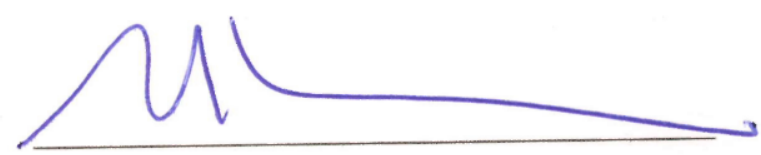

Prof. Dr. João do Espírito Santo Batista Neto__
Prof. Dr. Clovis Torres Fernandes 
Aos meus pais e itmãos,

A Iriane, é claro. 


\section{Agradecimentos}

À Dcus.

Aos meus pais, Estevam e Vera, pelo suporte psicológico e material.

À Iriane, minha esposa. Meu norte!

Aos meus irmãos, Júnior, Maria Clara e Verinha. Amo vocês.

Minha familia. Tios, primos, cunhados, Irred, Claudete. Pessoas especiais....

Fdson, meu orientador. Tantos anos de trabalho em conjunto. Tanta confiança depositada em mim.

\’ Fundação de Amparo à Pesquisa do Fstado de São Paulo, pelo apoio financeiro para realização da pesquisa.

Pessoal do Laboratório Intermídia. Aires, Martins, Taboca, Mauro, Dani, Bola, Boni, Roger, Chico, Rudinei, Mauro, Luciana, Rodrigo, Felix, Robson, Crawler e tantos outros. Essa foi minha segunda casa, seis anos de histórias para contar.

Fdílson, Leo, Carlos e Mello. Companheiros!

Professores e funcionários do ICMC. Fazer além do dever, com vontade e bem feito. F́. essa a imagem que levo de vocês.

Meus amigos de Garça. Os garcenses. Se não fossem os churrascos, os trucos e as histórias então acho que tudo seria mais difícil.

Todos aqueles que, de uma forma ou de outra, contribuíram para que eu chegasse até aqui torceram por mim. 


\section{Resumo}

Com o aumento da complexidade dos sistemas computacionais, fez-se necessária a utilização de diversas ferramentas para simplificar o processo de detecção de intrusão e de manutenção da segurança. A grande maioria dessas ferramentas baseia-se na geração de mensagens, denominadas alertas, que informam ao administrador sobre eventos ocorridos. Atualmente, não há uma classificação que permita interoperabilidade semântica dos alertas gerados pelas diferentes aplicações, fato que motivou este trabalho de mestrado, que visa estudar e propor o uso de uma ontologia para classificar vulnerabilidades de segurança.

A partir dessa motivação, foram iniciados estudos para a modelagem de uma ontologia de vulnerabilidades, especificando suas classes, atributos e relacionamentos. A ontologia proposta foi implementada utilizando a linguagem OWL e as informações catalogadas pelo projeto CVl: (Common V ulnerabilities and Exposures). Diversas vulnerabilidades foram classificadas e foram efetuados testes usando a linguagem RDQL, os quais permitiram comprovar a viabilidade na extração de informações da ontologia. 


\section{Abstract}

Computational systems have become complex therefore usually the use of diverse tools is necessary to ease the task of intruders' detection and security maintenance. The most tools are based in messages generation, called alerts, that inform administrators about occurred events. Currently, that's no classification that permit the correlation of alerts generated from different applications, fact that motivated this work, that aims to study and to consider the use of ontology to classify computer vulnerabilities.

The modeling of an ontology of vulnerabilities was done, with the specification of its classes, properties and relationships. The ontology was implemented using the OWL language and the database from CVE (Common Vulnerabilities and Exposures) project was used as source of information on vulnerabilities. Vulnerabilities have been classified in the ontology and some tests had been done using the RDQL language to ensure the viability to extract information from the ontology. 


\section{Lista de Figuras}

lïigura 1 - Exemplo de ataque classificado na ontologia de Pinkston et al. (2003) …...........................................17

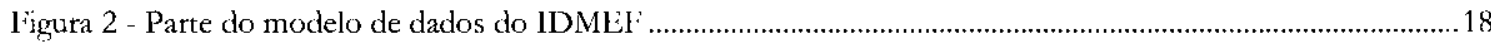

Figura 3 - Representação de ataque no padrào IDMEF (Curry \& Debar, 2003) ….................................................20

Figura 4 - Descoberta de vulnerabilidades com a utilização do CVE (Martin, 2001) …............................................2.

Figura 5 - Níveis de abstração em um domínio (Fukuda, 1995) ….........................................................................28

Figura 6 - Fistrutura de uma ontologia segundo I luhns e Singh (1997) ............................................................29

lïgura 7 - Ilustração de ontologia de bebidas (Sowa, 2002) …...............................................................................30

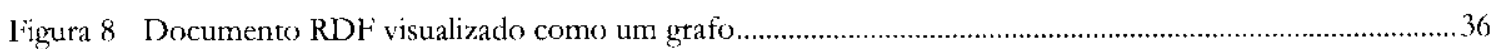

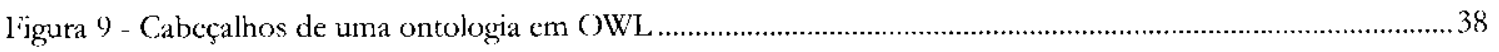

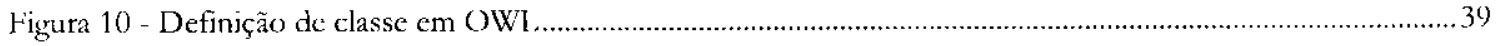

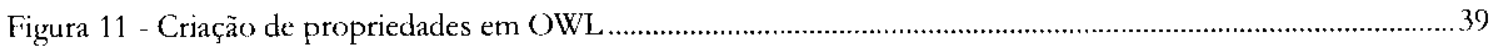

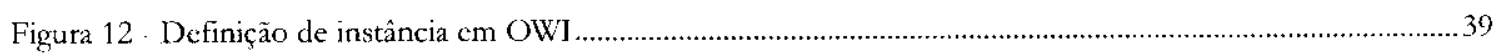

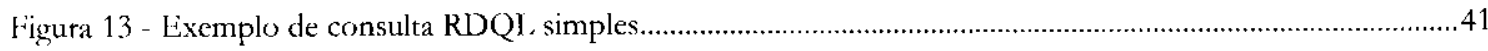

lïgura 14 - Arquitetura da Web Semântica (Kojvunen \& Miller 2001) …...............................................................42

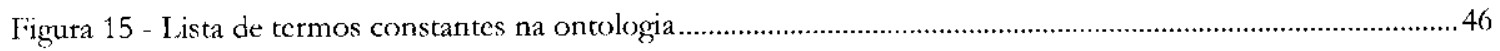

lïgura 16 - Hierarquia de termos para formação de classes e subclasses ...............................................................47

Fïgura 17 - Modelo conceitual da ontologia desenvolvida …........................................................................... 51

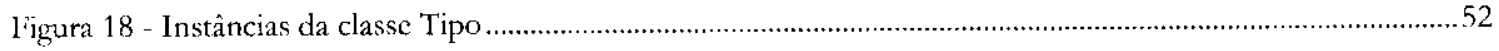

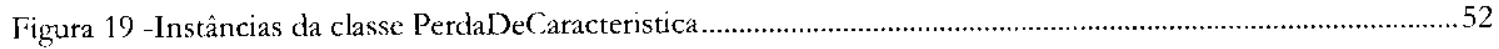


Figura 20 - Instâncias da classe Gravidade

Fïgura 21 - Instâncias da classe ComponenteAfetado

Figura 22 - Instâncias da classe Abrangencia .

Figura 23 - Cabeçalhos da ontologia implementada

Figura 24 - Exemplo de implementação: a classe Vulnerabilidade.

Figura 25 - Fxemplo de implementação: instância da classe Vulnerabilidade

Figura 26 - Consulta RDQL para busca por correções da vulnerabilidade CAN -2002-0387

lïgura 27 - Consulta RDQL para busca de vulnerabilidades exploradas pelo worm CODERHD

Figura 28 - Consulta RDQL para busca de worms que exploram a vulnerabilidade CVE-2001-0333

Figura 29 - Consulta RDQL para busca de nome e versão de produtos afetados pela vulnerabilidade CVLE-20010333

Figura 30 - Consulta RDQI para busca de vulnerabilidades que ocorrem no produto IIS 4.0

Figura 31 - Consulta RDQL para busca por worms que afetam o produto IIS 4.0.

Figura 32 - Consulta RDQL para busca por pré-requisitos para a exploração da vulnerabilidade CAN-1999-054766

I:igura 33 - Consulta RDQL para busca por vulnerabilidades que são exploradas em conjunto a CAN-2000-088467

Figura 34 - Consulta RDQL para busca por vulnerabilidades graves que possam ser exploradas remotamente ....67

Figura 35 - Consulta RDQL para busca por vulnerabilidades do tjpo BufferOverflow com conseqüência a perda de disponibilidade. .68 


\section{Lista de Tabelas}

Tabela 1 . Exemplo de diferentes nomes para uma vulnerabilidade (Martin, 2001)

'Tabela 2 - Resultado da busca por correções de uma vulnerabilidade.

Tabela 3 - Resultado da busca de vulnerabilidades exploradas por dado worm .64

Tabela 4 - Resultado da busca de nome e versão de produtos afetados por determinada vulnetabilidade.

Tabela 5 - Resultado da busca de vulnerabilidades que ocorrem em determinado produto

Tabela 6 - Resultado da busca por worms que afetam determinado produto .66

Tabela 7 - Resultado da busca por pré-requisitos de uma vulnerabilidade

Tabela 8 - Resultado da busca por vulnerabilidades que são exploradas em conjunto com uma outra vulnerabilidade

Tabela 9 - Resultado de busca por vuinerabilidades graves que possam ser exploradas remotamente

'Tabela 10 - Resultado da busca por vulnerabilidades por meio do tipo e da conseqüência da exploração 


\section{Sumário}

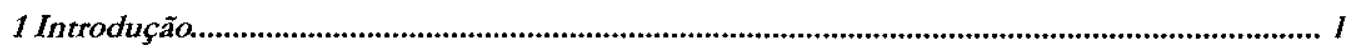

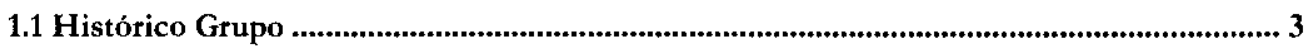

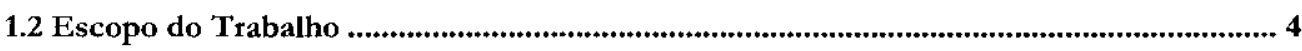

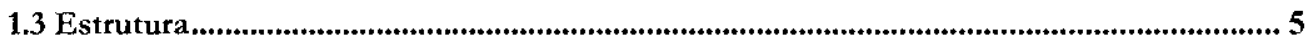

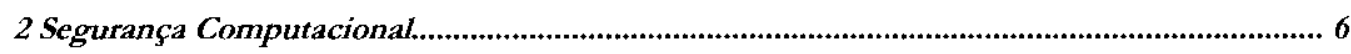

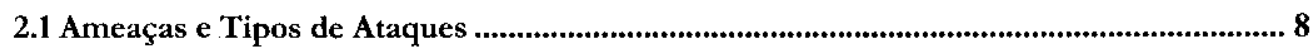

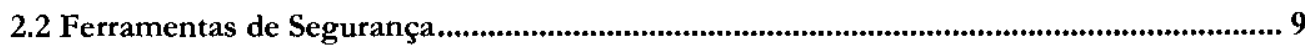

2.2.1 Monitoramento de Rede ................................................................................. 10

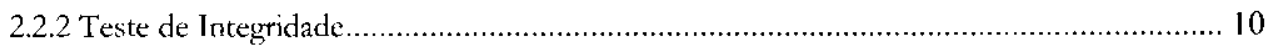

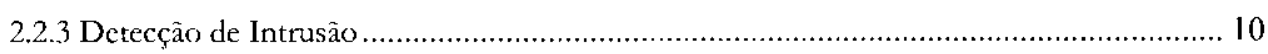

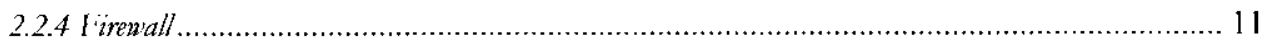

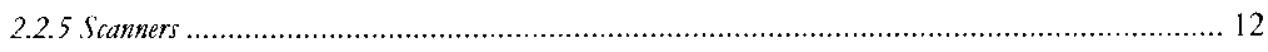

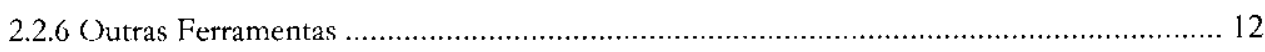

2.3 Características para Classificação das Ferramentas.......................................................... 13

2.3 .1 'lempo de tixecução ....................................................................................... 13

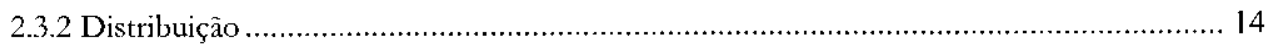

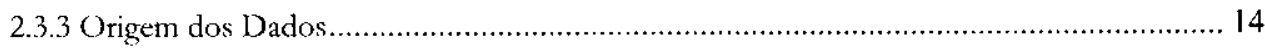

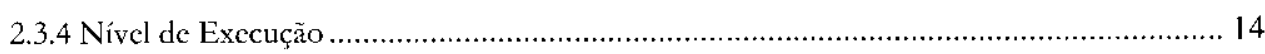

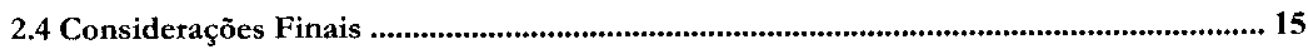

3 Iniciativas para Catalogação e Classificação de Vulnerabilidades....................................... 16

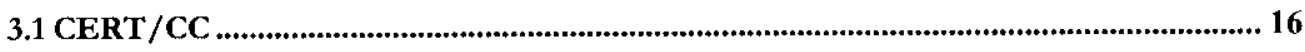

3.2 Trabalhos de Uso de Ontologias em Segurança Computacional...................................... 17

3.3 Intrusion Detection Message Exchange Format (IDMEF) ........................................... 17

3.4 Commom Vulnerabilities and Exposures (CVE) .......................................................... 20

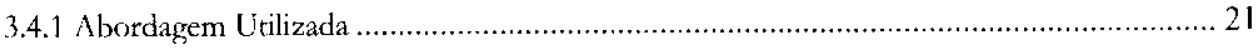

3.4.2 Metodologia de Manutençào do Repositório ............................................................. 23

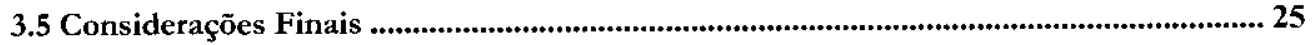




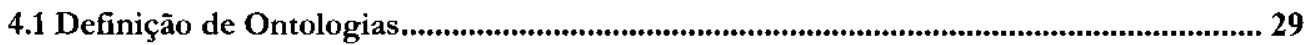

4.2 Custos e Benefícios do Uso de Ontologias ...................................................................... 31

4.3 Abordagens para construção de Ontologias...................................................................... 32

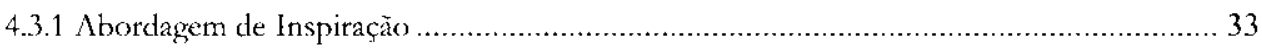

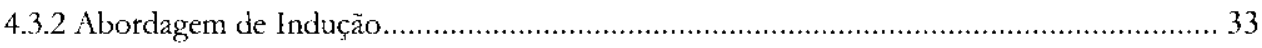

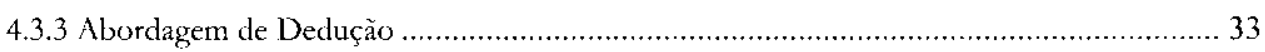

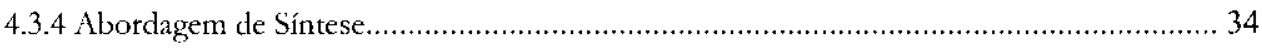

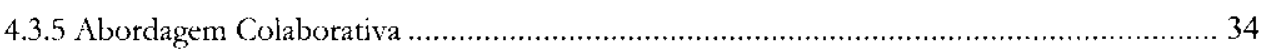

4.4 Linguagens para Representação de Ontologias................................................................35

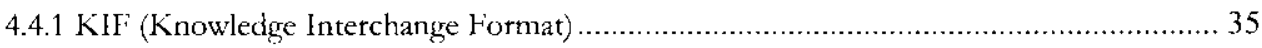

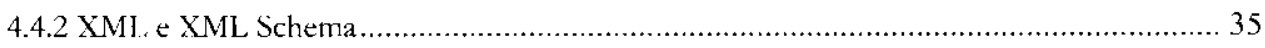

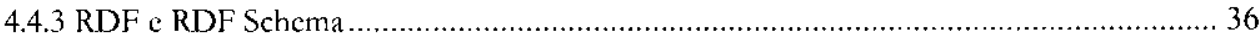

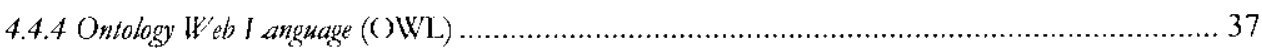

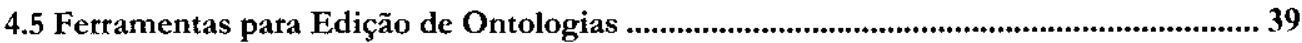

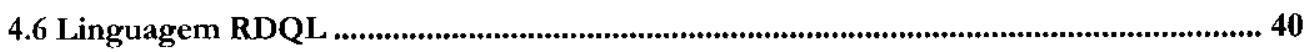

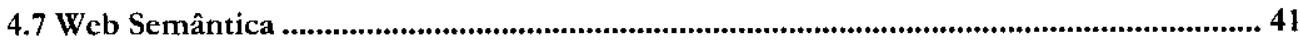

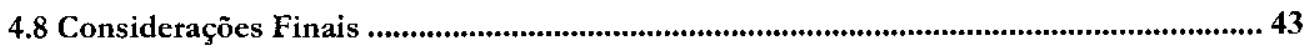

5 Uso de Ontologia para Classificação de Vulnerabilidades cm Sistemas Computacionais.... 44

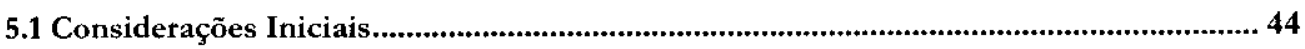

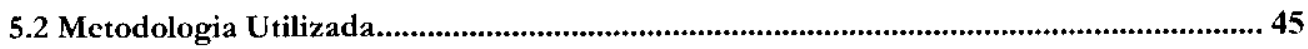

5.2.1 Determinação do domínio e escopo da ontologia ....................................................... 45

5.2 .2 Linumeração de termos importantes no domínio ................................................. 46

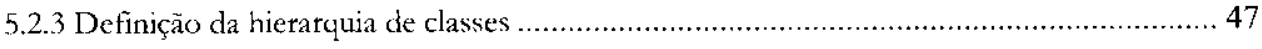

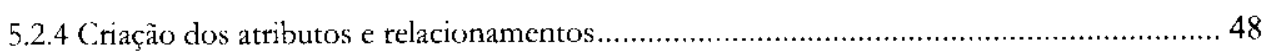

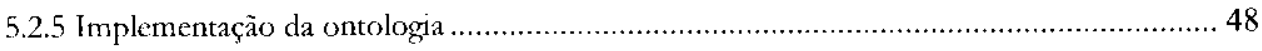

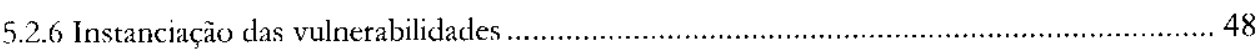

5.3 Modelo Conceitual da Ontologia Proposta ........................................................................ 49

5.4 Descrição das Classes e Relações da Ontologia............................................................ 52

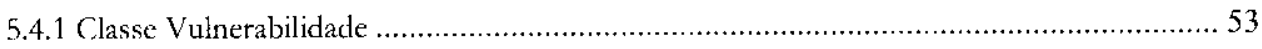

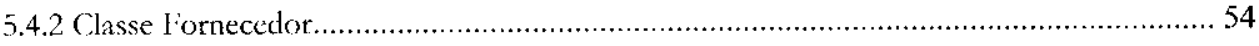

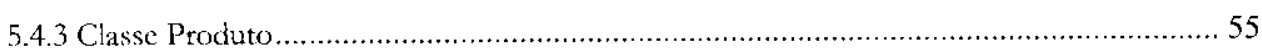




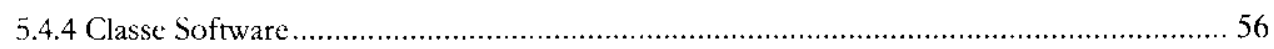

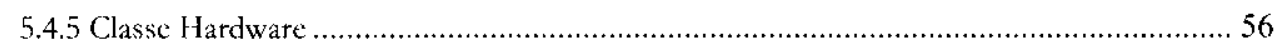

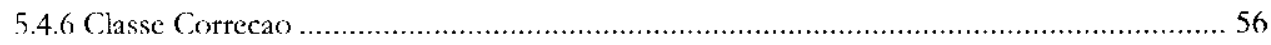

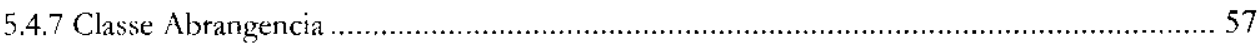

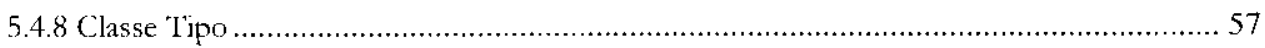

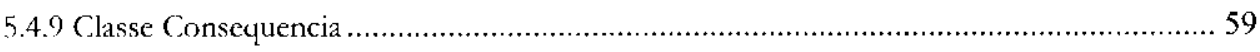

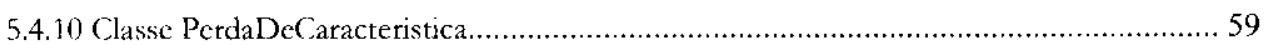

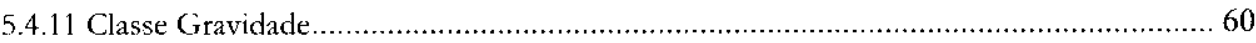

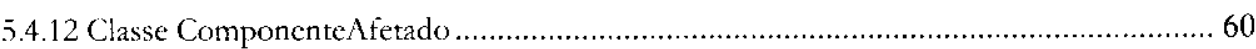

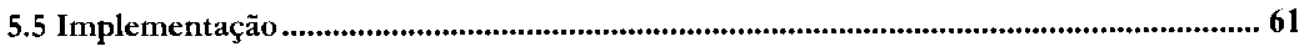

5.6 Testes efetuados no sistema implementado..................................................................62

5.6.1 Teste 1: Busca por correções de uma vulnerabilidade ............................................... 63

5.6.2 'leste 2: Busca por relações entre vulnerabilidades e worms......................................... 63

5.6.3 Teste 3: Busca por relacionamentos entre Vulnerabilidades e Produtos ......................... 64

5.6.4 'leste 4: Busca por relacionamento entre duas ou mais Vulnerabilidades........................ 66

5.6 .5 Teste 5: (Outras Buscas por Vulnerabilidades ....................................................... 67

5.7 Benefícios do uso de Ontologia de Alertas de Segurança .............................................69

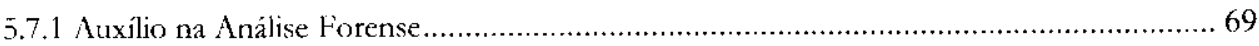

5.7 .2 Correlacionamento de alertas em tempo real ..................................................... 70

5.7 .3 Indicar a aplicação de correções (patches) .......................................................... 71

5.7.4 Documentar o conhecimento tácito $\mathrm{cm}$ segurança computacional ............................... 72

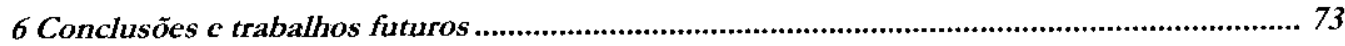

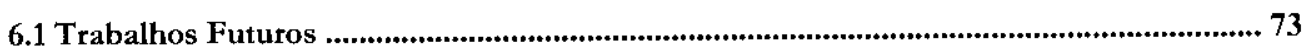

6.1.1 Classificar o restante das vulnerabilidades do projeto CVE....................................... 73

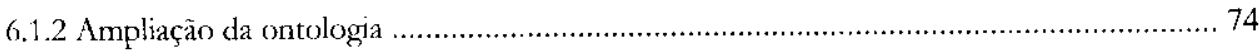

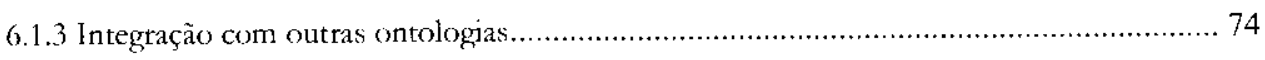

6.1.4 Desenvolvimento de ferramentas de segurança ................................................... 74

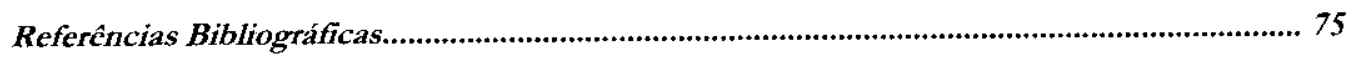

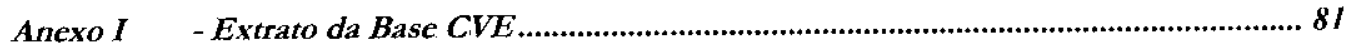

Anexo II - Código OWL da ontologia implementada...................................................... 87 


\section{Introduçio}

A conectividade de negócios via Internet e o compartilhamento de dados tornaram a informação um dos bens mais importantes e vulneráveis das empresas. Além disso, é crescente a demanda por aplicações on-line para diversos segmentos como: bancos, ensino à distância, comércio eletrônico e portais colaborativos. Devido a tais fatores, incidentes em redes de computadores passaram, cada vez mais, a afetar resultados de negócios e, conseqüentemente, a capitalização das corporaçōes.

Recente pesquisa aponta que nos últimos meses, $77 \%$ das grandes empresas brasileiras afirmaram ter sofrido algum tipo de invasão. Atualmente, 78\% das empresas no Brasil acreditam no aumento dos problemas relacionados à segurança da informação (Módulo, 2003).

Devido à complexidade das redes a serem administradas e à grande quantidade de serviços que podem apresentar eventuais falhas, diversas ferramentas foram desenvolvidas para ajudar os administradores na tarefa de descobrir quais vulnerabilidades estão presentes em seus sistemas.

Tais ferramentas têm bases de dados contendo assinaturas de ataques, cada uma organizada de forma particular e sem contar com cadastro de todas as vulnerabilidades existentes. $\mathrm{Na}$ verdade, essas bases de ataques são inerentemente incompletas, pois as ferramentas são designadas para detectar classes específicas de ataques. Por exemplo, os network scanners são ferramentas limitadas à detecção de vulnerabilidades exploráveis via rede $e$ por isso só têm cadastro desses ataques. 
Adiciona-se a esse cenário o fato das arquiteturas de segurança contemplarem o uso de diversas ferramentas e, muitas vezes, ser necessário correlacionar informações fornecidas por cada uma delas. Por exemplo, se um Sistema de Detecção de Intrusão (SDI) acusa um ataque, um scanner deve ser utilizado para descobrir quais máquinas estão expostas à vulnerabilidade. Atualmente, cabe ao administrador a tarefa de executar essa correlação entre os alertas.

Diferentes institutos de pesquisas têm realizado esforços no sentido de catalogar e classificar dados e informações relacionadas à segurança computacional. O projeto CVE: (Common Vulnerabilities and Exposures), desenvolvido no Instituto Mitre', apresenta um padrão para nomenclatura de vulnerabilidades que facilita a identificação de uma mesma vulnerabilidade em diferentes ferramentas (Mann \& Christey, 1999).

O CFRT/CC (Computer Emergency Response Team/Coordination Center) ${ }^{2}$, centro de informações de segurança computacional fundado pela Universidade de Carnegie Mellon nos Estados Ĺnidos, armazena grandes quantidades de dados relacionadas a vulnerabilidades, incidentes de segurança, alertas de vírus, entre outras.

Apesar dos avanços das iniciativas CERT e CVE, tais esforços não agregam semântica às informações das vulnerabilidades armazenadas e divulgadas. Entende-se por semântica a capacidade de processar o significado dos conceitos e não apenas a estrutura da informação. Sem o entendimento semântico, o agente de software fica incapaz de fazer relacionamentos, seja entre alertas de diferentes fontes, seja entre vulnerabilidades divulgadas por uma mesma fonte. Essa correlação é importante para estabelecer um vocabulário de conceitos e relacionamentos único e formal a respeito de um determinado domínio de aplicação.

\footnotetext{
${ }^{1}$ http://cve.mitrcorg

2 http://www.ccttotg
} 
A problemática de representação semântica acontece, também, em outros domínios do conhecimento, fazendo com que diversos pesquisadores estudem e apliquem ontologias no sentido de estabelecer um vocabulário único. Ontologias são representações formais dos conceitos de um domínio e suas relações (Gruber, 1995; Grüninger \& Fox, 1995; Guarino \& Giaretta, 1995; Uschold \& King, 1995; Uschold \& Gruninger ,1996; Fernández-López, 1996; Pacheco \& Kern, 2001; Grüninger \& I Lee, 2002; Herrera et al., 2002; Martimiano, 2003).

\subsection{Histórico Grupo}

O) Grupo de Segurança da Informação do Laboratório Intermídia do ICMC-USP iniciou seus trabalhos no início da década de 1990 com projetos relacionados ao gerenciamento de redes de computadores (Oda, 1994; Cicilini, 1994; Lieira, 1995; Moraes, 1995, Morishita, 1997). Já foram feitas pesquisas na área de segurança computacional com sistemas detectores de intrusões que usam redes neurais para o reconhecimento de padrões de ataques (Bonifácio, 1998; Cansian, 1997) e aplicam a tecnologia de agentes móveis para o gerenciamento da segurança (Reami, 1998), integração com sistema de gerenciamento SNMP (Brandão \& Moreira, 2002) e verificação de anomalias (Bernardes, 2000). Também foram desenvolvidas pesquisas sobre ambientes servidores para agentes móveis e ferramentas que conferem inteligència a tais agentes (Ambrósio, 2002).

A partir do segundo semestre de 2001, o grupo passou a integrar, juntamente com o Núcleo de Manufatura Avançada, a iniciativa brasileira pela cooperação com o projeto internacional DEEPSIA ${ }^{3}$, estabelecido por um consórcio entre diversas instituições e empresas européias, com o apoio da Information Society Technologies (IST).

Tal projeto estuda o uso de ontologias em Comércio Eletrônico e técnicas de busca, classificação, armazenamento e recuperação de informações de produtos a serem utilizadas em processos de compra na web.

3 http://www.decpsia.com 
Atualmente, o grupo de segurança está envolvido nas seguintes pesquisas: Bernardes (2002) propõe modelar sistemas de segurança computacional como sistemas de informação a fim de integrar e gerar informações a partir de dados coletados nas diversas fontes de dados de segurança. Visando facilitar essa integração, o gerenciamento dessas informações e, conseqüentemente, a tomada de decisão dos administradores de sistemas de segurança, Brandão (2002) e Martimiano (2003) pesquisam o uso de ontologias para atribuir semântica $\mathrm{e}$ estruturar o conjunto de dados armazenados nos sistemas de segurança computacional.

\subsection{Escopo do Trabalho}

A problemática de correlacionamento de informações a respeito de incidentes de segurança decorre do fato de que cada ferramenta trabalha com modelo diferente para geração de mensagens informativas a respeito de eventos detectados.

A partir do ponto em que ferramentas utilizem um mesmo vocabulário para representar alertas gerados, então o administrador poderá facilmente detectar quando ferramentas diferentes estão tratando de vulnerabilidades correlacionadas. Além disso, ferramentas de gerenciamento poderão ser desenvolvidas para incorporar diversos alertas e sugerir ações com base nos eventos detectados em diferentes pontos.

Baseando-se neste contexto, o presente trabalho tem como objetivos investigar o uso de ontologias para classificação de vulnerabilidades em sistemas computacionais. O intuito é auxiliar a interoperabilidade semântica entre os alertas gerados por diferentes ferramentas de segurança.

Para atender esses objetivos, partiu-se da base de vulnerabilidades cadastradas do projeto CVE (Mann \& Christey, 1999) e foi especificada e implementada uma ontologia com suas classes, atributos e relacionamentos. A ontologia implementada é capaz de armazenar as vulnerabilidades atualmente conhecidas, relacionadas com seus respectivos tipos, softwares afetados, fornecedores e correções. 


\subsection{Estrutura}

Este capitulo apresentou a introdução e o contexto do grupo de pesquisas. $O$ capítulo 2 traz fundamentos sobre o tópico de segurança computacional, o capítulo 3 faz breve explanação a respeito de ontologias, o capítulo 4 apresenta iniciativas anteriores para catalogação e classificação de vulnerabilidades. O capítulo 5 apresentada a proposta de trabalho, metodologia, a ontologia desenvolvida e os testes realizados. Por fim, capítulo 6 traz. as considerações finais e propostas para trabalhos futuros. 


\section{Segurança Computacional}

lista seção traz conceitos a respeito de segurança computacional, com destaque às suas definiçōes básicas, principais ameaças, tipos de ataques, ferramentas utilizadas para manutençào de segurança e diferenças de operação entre essas ferramentas.

Segurança em redes de computadores transformou-se em palavra de ordem e o tema atingc cada vez mais o interesse das pessoas, estejam elas preocupadas com seus sistemas ou interessadas em efetuar invasões a sistemas alheios.

() termo segurança é usado com o significado de minimizar a vulncrabilidade de bens, qualquer coisa de valor, e recursos. Vulncrabilidade é qualquer falha que possa ser explorada para se violar um sistema ou as informações que ele contém (ISO, 1989).

O surgimento de aplicações de comércio eletrônico, a adoção de ambientes de trabalho cooperativo pela weh e muitos outros serviços oferecidos pela Internet não eram sequer supostos pelos projetistas e técnicos. Atualmente, cada computador é um alvo potencial e as novas aplicações da Internet demandam por tecnologias que ofereçam alto grau de confiabilidade aos sistemas.

A atual conjuntura de redes e comunicaçôes inseguras deve-se, em parte, ao modo como a Internet foi projetada. O principal foco do projeto da Internet e do protocolo TCP/IP estava muito distante das atuais aplicações. Seu projeto previa inicialmente o uso por instituições militares e de pesquisa (Bernardes, 2000).

Scgurança está relacionada à necessidade de proteção contra o acesso ou manipulação de informações confidenciais por elementos nâo autorizados e à utilização não autorizada do computador ou de seus dispositivos periféricos. 
Segundo Bonifácio (1998), a segurança de uma rede de computadores pode ser comparada à segurança de uma casa. Não importa qual grau de segurança exista, não importa que sistemas ou trancas sejam usados, é importante saber que quando alguém decide, com suficiente empenho, invadir, provavelmente terá êxito. De modo análogo, todas as medidas no sentido de se aumentar a sçurança de uma rede têm como objetivo torná-la tão scgura quanto possivel, já que nenhum sistema conhecido garante total proteção.

Geralmente, um atacante irá analisar a relaçăo custo/benefício, ou seja, o quão custoso e complicado será invadir um determinado sistema e fará ponderaçòes com o lucro que alcançará com tal invasão. Uma vez que essa proporção seja inviável, pode-se dizer que foi atingido um bom grau de segurança.

A necessidade de proteção deve ser definida em termos das possiveis ameaças e riscos e dos objetivos de uma organização, formalizada nos itens de uma política de segurança (Soares et al., 1995). Sistemas computacionais estão expostos a diversos riscos, como a destruição de informações ou de outros recursos, modificação da informação, roubo de recursos e interrupção de serviços. Os ataques são cada vez mais sofisticados e geram diversos tipos de danos.

Garfinkel e Spafford (1996) definem como um sistema seguro aquele que se comporta da maneira esperada. Assim, uma política de segurança deve ser feita para o sistema, determinando como cada parte deve funcionar, para que deve ser utilizada e quais os deveres e direitos de cada pessoa que a utiliza. Deve ainda especificar sobre qual grau de confidencialidade, integridade, disponibilidade, controle e autenticação o sistema deve rodar $\mathrm{c}$ como este grau scrá mantido. Como exemplo, os fatores críticos da segurança em um banco são autenticidade c integridade, enquanto que em um sistema militar o mais importante é confidencialidade.

$\Lambda$ política de scgurança ainda deve prever quais açòes deverào ser tomadas caso uma intrusão scja detectada. Dessa forma, o nível de confiança do sistema é obtido pela comparação entre a forma como ele se comporta e a forma especificada em sua política de segurança. 


\subsection{Ameaças e Tipos de Ataques}

Ameaças a sistemas computacionais podem ser divididas em internas e externas. Entende-se por ameaças internas aquelas causadas por agentes já presentes na organização, tais como: funcionário, ex-funcionários e prestadores de serviço. As ameaças cxternas, são causadas por agrentes de fora da organização, como: hackers, virus e concorrentes. É comumo menosprezo dos riscos decorrentes das ameaças internas e, devido a isso, são comuns incidentes relacionados a essa classe de ameaça.

Lim recente pesquisa (Módulo, 2003) entre as empresas brasileiras que detectaram incidentes de segurança $\mathrm{cm} 2003$, 32\% apontaram os backers como os principais responsáveis. İm scgundo lugar, com 23\% das indicações, aparecem os próprios funcionátios. Fm seguida estão os prestadores de serviço (4\%), ex-funcionátios (4\%) e concorrentes (1\%). Em 26\% dos casos as empresas não conseguiram detectar a origem do incidente.

Os dados dessa pesquisa ilustram que mais da metade das empresas invadidas indicam fatores internos como responsáveis. Tal constatação aponta para a defasagem para soluções tradicionais de scgurança que utilizam apenas firewall na porta de entrada da Internet para rede corporativa, pois nos casos internos o invasor já faz parte da rede. Soluções robustas devem ser híbridas e integrar diversos Sistemas de Detecção de Intrusão (SDI). Deve se, portanto, preocupar-se e investir em meios para a correta integraçào desses sistemas.

(jhosh (1998), Bernstein et al. (1996), Stein (1998) e Carfinkel e Spafford (1996) apresentam estudos sobre tipos de ataques possíveis via Internet. As seguintes ameaças são, identificadas por scus trabalhos: destruição de informações ou de outros recursos (sabotagem), modificação de informações na forma de fraude, roubo de informaçōcs e interrupção ou negaçâo de serviços (Denial of Serrice).

Scgundo (Ghosh (1998), a alteração de páginas web é o incidcnte de scgurança que mais recebe atenção. Conhecida como web defacing, essa atividade é o meio mais conhecido de invasão. De acordo com reportagem do jornal Folha Online, no Brasil diversos grupos de backers se dedicam a cssa atividade e o pais lidera o ranking mundial desse tipo de crime virtual".

\footnotetext{
4 ]inte: Folha (Online - http://www1.folha.uol.com.lor/folha/informatica/ult124u1 1009.shtml
} 
A extensão e consequêencias decorrentes da desfiguração de página web varia caso a caso. De maneira geral, a instituição invadida argumenta que sua rede corporativa não foi comprometida e que os danos limitaram-se ao servidor de páginas web. Invasores, entretanto, geralmente argumentam ter acesso a dados importantes c confidenciais.

No caso do servidor web ser hospedado por outra organização, de forma que seja completamente isolado da rede interna da entidade, então, o comprometimento dessa máquina não deve, por si só, comprometer o restante da rede. Essse é o caso de organizaçōes que contratam soluções de data-centers para hospedagem de sites. Por outro lado, se o servidor ć parte integral da rede corporativa então certamente é uma porta de entrada para invasores e o comprometimento dessa máquina pode comprometer as demais. Independentemente do alcance conseguido pelo invasor, a desfiguração de páginas web̆, certamente, é bastante prejudicial, pois passa a imagem de que a organização é vulnerável.

Outro fator de risco é que, ao comunicar-se pela Internet ou efctuar transações on-line, pessoas tendem a assumir que scus dados permanecem fora do alcance de terceiros. Porém, geralmente ocorre justamente o contrário: serviços básicos da Internct ainda funcionam $\mathrm{cm}$ texto puro e podem ser facilmente interceptados pelo caminho em que trafegam os dados. Mcnsagens são transmitidas por meio de diversos computadores antes de chegar no destino final. Fim cada um desses computadores (ou roteadores) pode haver um agente hostil, capaz de copiar, modificar ou apagar essas mensagens. Para garantir a privacidade, soluçōes de criptografia tèm sido utilizadas tanto na transmissão quanto no armazenamento de informaçōes.

\subsection{Ferramentas de Segurança}

De acordo com o mencionado, sistemas computacionais tornaram-se complexos e freqüentemente é neccssário o uso intcgrado de diversas ferramentas de segurança. Cada ferramenta ć especialista $\mathrm{cm}$ sua função, isto é, geralmente não é possível o uso de uma mesma para desempenhar diversos papéis. As funções geralmente são classificadas nas categorias apresentadas nas seções seguintes. 


\subsubsection{Monitoramento de Rede}

Ferramentas de monitoramento visam prover auditoria em nível de rede, possibilitando a busca por comportamentos não convencionais, como aumento do volume de certo tipo de pacote ou interrupção de determinado serviço (Rufino, 2002). Também permitem o disparo de mecanismos de captura de tráfego de forma a gravar conexôes suspeitas. Exemplos de ferramentas que pertencem a essa classe são: Tcpdump ${ }^{5}$, Etherreal ${ }^{6}$, Ngrep ${ }^{7}$ e Argus".

\subsubsection{Teste de Integridade}

Ferramentas de teste de integridade (Garfinkel \& Spafford, 1996) verificam arquivos importantes do sistema para constatar se houveram modificaçöes. Invasores geralmente instalam programas que facilitam uma nova invasão caso o administrador retome o controle do sistema. Fsses programas, conhecidos como backedoors, são instalados por meio da modificação de arquivos binários do sistema. Assim, em um sistema invadido é necessário checar sc arquivos não foram modificados.

As ferramentas de teste de integridade utilizam criptografia para geração de assinaturas digitais dos arquivos, as quais são verificadas em intervalos periódicos para comparação em busca de modificações. Iixistem diversas ferramentas utilizadas para teste de intcgridade. Entre elas, destacam-se o Chkrootkit", Tripwire ${ }^{(t)}$ e o Aide".

\subsubsection{Deteç̧ão de Intrusão}

Sistemas de Detecção de Intrusão (SDI) monitoram o sistema em busca de ataques, que podem ser sinalizados por uma simples ação, como conexâo em determinada porta, ou envolver sequêencias complexas de açòcs ( $A$ xelsson, 2000).

\footnotetext{
${ }^{5}$ http: / / www.tcpdump.otg

intp://wwwisthereal.com

'http://www.packetfactory.net/projects/ngrep/

rhup://gosient.com/argus/index.htm

${ }^{19} \mathrm{http} / /$ waw.chkrootkit.org/

"hetp://sourceforge.net/projects/tripwirc/

il htup: //www.cs.tut.fj/ rammer/aide.html
} 
É comum a divisão de SDIs em: baseados em abuso e baseados em anomalia. $O$ primeiro tipo monitora pontos-chave do sistema e quando alguma ação for efetuada nesses pontos o alarme é disparado. Por exemplo, o acesso ao arquivo de senhas scria motivo para disparar o alarme.

Em SDIs baseados em anomalia, são produzidas estatísticas de uso do sistema e sabese, então, qual o comportamento esperado. Dessa forma, se a conta de um funcionário estiver sendo utilizada em um final de semana, isso torna-se uma forte evidència que a anomalia corresponde a um ataque em andamento.

SDIs são executados em tempo real e de forma contínua, podendo inclusive ser integrados com firenalls para implementação de contra-medidas. (Os softwares Snort'2 e Shadow ${ }^{1.3}$ săo os principais sistemas de detecção de intrusão usados atualmente.

\subsubsection{Firewall}

Fïrenalls são dispositivos usados para evitar o acesso de conexões externas para a rede interna. Geralmente, integram soluções de software e hardware e implementam uma série de regras que habilitam ou negam o acesso. Tais regras são executadas, na maioria das vezes, em nível de rede, isto é, a filtragem leva em conta os endereços IPs de origem c destino e as portas de comunicação.

No firewall são implementadas decisões previstas na política de segurança, sendo quc duas abordagens básicas são possíveis: permissiva e proibitiva. Na abordagem permissiva, tudo que não é expressamente proibido é permitido e na abordagem proibitiva, tudo que não $e ́$ expressamente permitido é proibido.

\footnotetext{
12 http: $/ /$ www.snott.ory/

$1^{13} \mathrm{http:} / /$ www.nswe.navy.mil/1SSFC/(C1)/
} 
A abordagem permissiva apresenta a configuração mais flexivel em que cabe ao administrador implementar regras referentes a cada uma das ações que não sào permitidas pela política de segurança. Já a proibitiva é mais rígida. O firewall bloqueia todos os serviços e libera apenas aqueles que são previamente aprovados. Pode-se, assim, melhorar a capacidade de precaução a ataques não previstos até então. O software Iptables ${ }^{14}$ é um dos firenalls mais utilizado, por tratar-se de um software livre e robusto.

\subsubsection{Scanners}

Scanners são programas que automaticamente detectam falhas de segurança em sistemas remotos ou locais. Geralmente, são executados em intervalos regulares de tempo, podendo ser configurados para diferentes aplicações. Por exemplo, há scanners capazes de detectar falhas de segurança em aplicações web, bem como scanners que detectam contas de usuário com senhas de fácil dedução em sistemas operacionais.

Tim alguns casos scanners reportam informações referentes às falhas detectadas, indicando quais os procedimentos necessários para corrigi-las. Fissas ferramentas também são freqüentemente utilizadas para homologação de sistemas em relação à política de segurança, verificando se as configurações estão de acordo como esperado.

Dezcnas de scanners têm sido desenvolvidos. Destacam-se entre eles o Nmap ${ }^{15}$ que vasculha a rede de forma a identificar as máquinas ativas e seus serviços, o Whisker 'to que busca por vulnerabilidades em servidores web e o Nessus ${ }^{17}$, especializado em buscar vulnerabilidades em conjuntos de máquinas e indicar quais correções (ou patches) devem ser aplicados.

\subsubsection{Outras Ferramentas}

Além das ferramentas anteriormente citadas, há também produtos dedicados à autenticação dos usuários envolvendo novos protocolos, como Kcrberos ${ }^{16}$ e ( )pen Ldap ${ }^{1 "}$.

\footnotetext{
"http:/ www.net filtst.org

$15 \mathrm{http} / /$ www.insccure.org/nmap/

16. http: $/ /$ www.wiretrip.nct $/ \mathrm{rip} / \mathrm{p} / \mathrm{doc}$ asp $/ \mathrm{i} 2 / \mathrm{d} 21$.htm

l"hitp://www.nessus.org/

is http://web.mit.edu/kcrberos/www/

ihttp://www.openldap.org/
} 
Em alguns casos, administradores têm como objetivo atrair invasores com o intuito de analisar o comportamento e as técnicas utilizadas por essas pessoas. Nesses casos, utilizamse ferramentas conhecidas como boneypots (potes de mel), e um bom exemplo é o software Honeyd ${ }^{24}$.

Outra classe de ferramentas que recebe atenção da comunidade de scgurança é a das ferramentas de análise forense. Destinadas à coleta e análise de informaçòes de sistemas em que ocorreram incidentes de segurança, tais ferramentas provem uma maneira adequada de reconstituir ataques e coletar evidências sem que o cenário seja alterado. A principal ferramenta dessa classe é o The Coroners Toolkit ${ }^{21}$.

\subsection{Características para Classificação das Ferramentas}

Por apresentarem diferentes propósitos, ferramentas de segurança apresentam diferentes formas de funcionamento $e$, conseqüentemente, detectam diferentes classes de alertas. Гssa seção apresenta as principais características que podem diferenciar ferramentas, a forma como funcionam e que geram relatórios.

\subsubsection{Tempo de Execução}

De acordo com o observado por Escamilla (1998), em relação ao tempo de execução, as ferramentas podem ser baseadas em execução contínua ou cm intervalos. No primeiro caso, a ferramenta busca por ataque durante todo o tempo. Já no segundo, a ferramenta é disparada de tempos em tempos para entâo gerar os alertas adequados.

A característica de execução em tempo contínuo geralmente é utilizada por SDI e Firenalls, pois devem ser capazes de prover pronta resposta a incidentes. Scanners de rede, fertamentas de análise forense e de teste de integridade são, por padrão, baseados em intervalos - não há a necessidade de serem executados o tempo todo.

\footnotetext{
20 http://wrw.citi.umich.edu/u/proves/honeyl/

2thte://www porcupinc.otg/forensics/tet
} 


\subsubsection{Distribuição}

Nertas de segurança podem ser gerados a partir do gerenciamento centralizado ou distribuído. Isto é, algumas ferramentas se baseiam em um ponto centralizado de coleta e processamento de informações, outras distribuem agentes de software capazes de executar tal tarefa

Bernardes (2000) apresenta diversas consideraçôes a respeito das vantagens e desvantagens dos sistemas distribuidos. Segundo ele, sistemas distribuidos tèm maior tolerância à falhas, já que caso um dos agentes seja afetado, apenas a funcionalidade coberta por esse agente deixará de funcionar.

Por outro lado, apesar das vantagens citadas por Bernardes, sistemas distribuidos devem, necessariamente, apresentar formas de gerenciamento centralizado. Isto é, mesmo que pontos de coletas de informações estejam distribuidos, tais informaçōes devem ser centralizadas para facilitar a administração.

\subsubsection{Origem dos Dados}

Uma parcela das ferramentas utiliza como fonte de informaçâo dados já coletados pelo sistema monitorado. $\Lambda$ ssim, não é necessário o armazenamento de novos registros de acesso. Outras ferramentas necessitam de novas informaçies especificas para tomada de decisão. Um exemplo de ferramenta quc utiliza registros previamente coletados é o Snort ${ }^{22}$, que intercepta as conexões de rede em busca de invasões. Já o I.ogwatch" ${ }^{23}$, precisa que o sistema seja configurado para gerar arquivos especiais de registros para que possa analisá-los e identificar invasões.

\subsubsection{Nível de Execução}

Alguns produtos baseiam-se em análises de informações colctadas da rede em que o computador se encontra (network-based). Outros, têm seu foco na análise de dados referentes apenas ao sistema onde é executado (bost-based).

\footnotetext{
$\therefore$ bttp://www.snort.org/

$2^{2} \mathrm{http} / /$ www.logwatch.org/
} 
Por excmplo, ferramentas de teste de integridade analisam arquivos do computador em busca de modificações e são, portanto, bost-based. Alguns SDIs também são bost-based, jả que buscam por ataques analisando padrões de uso do sistema pelos usuários, enquanto que outros analisam apenas o tráfego da rede.

\subsection{Considerações Finais}

Esta sessão apresentou conceitos referentes à Segurança Computacional c as principais ferramentas utilizadas para auxiliar a tarefa de manutenção da segurança. Na realidade, para cada forma de ataque existe uma grande quantidade de ferramentas que podem auxiliar a tarefa de manutenção de segurança nos sistemas e, geralmente, é necessário o uso de soluções híbridas.

As ferramentas mostradas diferenciam entre si, tanto pelas caracteristicas mostradas nesse capítulo, quanto por outras, decorrentes da forma como foram planejadas e/ou implementadas. lissa diferenciação faz, via de regra, com que as ferramentas não se comuniquem. $\Lambda$ ssim, ao operar seu sistema, o administrador tem em mãos grande quantidade de informações provenientes de cada uma das ferramentas utilizadas e deve analisar e correlacionar alertas gerados para só cntão tomar a decisào de qual contra-medida adotará.

Portanto, é evidente a necessidade de pesquisas que auxiliem a interoperabilidade dessas ferramentas. A Seção 3 irá mostrar iniciativas para esse fím. 


\section{Iniciativas para Catalogação e Classificação de Vulnerabilidades}

\subsection{CERT/CC}

O CERT Coordination Center (CHRT/CC) $)^{21}$ foi criado como sendo parte do Instituto de lingenharia de Software (SI:I - Software Engineering Institute) da Universidade de Carnegie Mellon nos EUA, com o intuito de prover uma organização capaz de coordenar respostas a incidentes de segurança na Internet.

O ClERT/CC desenvolve diversos trabalhos com objetivo de auxiliar na prevenção de incidentes de segurança. Entre os trabalhos está a divulgação de advisories, que são boletins informando a descoberta de problemas de segurança. Tais boletins não englobam apenas alertas descobertos. Por exemplo, recentemente, o servidor fth do projeto GNU2.5 foi invadido (Cert, 2003), levantando suspeitas sobre a possivel modificação de programas copiados por milhöes de pessoas de todo o mundo. Esse evento não consiste em uma vulnerabilidade, mas sim uma invasão que explorou determinada vulnerabilidade.

Devido a essa característica, os boletins do CIRT/CC podem ser usados como fonte de eventos significativos, mas não constituem uma base de vulnerabilidades conhecidas, já que nem todas as vulnerabilidades são cobertas pelos scus boletins e há boletins que năo tratam especificamente de vulnerabilidades.

24 http://www.cert.org 


\subsection{Trabalhos de Uso de Ontologias em Segurança Computacional}

Raskin et al. (2001) iniciaram a discussão do uso de ontologias no domínio de segurança da informação. Foi proposta uma ontologia que utiliza língua natural para representar um conjunto de alto-nível de termos relacionados a incidentes de segurança.

A ontologia em questão não conta com dados referentes a vulnerabilidades $\mathrm{em}$ sistemas computacionais e por representar apenas conceitos em alto-nível, não permitc que agentes de softwarc utilizem as instâncias para inferências em casos de alertas de vulnerabilidades ou deteç̧ões de intrusões. Na realidade, os próprios autores mencionam que o principal objetivo da ontologia é permitir uma maior interação entre pesquisadores sobre incidentes.

Já Pinkston ct al. (2003) propuscram a idéia de uma ontologia para modelar ataquucs cm redes de computadores baseados nas características: localização do invasor, meios do ataque c conseqüência. Os autores utilizaram a linguagem RDF para implementar a ontologia. A Figura 1 mostra exemplo de ataque do tipo syn-flood classificado. Como se pode perceber, nào há na ontologia referência específica das vulnerabilidades exploradas e o trabalho não deixa claro se houve implementação de ferramentas capazes de entender o modelo proposto.

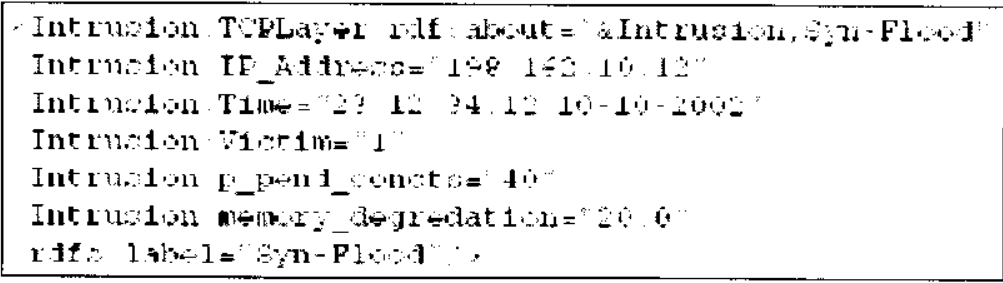

Figura 1 - Exemplo de ataque classificado na ontologia de Pinkston et al. (2003)

\subsection{Intrusion Detection Message Exchange Format (IDMEF)}

Preocupado com a problemática de interoperabilidade entre ferramentas dc segurança, o grupo Intrusion Detection Working Group (IDWWG) do Intemet Lingineering Task. Force (IFTF) tem trabalhado no desenvolvimento de um padrão para troca de mensagens entre Sistemas de Detecção de Intrusão (SDI).

\footnotetext{
$25 \mathrm{http:} / /$ www.gnu.org
} 
O IDWG pretende prover maneira padronizada para SDIs relatarem eventos considerados suspeitos, de maneira a possibilitar a interoperabilidade entre diferentes SDIs e permitindo ao usuário combinar o uso de diferentes ferramentas.

Para a representação das mensagens, o IDWG optou pela utilizaçâo da linguagem X.MI. O modelo divide os alertas em claises e subclasses. A Figura 2 apresenta visão geral do modelo proposto.

Todas as mensagens trocadas pertencem à classe IDMFF-Mcssage, que se divide nas subclasses Alert e Heartheat. A primeira é utilizada para enviar informaçòes sobre alcrtas de invasão, disparadas no momento da detecçào. Já a segunda classe é usada para envio de mensagens de status, disparadas em intervalos regulares.

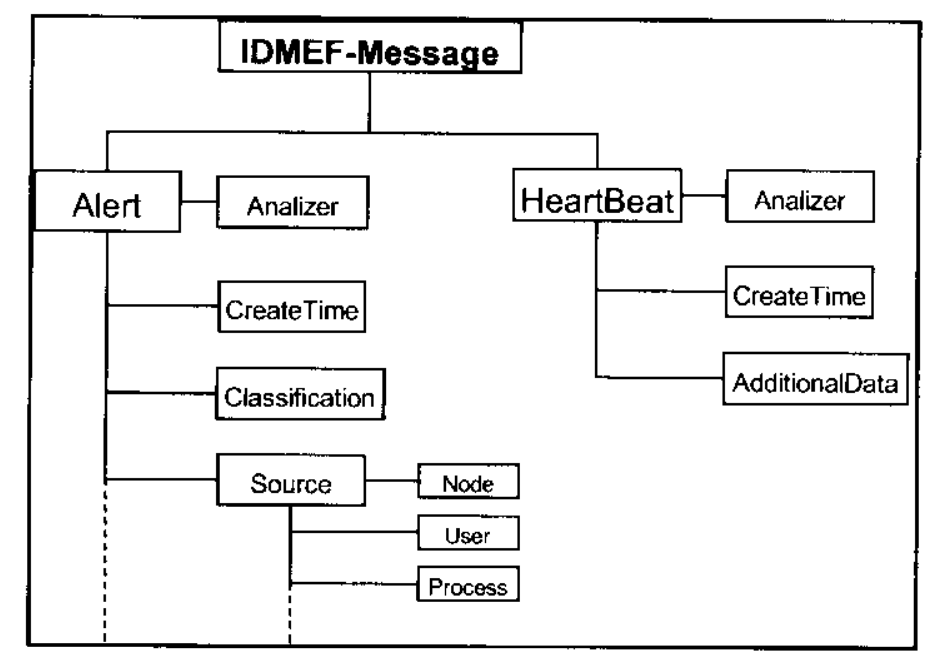

Figura 2 - Parte do modelo de dados do IDMEF

Como pode ser notado na Fïgura 2, a classe Alert tem atributos relativos à atividade reportada. São eles:

- Analyzer: Identificação do agente (ferramenta de segurança) que gerou o alerta;

- Create Time: Hora de criação do alerta;

- Detecitime: I tora de detecçâo da atividade suspeita.(Geralmente tem o mesmo valor que o atributo anterior; 
- AnalyzerTime: Indica a hora corrente no agente gerador do alerta;

- Source: Indica a origem do ataque;

- Target: Alvo a que se destina o ataque;

- Classification: Indica o nome do alerta ou outra forma de identificá-lo. Pode-se, por exemplo, utilizar o padrão CVE;

- Assessment: Fstima o impacto do ataque, contra-medidas adotadas e o grau de sigilo da atividade ocorrida;

- Additionall )ata: Informações extra a serem incluídas e que não se encaixam na estrutura modelo.

A classe Heartbea1, algo similar a status do batimento cardiaco, de acordo com a tradução literal, utiliza os seguintes atributos:

- Mnalyzer. Identifica o agente gerador da mensagem;

- Create Time: Indica o horário de criação da mensagem;

- Aditionall)ata: Informações extras a serem incluídas e que não se encaixam na estrutura do modelo.

O grupo de trabalho representou o modelo em um DTD, que pode ser encontrado em (Curry \& Debar, 2003). A Figigura 3 ilustra como um alerta de ataque pode ser representado. N'csse exemplo, é mostrado um relatório de ataque à uma vulnerabilidade presente vulnerabilidade em um programa de agenda, conhecido como PHF. Explorando essa falha, o invasor poderia executar códigos arbitrários no servidor web e, eventualmente, modificar conteúdo de dados. 


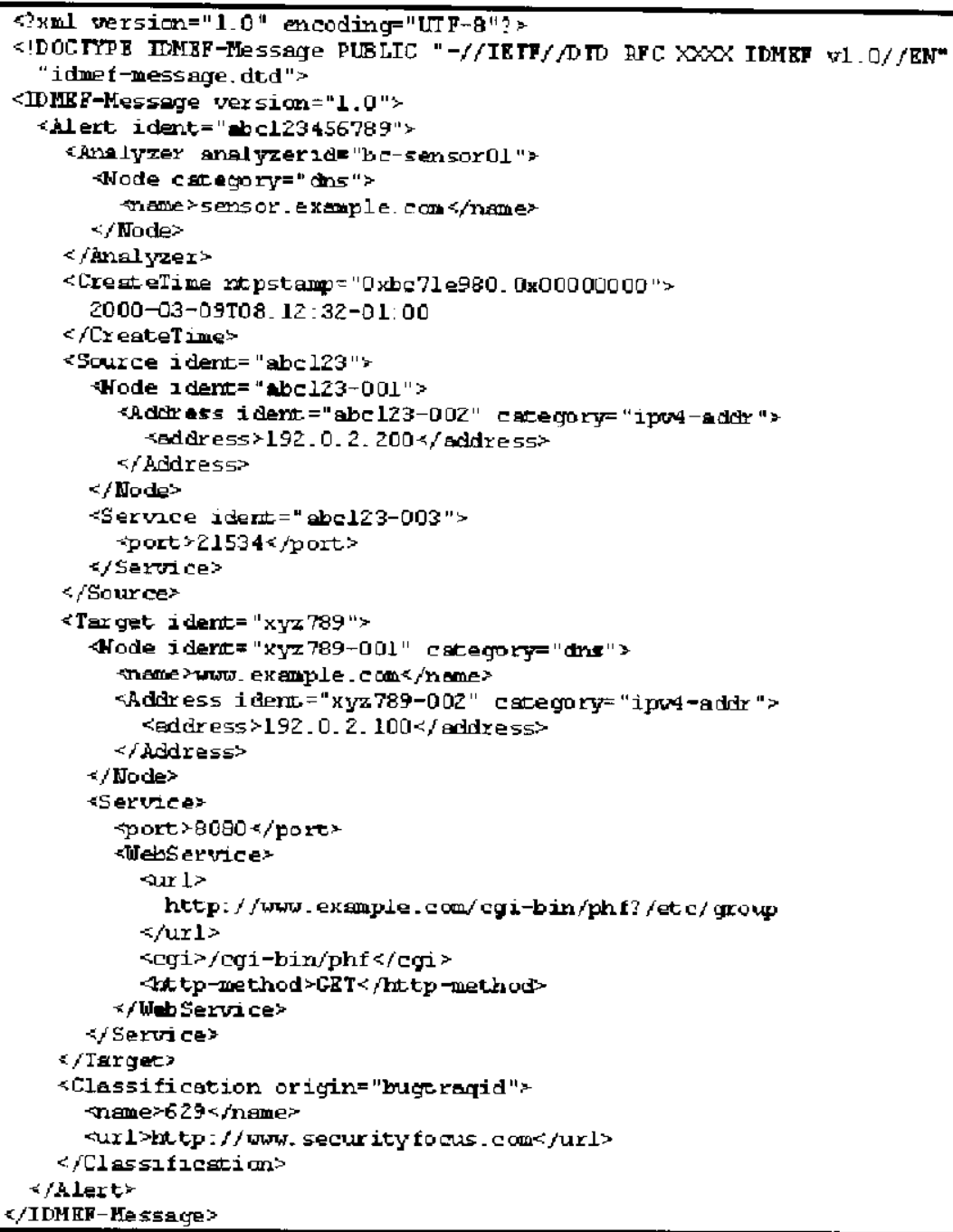

Figura 3 - Representação de ataque no padrão IDMEF (Curry \& Debar, 2003)

\subsection{Commom Vulnerabilities and Exposures (CVE)}

O Instituto Mitre, organização que provê pesquisa e desenvolvimento $\mathrm{cm}$ tecnologia da informação para o governo americano, propôs um padrão para gerenciamento de vulnerabilidades provenientes de diferentes fontes.

Foi observado que não havia consenso em pesquisas anteriores sobre definição de esquemas estruturados e taxonomias para represcntação de vulnerabilidades enquanto era grande a demanda por um padrào que permitisse imediata interoperabilidade cntre as ferramentas de segurança (Mann \& Christey, 1999). 
Esse problema é agravado pela falta de padrão para o nome de vulnerabilidades utilizados em diferentes ferramentas. $\Lambda$ Tabela 1 mostra as nomenclaturas de uma mesma vulnerabilidade em 12 diferentes organizações/ferramentas. Essa vulnerabilidade foi descoberta em um script que consiste em uma agenda, conhecida como PHF. Fxplorando cssa falha, o invasor podcria executar códigos arbitrários no servidor web e, eventualmente, modificar seu conteúdo.

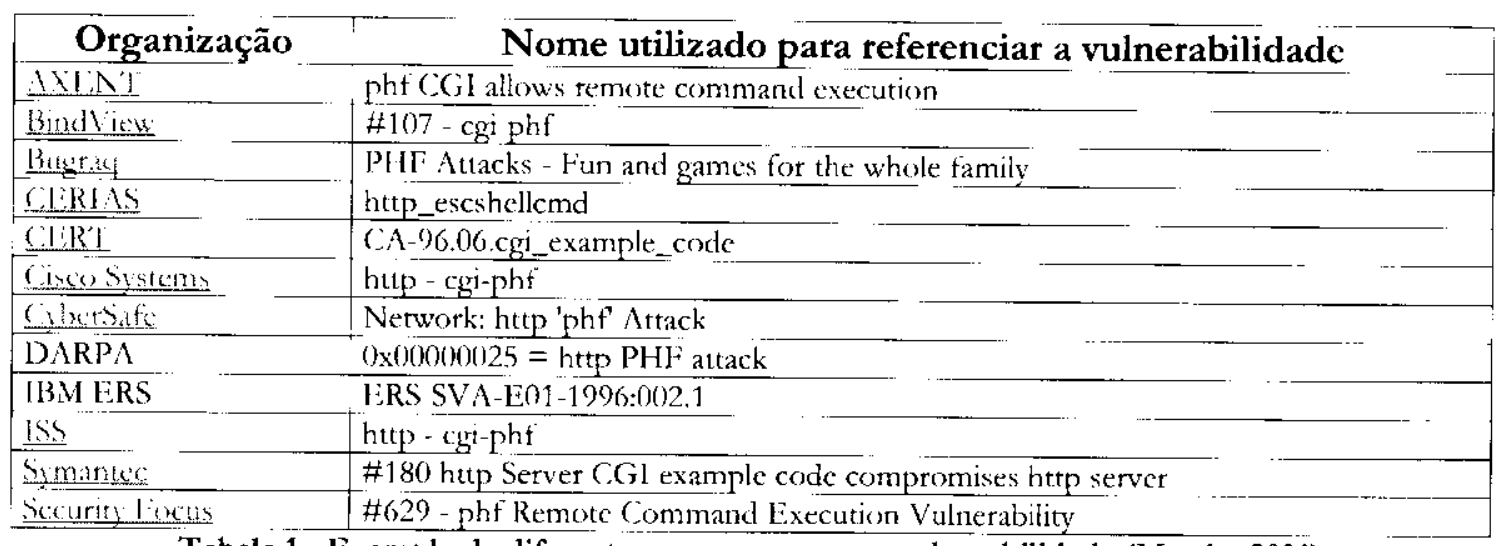

Tabela 1 - Exemplo de diferentes nomes para uma vulnerabilidade (Martin, 2001)

\subsubsection{Abordagem Utilizada}

Visando desenvolvimento rápido e consistente, optou-se por cstratégia mais pragmática: não representar as vulnerabilidades nem classificá-las, apenas noméd́-las. $A$ idéia ć uma base centralizada de nomenclatura tal que satisfaça os seguintes objetivos:

- Enumerar todas as vulnerabilidades conhecidas,

- Atribuir um nome padrão e único para cada vulnerabilidade,

- Ser independente das diferentes perspectivas $\mathrm{cm}$ que a vulnerabilidade ocorre,

- Scr abcrto c compartilhado sem restriçōes

Para garantir independência de perspectiva são utilizados apenas atributos e conceitos amplamente aceitos pela comunidade de segurança c para garantir essa aceitação um fórum entre diversas empresas foi criado. 
Diversas questões práticas tiveram de ser enfrentadas pelo grupo do projeto de forma a atingir os objetivos citados. Por exemplo, como relatar quais sistemas operacionais são afctados por cada vulnerabilidade (Mann \& (hristcy, 1999). Diferentes granularidades poderiam ser adotadas: por um lado, poder-se-ia separar as diferentes distribuiçóes de linux, diferenciar versões de kernels e semices packs do windows. Por outro, apenas difcrenciar plataformas: Microsoft, Unix e Macintosh. A solução encontrada foi não especificar os sistemas operacionais referentes a cada vulnerabilidade.

A problemática e a solução usada no quesito de sistemas opcracionais ilustram a abordagem adotada em todo o projeto: simplicidade. Existe um modelo que contempla apenas um nome único e uma descrição básica para cada vulnerabilidade. Nomes são formados pela concatenação do ano de descoberta com um número seqüencial e as descrições não contam com qualquer estrutura. Tal como CVH-2002-0067 que indica a sexagésima vulncrabilidade catalogada em 2002. () Anexo I apresenta extrato de parte da base de vulnerabilidades CVI: com as respectivas descriçōes.

Formou-se assim o Common Vulnerabilities and lixposures (CVI) que rapidamente tornou-se um padrão de fato. O projeto conta hoje, contam com a participaçào de 96 organizações e é utilizado em 157 produtos (CVE, 2004).

A Figura 4 ilustra o processo de descoberta de correção de vulnerabilidades em ambiente computacional em que ferramentas de segurança estão padronizadas com a nomenclatura (VI: (Martin, 2001). Inicialmente, em (A), o Sistema de Detecção de Intrusão) (SDI) detecta um ataque a uma vulncrabilidade ou um scanner detecta aplicativos com vulnerabilidades não corrigidas. Fssas vulnerabilidades são referenciadas pelas ferramentas por mcio dos respectivos nomes CVIs (B). O administrador visita o site do projeto (VEF onde consegue maiores informações (C). A partir disso, o administrador usa o nome (VF para busca por correções (patches) disponibilizados pelo fabricante (D). 


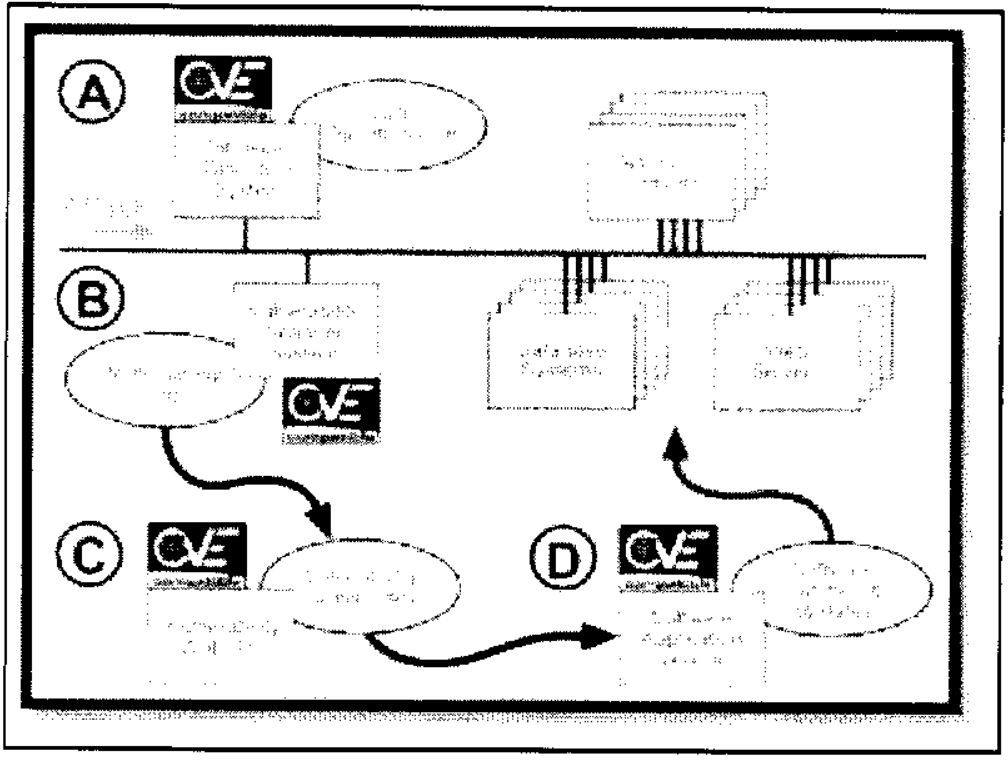

Figura 4 - Descoberta de vulnerabilidades com a utilização do CVE (Martin, 2001)

\subsubsection{Metodologia de Manutenção do Repositório}

() cadastro de novas vulnerabilidades no catálogo passa por ampla discussão do fórum CVI: Editorial Baard, coordenado por um Editor (Martin, 2001). O processo inicia pela descoberta de uma vulnerabilidade potencial, que é tratada como candidato a CVE e recebe um número atribuído pela Candidate Numbering Authority (CNA). Em seguida o candidato é colocado em discussão no fórum onde ć votado, podendo ou não ser aprovado.

As seguintes fases são previstas para que o candidato se torne um padrão de fato:

- Descoberta: A vulnerabilidade é descoberta por alguma instituição participante do projeto.

- Anúncio Público: É feito anúncio público sobre a potencial vulnerabilidade com postagens a listas de discussão, neusgroups, boletins de segurança, etc. Após () anúncio as informações são submetidas ao CNA. 
- Atribuiçào: ( ) CNA verifica se a vulnerabilidade ainda não está cadastrada. Caso negativo atribui um número a ela. Somente o CNA tem a prerrogativa de atribuir númcros a candidatos. İm alguns casos, o $\mathrm{CN} \Lambda$ fornece intervalos de números às organizações de forma que possam atribui-los c incluir essa informação em anúncios públicos de novas vulnerabilidades.

- Proposta. (Os membros do Liditorial Board discutem e votam no candidato. Cada membro pode votar por Accitar, Rcjeitar, Reformar (solicitar grandes reformulaçōes), Modificar (pequenas alterações) ou preferir Não (Opinar. Os votos e comentários são armazenados para referência futura.

- Modificafáo: Se aplicável, o candidato passa por essa fase em que as alteraçóes solicitadas são aplicadas. Se as alterações forem resultantes de um voto de Reformar então o candidato deve passar por nova votação.

- Decisões de Ínterim: $\Lambda$ discussão em torno da nova vulnerabilidade pode estender-se de acordo com o número de novas modificaçôes e votaçôes necessárias. () Fiditor é o responsável por determinar o momento em que o candidato deve passar para a fase final.

- Decisão Finat: Caso o fórum chegue a um acordo em relação ao aceite do candidato, o Editor informa todos os membros que o candidato foi aceito e qual o nome atribuído a ele. Caso a inserção seja negada, então o motivo é divulgado.

- Publicafăo: Ĺma nova versão da base (VVF é produzida e disponibilizada no site do projeto, de forma a englobar também a nova vulnerabilidade.

- Reavaliafáo: Fiventualmente, uma entrada CVE pode ser recolocada em discussào para modificação. lisse processo envolve as mesmas fases necessárias para inserção de uma nova entrada.

- Cancelamento: Em casos raros, entradas podem ser retiradas. Por exemplo, pode-se determinar maior nível de abstração à base de vulnerabilidades ao retirar vulnerabilidade de baixo nivel. 
Atualmente o Instituto Mitre exerce os papéis de CNA e Editor CVE.

\subsection{Considerações Finais}

As iniciativas de classificação e catalogação de vulnerabilidades demonstram a importância que o tema tem para auxiliar no gerenciamento de segurança. Entre os projetos mostrados, certamente o IDMEF c o CVE são os principais.

O modclo proposto pelo IDMFГ apresenta grande e importante esforço para estabelecer padrão para representação de intrusões. Além da proposta de modelo para representaçào das mensagens, o Intrusion Detection W'orking Group também trabalha no desenvolvimento de protocolos para comunicação entre as ferramentas (Feinstei et. al, 2002).

O IDMEF tem como objetivo representar incidentes de segurança. Caso haja determinada vulnerabilidade que não venha a ser explorada, então, não será reportada em um alerta. Até o momento não é possivel prever qual será a aceitação do modelo pela comunidade, já que o modelo ainda está em desenvolvimento.

O uso de XML acarreta cm algumas limitações ao IDMEF'. Por exemple, XMI. não conta com o conceito de herança e não há representação de correlacionamento entre mensagens. Além disso, o significado do conteúdo XMI. é baseado na interpretaçào dos nomes das marcações e não é possível ao agente de software fazer inferências a partir de seu conteúdo.

Já em relação ao projeto (CVI; pode-se dizer que é uma iniciativa de sucesso. Seu desenvolvimento preencheu importante lacuna ao oferecer maneira padronizada para referência a vulnerabilidades. Tal sucesso pode ser medido pela grande quantidade de organizações que aderiram ao padrão. Porém, a iniciativa não oferece avanços na correlação entre vulncrabilidades e na extração de valor semântico em cada uma, já que a simplicidade do projeto privou-o da possibilidade de relacionar maiores informações referentes a vulnerabilidades catalogadas. Além disso, o uso de nomes seqüenciais impede o corelacionamento entre diferentes entradas. Por exemplo, é impossível prever qual a relação entre (CVE-2001-0012 e CVE-2002-0301. 
Soma-se a este fato o uso de descrições não cstruturadas que impedem a extraçầo automática do valor semântico correspondente. É perfeitamente possivel saber quando difcrcntes ferramentas referenciam a mesmo vulncrabilidade. Porém, descobrir do que se trata cfetivamente esta vulncrabilidade e qual a rclaçào entre essa e outras anteriormente detectadas depende completamente do conhecimento do administrador. 


\section{Ontologias}

A crescente quantidade de informações e o uso de diferentes estruturas $\mathrm{dc}$ armazcnamento tèm acarretado problemas para interoperabilidade entre aplicações. Isto c, têm-se detectado problemas com a capacidade dos sistemas compartilharem e trocarem grandes volumes de informaçōes.

De acordo com Fonscca c Borges (2000), para fazer um bom uso das informaçōes disponiveis na Internet e computaçào distribuida, a nova geração de sistemas de informaçào deverá ser capaz de resolver interoperabilidade scmântica, na qual um fato pode ter mais que uma descrição. Sistemas deverão entender o modelo que o usuário faz do mundo e seus significados e entender também os modelos por trás das fontes de informação.

Fukuda (1995) apud Ortèncio (2001) apresenta uma análise da geração do conhecimento a partir de níveis de abstração notados em um domínio, conforme mostrado na Figura 5. De acordo com o proposto, cada nivel é descrito individualmente como:

- Ambiente real: coisas ou eventos que existem no mundo real ou ideal;

- Dados: percepções da realidade expressadas em símbolos ou imagens, tornados persistentes por meio de registros em arquivos e bancos de dados. Coletam e simbolizam a realidade;

- Informação: formada de dados, adquirida como resultado de uma seleção de dados úteis à atividade que o sujeito esteja interessado em desempenhar. Provê a eliminação de incertezas;

- Conhecimento: o conhecimento explícito é o resultado de um refinamento da informação. Neste processo, informações com potencial para sercm utilizadas novamente são sistematizadas; 
- Teoria: é a explicitação do conhecimento generalizado, organizado;

- Inteligência: é a capacidade de aplicaçào dos meios disponiveis para resoluçào de problemas de maneira satisfatória.

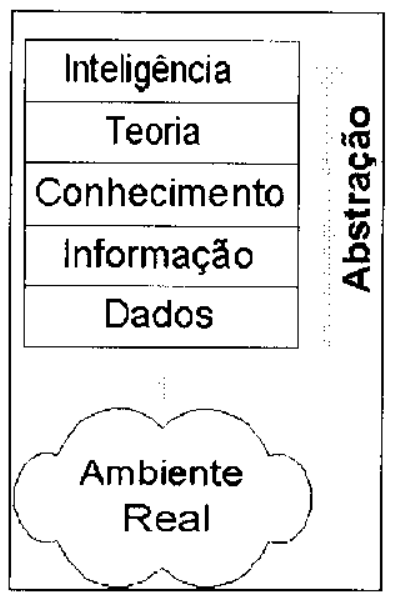

Figura 5 - Níveis de abstração em um domínio (Fukuda, 1995)

Observando o modelo proposto por Fukuda, ontologia é a representação explícita e estruturada de informações em niveis de abstração superior ao nivel da informação: o conhecimento.

Diversas publicações têm dedicado espaço a pesquisas envolvendo ontologias. Temse pesquisado a definiçăo de linguagens para representação de ontologias (lopez et al., 1999), métodos para implementação de sistemas que utilizam ontologias (Valente, 1999) (BenchCapon \& Visser, 1997), criação de ontologias em larga-cscala e metodologias para criaçào de ontologias (I folsapple \& Joshi, 2002; Fernández-L ópes et al., 1999).

Nos últimos anos, também se tornaram freqüentes pesquisas envolvendo aplicações práticas para ontologias. Na web, ontologias têm sido utilizadas para classificaçào de sites (Yahoo) e produtos (Amazon). O projeto Deepsia ${ }^{26}$, desenvolvido pelo ICMC-USP junto com diversas organizações européias, utiliza a ontologia $\mathrm{ECCMA}^{27}$ na categorizaçâo de produtos a serem disponibilizados $\mathrm{em}$ um sistema de compra.

$26 \mathrm{http} / /$ www.deepsia.com/br

$27 \mathrm{http}: / /$ www.eccma.org/ 


\subsection{Definição de Ontologias}

A literatura apresenta várias definições acerca de ontologia, sendo assim, não há ainda um consenso sobre ontologias em sistemas de informação (Zúñiga, 2001). Uma definiçào comumente utilizada e aceita é a proposta por Grubber (1993): "Ontologia é uma

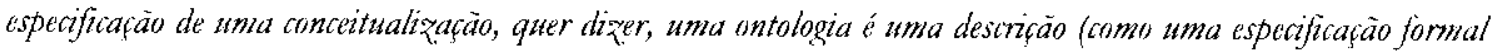
de um programa) dos conceitos e relacionamentos que podem existir para um agente ou uma comunidade de agentes".

Para I Huhns \& Singh (1997) ontologia deve ser vista como um modelo computacional de alguma porção do mundo. A ontologia pode ser fisicamente estruturada como uma rede semântica ou um grafo, onde os nós são objetos individuais e os arcos representam relações ou associações entre eles. Relacionamentos, atributos, limitaçõcs, funções e regras são acrescentadas a tal rede para a caracterização e descrição do comportamento dos conceitos. $A$ IFigura 6 ilustra um exemplo de estrutura proposta por eles.

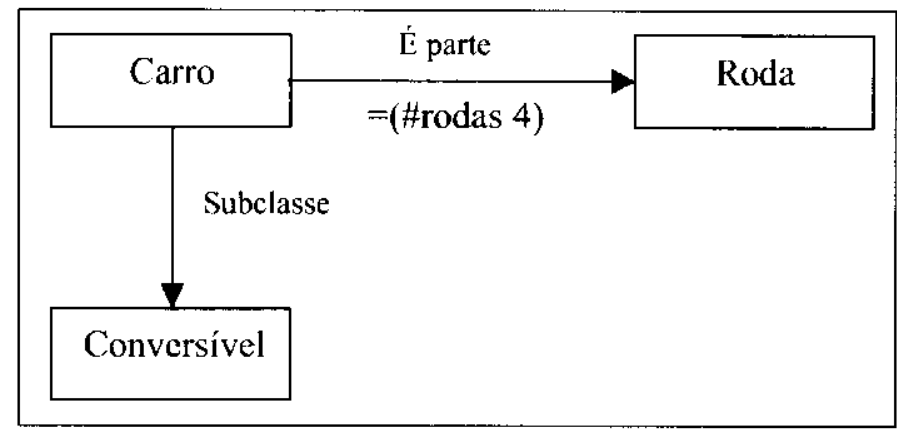

Figura 6 - Estrutura de uma ontologia segundo Huhns e Singh (1997)

Ontologias podem ser utilizadas para organizar palavras-chave e conceitos de bancos de dados por meio da captura das relações semânticas. Tais relações oferecem visão abstrata da informação no domínio de interesse.

Grüninger (1996) alerta que para a correta utilização de ontologias na representação semântica de objetos em modelagens de problemas e domínios, devem ser aplicados conjuntos apropriados de axiomas na descrição de tais objetos. A criaçâo de axiomas adequada de objetos, independentemente de contexto ou língua, pode ser útil para a reutilização dos conceitos descritos pela ontologia, c importante para a comunicação de conhecimentos entre agentes inteligentes. 
Resumidamente, podemos assumir que ontologia é a descrição formal de conceitos (ou classes) em um domínio e das propriedades desses conceitos. Classes descruvem os objetos no domínio específico. Por excmplo, uma classe de carros representaria todos os carros existentes. Classes podem ser especializadas em subclasses para representaçăo de conceitos mais cspecíficos, como na Figura 6 é feito com carros conversiveis.

A Fïgura 7 ilustra parte de uma ontologia apresentada por Sowa (20)2). No gráfico, que é similar a uma árvore, são catcgorizadas bebidas (beverage). Na parte inferior pode-se observar os itens café (coffee), cerveja (beer), champanhe (champagne), vinho (uine) c cola (cola). Por meio da ontologia é possivel deduzir que café contém cafeína (caffeinic) e é não alcoólico (nonAlcobolic), enquanto ccrveja é bebida alcoólica (alcobolic) e com gás (sparkling).

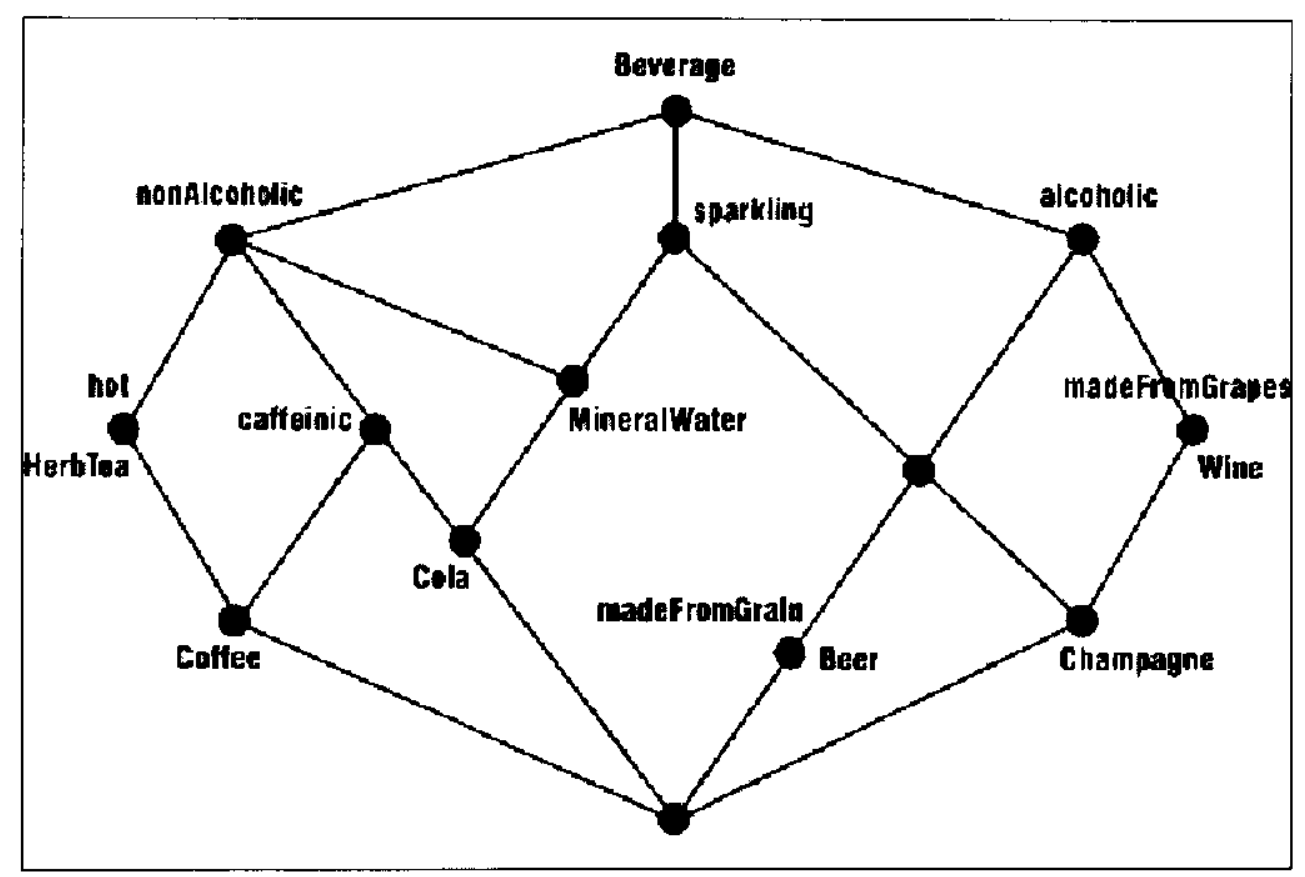

Figura 7 - Ilustração de ontologia de bebidas (Sowa, 2002)

A Fïgura 7 é bastante útil para um primeiro entendimento acerca do conceito de ontologias e está de acordo com a definiçào proposta por Grubber. Porém, essa ontologia de bebidas contém apenas relações do tipo pai-filho, isto é, nào há outro tipo de relação entre os itens classificados.

De acordo com Huhns e Singh (1997), os tipos de relações entre classes significativas que são representadas $c$ suportadas pelas ontologias geralmente são: 
- Cieneralização e berança - expressam a relação entre classes que compartilham similaridades, mas mantêm particularidades. A generalização relaciona uma classe a uma ou diversas outras versōes refinadas dela própria. Na herança, cada subclasse herda caracteristicas de sua superclasse alem das caracteristicas particulares;

- Agregaçäo - classes que representam objetos são relacionadas como partes de um todo c associadas a uma nova classe, que representará o conjunto como um único objeto. Algumas propriedades da classe composta podem ser propagadas para as classes agregadas (componentes);

- Instanciaģa - é a relação cntre uma classe c cada um dos indivíduos que a constituem.

Segundo Holsapple c Joshi (2002), é importante fazer a seguinte distinção: em um lado há a ontologia propriamente dita, que especifica os conceitos utilizados no domínio e suas relações. Por outro, há os fatos cmpíricos referentes a esses conceitos e relações, fatos que são resultantes da aplicaçâo prática e que não fazem parte da ontologia, mas são estruturados por ela. Isso ocorre porque tais fatos são resultantes do contexto e podem ser modificados.

Fixemplo da separação defendida por eles pode ser encontrado no domínio de segurança da informação. Conceitos como política de segurança, antivirus e backers estariam presentes na ontologia. Porém, a definiçào da periodicidade de atualização do anuivírus pode variar conforme o contexto e não fał parte da ontologia.

\subsection{Custos e Benefícios do Uso de Ontologias}

Atualmente, diversas pesquisas tèm defendido os benefícios do uso de ontologias. Segundo Noy e McGuinness (2001), o uso de ontologias possibilita diversas vantagens, entre elas:

- Compartilhar a estrutura de informação e conhecimento que são comuns a outras pesscoas ou agentes de softwarc. Por exemplo, sites de comércio eletrônico que compartilham seus catálogos de produtos; 
- Permitir a reutilização de um domínio de conhecimento. Ontologias podem ser reaproveitadas. Novas ontologias podem, em parte, ser fcitas utilizando ontologias já existentes;

- Tornar explícitos conceitos assumidos no dominio. $O$ uso de definições explícitas facilita a manutenção do conhecimento e permite entendimento por novos usuários;

- Analisar o conhecimento representado. Análises formais permitem a reutilizaçào de ontologias existentes e facilitam a expansão das mesmas.

Porém, de acordo com o observado por Menzies (1999), resultados de pesquisas em engenharia de software e gerência dc conbecimentos sugerem que estruturação c rcaproveitamento podem ter um alto custo. $O$ autor argumenta que modelos de estimativa de custo para adaptação de sub-rotinas de software em novos projetos ilustram que o tempo necessário para um novo usuário adquuirir conhecimento suficiente sobre a sub-rotina e então) utilizá-la é o tempo equivalente a re-escrever $60 \%$ da sub-rotina. Tal fato ocorre devido à necessidade de familiarização com os componentes de software antes que os mesmos possam ser corretamente utilizados.

F́: também notado por Mcnzies que não há garantias que tais resultados possam ser extrapolados para ontologias, porém servem para alertar que a simples possibilidade de usar uma ontologia não garante por si só aumento de produtividade. Ontologias precisam ser aprendidas antes de serem utilizadas e o tempo de aprendizado pode ser significativo no desenvolvimento do projeto.

Outro ponto a ser considerado é eventuais instabilidades da ontologia adotada devido a correções de erros nào anteriormente detectados (Preece, 1992) ou outras alterações tais como adicionar novos niveis de abstração.

\subsection{Abordagens para construção de Ontologias}

A engenharia de ontologias é a ciência que se dedica ao estudo de técnicas para desenvolvimento, manutenção, aplicação e teste de eficácia de ontologias. Holsapple \& Joshi (2002) identificam cinco abordagens distintas que podem ser adotadas para construção de ontologias: 


\subsubsection{Abordagem de Inspiração}

No desenvolvimento com abordagem pela inspiração o desenvolvedor parte de uma premissa da necessidade de uma ontologia. Utilizando imaginação, criatividade e sua visão pessoal a respeito do domínio em questão, o desenvolvedor passa a construir a ontologia com objetivo de satisfazer a necessidade detectada.

Ontologias descnvolvidas com essa abordagem tendem a ser desalinhadas com a visão global da comunidade a respeito do domínio e serem pouco aceitas, representando a visão pessoal do desenvolvedor. Tal situaçào é evitada apenas quando o descnvolvedor tem a pretrogativa de ditar a adoção da ontologia ou quando sua visão a respeito do domínio esteja extremamente alinhada com a visão de uma grande parcela da comunidade

\subsubsection{Abordagem de Indução}

Para a criação de ontologia utilizando a abordagem de indução o desenvolvedor observa e analisa um caso específico dentro do domínio abordado. O resultado conseguido é então expandido e aplicado a outros casos do domínio. Por exemplo, baseando-se no comportamento de intrusos em determinado sistema computacional aplica-se a indução de maneira a considerar o mesmo comportamento em outros sistemas e faz-se uma ontologia a respeito do comportamento de intrusos de maneira geral.

Tal abordagem não ć satisfatória porque aplica peculiaridades de um caso específico da ontologia a todos os outros casos. Na utilização da abordagem de indução propriedades marcantes na maioria dos casos podem ficar excluídas da ontologia por não estarem presentes no caso analisado. No exemplo mencionado, poder-se-ia utilizar para estudo de caso o comportamento de intrusos em um sistema atípico, cujas características teriam pouco em comum com sistemas em geral.

\subsubsection{Abordagem de Dedução}

A utilização desta abordagem consiste em adotar estratégias gerais para confecção de ontologias e, itcrativamente, aplicá-los para os casos de um domínio, de forma a deduzir a ontoloyia resultante. 
$A$ atividade envolve muitas vezes o precnchimento de detalhes especificos do domínio, produzindo uma ontologia que é a instanciação de noções gerais. Tal abordagem pressupõe a existência de conhecimento prévio para adoção das estratégias gerais.

Um excmplo da possivel adoção da abordagem de dedução seria utilizar um framenurerk. sobre segurança computacional como ponto de partida para dedução de uma ontologia especifica de políticas de segurança.

\subsubsection{Abordagem de Síntese}

O desenvolvimento pelo uso da abordagem de sintese consiste em identificar um conjunto de ontologias e combiná-las com outros conceitos referentes ao domínio a ser enquadrado de forma a sintetizar uma ontologia unificada.

() processo de síntese deve envolver integração sistemática de conceitos, eliminaçào de eventuais redundâncias entre duas ou mais ontologias e o reconhecimento de diferentes nomenclaturas para o mesmo objeto ou propriedade.

\subsubsection{Abordagem Colaborativa}

Com a abordagem colaborativa o desenvolvimento é feito por esforço em conjunto resultante de experiências e visões de pessoas que intencionalmente colaboram para a produção da ontologia. O processo pode ser ancorado a uma ontologia pré-existente servindo como guia e podendo ser melhorada.

Quando essa abordagem é utilizada são maiores as chances de ampla adoção da ontologia caso participem do processo diversas pessoas com diferentes contribuiçies. () desenvolvimento coopcrativo reduz a existència de pontos-cegos, ou seja, conceitos erroneamente năo cobertos pela ontologia (Sure et al., 2002).

Cada uma das abordagens mencionadas apresenta vantagens e desvantagens e raramente uma nova ontologia será desenvolvida utilizando apenas uma delas. Devido a inerente necessidade de ontologias serem amplamente aceitas, a abordagem colaborativa apresenta maiores vantagens e deve ser preferencialmente adotada. 
() uso de uma ontologia desenvolvida com abordagem de sintese como âncora do desenvolvimento colaborativo permite a combinação de vantagens das duas melhores técnicas.

\subsection{Linguagens para Representação de Ontologias}

Para a representação de ontologias deve-se utilizar linguagens que permitam a definição de termos de maneira estruturada. A seguir são descritas sucintamente as principais linguagens utilizadas para representação de ontologias.

\subsubsection{KIF (Knowledge Interchange Format)}

$\Lambda$ linguagem $\mathrm{KJF}$ (Knowledge Interchange Format) é uma notação prefixa para lógica de predicados de primeira ordem com termos funcionais e de igualdade (Genesereth \& Fikes, 1992). Foi especificada com dois propósitos: ser uma linguagem de conteúdo em mensagens entre agentes, e servir como uma interlingua na tradução cntre linguagens de formalismos de representaçăo.

Mesmo após muito tempo do lançamento da linguagem $\mathrm{KIF}$, ainda não foi desenvolvido motor de inferência capaz de processá-la. Motores de inferência são algoritmos capazes de entender a semântica representada pela linguagem e efetuar inferências a respeito de determinado conteúdo. $A$ falta do motor de inferência limita fortemente as possibilidades de uso da linguagem.

\subsubsection{XML e XML Schema}

A linguagem XML (Extented Markup I anguage) (Bray et. al, 1998) permite a inserção de marcaçòes customizadas no documento, o que possibilita a distinção das partes que o compõe. Assim, sabe-se, por exemplo, que determinada parte do documento descreve o autor, o título ou ISBN de um livro pela inserção de marcações como <autor $>,<$ titulo $>$ e <isbn $>$.

Já XML, Schema (Thompson et al., 2001) provê a especificação de quais elementos são esperados cm documentos XML. Isto é, define qual a gramática válida para o documento) XMI, os tipos de dados permitidos em cada marcação e qual a hierarquia de marcações é esperada. 
Dado esse fato, tende-se a aceitar que XML seja utilizado para representação de informação semântica. Porém há alguns problemas: o significado inferido a partir de documentos XMI depende da interpretação do nome de suas marcações. ()u seja, agentes de software podem facilmente detectar quais são os elementos existentes no documento, mas não quais as referências semânticas entre eles. Tim XMI. o software consegue descobrir que o valor da marcação <periodoLiterario> é "romantismo", mas não é capaz de cntender o significado dessas palavras.

\subsubsection{RDF e RDF Schema}

A linguagem RI)F (Resource Description Frameurork) (Brickley \& Guha, 2003) foi desenvolvida pelo W3C: com o objetivo de servir como subsídio para a Web Semântica. Suas funcionalidades são obtidas pela extensão do XMI, adicionando a representação de relações cntre objetos e funcionalidades para representar semântica.

Documentos RDF são compostos por declarações sobre os recursos ou objetos representados, sendo que cada declaração é composta pelo objeto, uma propriedade e o valor dessa propriedade. Valores de propriedades podem ser outros objetos, criando assim declarações aninhadas. Permite que documentos RDF sejam visualizados como grafos, em que os arcos representam as propriedades. $\Lambda$ Figura 8 mostra um documento RDF que indica qual o periodo literário de um livro. Nesta figura, pode-se notar que recursos são definidos com uso de LRIs (Universal Resource Identiffer).

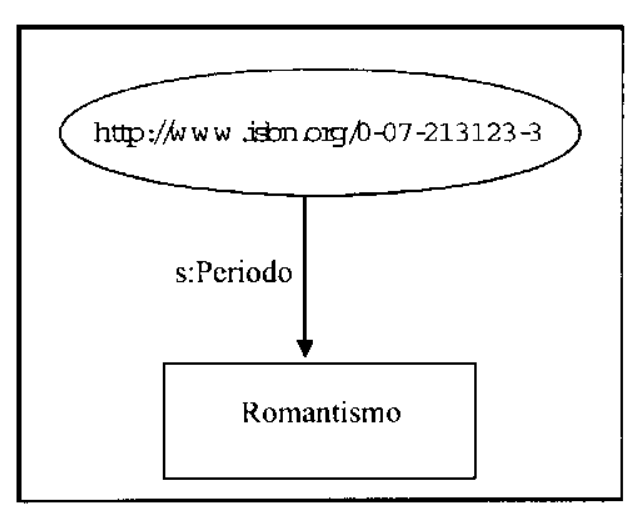

Figura 8 - Documento RDF visualizado como um grafo 
Uma das vantagens do RDF sobre o XML é que em RDF não é necessário que os agentes de software concordem previamente com determinada estrutura para o documento, já que as marcações utilizadas têm significado pré-definido. Por exemplo, as marcações $<$ rdf:Resource>, <rdf:Property $>$ e <rdf:Statement $>$ indicam, respectivamentc, o recurso, sua propriedade e o valor para essa propriedade. Qualquer aplicação compativel com RDF’ é capa» de entender tais marcações.

Enquanto RDF define um modelo para descrição de relaçöes entre objetos cm termos de propriedades e valores, a declaração dessas propriedades, suas regras de uso e a respectiva semântica são apresentadas no RDF Schema, por meio do uso de diversas marcaçōes como: <rdfs:subClass()f>, <rdfs:type>, <rdfs:property>, <rdfs:subProperty()f>, $<$ rdfs:domain $>$ e < rdfs:constraintProperty > ( ) RDF Schema permite, portanto, a definiçào de um domínio, seu vocabulário, e as relações entre seus conceitos. Isto é, permite a definição de uma ontologia.

\subsubsection{Ontology Web Language (OWL)}

Da mesma forma que RDF e RDI Schema funcionam sobre XMI, a linguagem (OWI. (Ontology Wel Language) estende as funcionalidades de todas as outras, inscrindo novas marcações, com maior nível de detalhe na definição de objetos e relacionamentos (Dean \& Schreiber, 2004).

A OWL. foi inicialmente desenvolvida por dois grupos distintos, que desenvolveram as linguagens DAML e (OII, e que depois se uniram formando a linguagem DAMT.+OIL. Posteriormente, DAMI.OII foi submetida ao consórcio W3C e foi aprovada como padrão, com novo nome: OWL (Smith et al., 2003, Dean \& Schreiber, 2004).

Para facilitar o uso e o desenvolvimento de apliçaçocs, a linguagem OWL foi dividida em 3 sublinguagens com niveis crescentes de complexidade e expressividade:

- (OWI I Ite: abrange lógica de descrições, com algumas restrições. Por exemplo, a cardinalidade máxima ou mínima assume apenas os valores 0 ou 1 . Oferece possibilidade de declaração de atributos com transitividade, simetria, atributos inversos e propriedades funcionais. 
- OWL I I: oferece toda a expressividade da lógica de descrições, com maior expressividade que a anterior: permite a união, interseção e complemento de classes para formar novas classes.

- OWI. Full: fornece a expressividade das anteriores com a possibilidade de usar RDF para criação de novas metaclasses. A utilização de (OWI. Full não garante a computabilidade.

Por ser construida sobre as linguagem RDF c XML, documentos (OWI, tèm aparência muito similar ao dessas linguagens. Na verdadc, pode-se dizer que todo documcnto OWL é também um documento RDl* e também é um documento XML.

A definição de documentos OWL inicia-se pelos headers em que se define os namespaces utilizados, o tipo de documento e quais classes devem ser importadas de outros documentos.

A Figura 9 mostra exemplo do cabeçalho de uma ontologia feita em OWL. A primeira linha indica que se trata de um documento que segue os padrões da linguagem RDI: A segunda nos indica qual será o namespace padrão da ontologia. Isto é, classes, instâncias, propriedades e relações que não tiverem a indicação de um namespace serão entendidos como definidos no documento referenciado na segunda linha.

As linhas 3 e 4 indicam a importaçăo de definiçōes feitas em outras ontologias e define com quais namespaces essas outras ontologias serão referenciadas. Já a linha 5 importa as definições da linguagem OWL. É esta linha que permite utilizar as marcações da linguagem ()WL no decorrer do documento.

Finalmente, as linhas 6,7 e 8 importam as definições das linguagens RDF, RDF Schema e XML Schema.

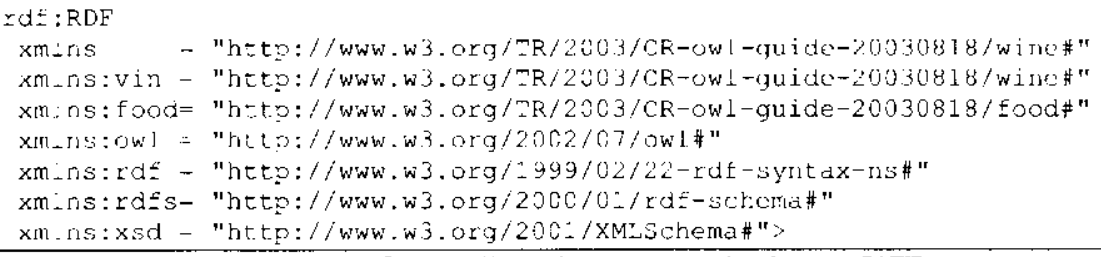

Figura 9 - Cabeçalhos de uma ontologia em OWL 
tim OWL, classes são definidas com a marcação <owl:Class ..>, sendo que a indicação de subclasses é feita com a marcação <rdfs:subClass Of ..> . Dessa maneira, a Figura 10 mostra o código de definição da classe WineGrape, em que indica-se que esta é subclasse da classe Grape presente no namespace food.

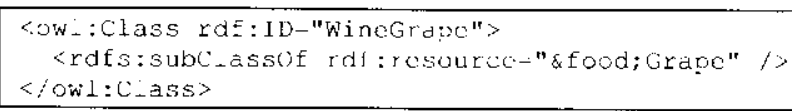

Figura 10 - Definição de classe cm OWL

Propriedades podem ser de dois tipos: object properties e datatype properties. No primeiro caso, os valores possiveis para propriedade são instâncias de outras classes. Já no segundo, a propriedade pode assumir qualquer valor definido na linguagem RDF Schema (string, inteiro, data, etc.). Propriedades do tipo object são comumente chamadas de relações.

Propriedades do tipo object são construídas com a marcaçâo <owl:ObjectProperty ..> e as do tipo datatype são construídas com a marcação <owl:DatatypeProperty ..> A Fïgura 11 mostra a criação de uma propriedade de cada tipo.

<ow-:Datatypeproperty rdf:ID-"yearvaiue" $/>$

<ow-:ObjectProperty rdf:ID-"madoFromorapo" />

Figura 11 - Criação de propriedades em OWL

Individuos, também chamados de instâncias, podem ser criados utilizando-se como marcação o próprio nome da classe que irá pertencer. Assim, a Fïgura 12 mostra a criação do tipo Wine Grape.

<ineGrape rof:ID-"Chateu" $/>$

Figura 12 - Definição de instância em OWL

A linguagem OWL conta com muitas outras construções além das que foram aqui mostradas. Maiores detalhes a respeito da linguagem podem ser obtidos em (Dean \& Schreiber, 2004).

\subsection{Ferramentas para Edição de Ontologias}

Diversos softwares têm sido criados para edição de ontologias. Tintre cles, se destacam o Protégé (Noy et al., 2001), da Universidade de Standford, o OilEdit (Bechhofer et al., 2001), da Universidade de Manchester e o Kaon (Maedche \& Staab, 2(0)3), da Universidade de Karlsruhne. 
() Protégé2. vem ganhando espaço devido à uma ativa comunidade de usuários $\mathrm{e}$ desenvolvedores. (O software provê uma ferramenta gráfica em que ontologias são construídas de maneira hierárquica, partindo-se das classes mais abrangentes, para chegar nas mais cspecificas (Noy et al., 2001). Como padrão, o Protégé ć capaz de armazenar as ontologias em bases de dados, arquivos textos e arquivos RDF Schema, sempre utilizando a notação de triplas N3 (sujeito, verbo, predicado).

Uma das vantagens do Protégé é a capacidade de ser expansível, por meio do desenvolvimento de plugins. $\mathrm{Na}$ realidade, diversos plugins foram desenvolvidos pela comunidade e estão disponiveis para cópia na página do projeto. Entre cles, está o plugin que habilita ao Protégé a edição de ontologias em formato OWL.

Soma-se também às vantagens do Protégé o fato de ser desenvolvido em Java e, portanto, ser multi-plataforma. Além disso, scu uso é livre com código fonte disponivel. Baseando-se nessas vantagens, o Protégé foi escolhido como software de edição utilizado neste trabalho.

\subsection{Linguagem RDQL}

A linguagem RDQL (RDF: Data Query Language) (Seaborne, 2004) possibilita a consulta em documentos no formato RDI de maneira similar à feita pela linguagem $S Q I . \mathrm{cm}$ bases de dados.

Como já mencionado, documentos RDF são formados por triplas do tipo (objeto, verbo, predicado). No caso da linguagem OWL essas triplas se mantém, sendo que as classes ou instâncias fazem o papel de objeto, as propriedades ou relaçōes fazem o papel de verbo e o predicado é o valor dessas propricdades ou relações. Dessa forma, pode-se utilizar RDQI, para consultas em documentos OWL.

A Figura 13 mostra uma consulta RDQL simples. Nela pode-se perceber os elementos fundamentais das consultas RDQL. $A$ primeira linha traz a lista de variáveis consultas, representadas por sinais "?" (interrogação) antes de seu nome. No caso, estamos procurando por valores de var1 e var2.

\footnotetext{
2s http://protege.standford.cdu
} 
A segunda linha traz a condição que deve ser satisfeita, no formato de triplas. Neste caso estamos buscando por possiveis valores de var1, que tenham a propricdade nm:propricdade e que cssa propricdade tenha valor var2. Valores que objetos do documento (instâncias, classes, propriedades, namespaces, etc.) são delimitados por sinais de $<\mathrm{e}\rangle$.

A terceira linha é opcional e indica os namespaces utilizados. No exemplo, é indicado que nm é a abreviação para o namespace <http://www.exemplo.com.br/exemplo.rdf\#>. (Caso) o namespace não seja especificado então será assumido sempre o namespace padrão do documento. Dessa maneira, a consulta retorna conjuntos de valores para varl e var2 que satisfaçam a tripla em questão.

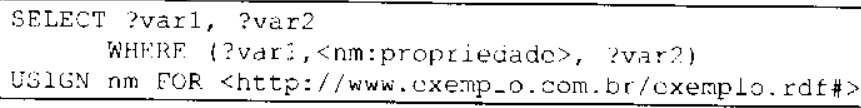

Figura 13 - Exemplo de consulta RDQL simples

\subsection{Web Semântica}

L'ma das iniciativas mais relevantes envolvendo ontologias é a Web Semântica. () projeto é gerenciado pelo World W'ide W'eh Consortium (W3C) ${ }^{x}$ e tem como principal objetivo modificar a forma como a web é desenvolvida c utilizada. A idéia é possibilitar serviços inteligentes com processamento automático e criar ambiente no qual agentes de software e usuários possam trabalhar de forma cooperativa (Berners-Lee et al., 2001).

Originalmente a web foi construída para concepção humana e as páginas H'I'MIs não são semanticamente assimiláveis para computadores por não terem representação formal apropriada. Para suprir essa deficiência, a Web Semântica utiliza os padrōes XML, RDF, RDF Schema e ()WL para classificação dos conteúdos dentro em ontologias.

\footnotetext{
${ }^{24}$ http://www.w3c.org
} 
A maior motivação do projeto é transformar dados c aplicativos em elementos úteis, legivcis e compreensíveis para o software, ou, mais exatamente, para os agentes inteligentes, de forma a facilitar-lhes a comunicação dinàmica, a cooperação e o comércio eletrônico entrc empresas Para isso, oW3C definiu nova hierarquia de camadas (Figura 14) (Koivunen \& Miller 2001) e sugeriu linguagens e padrões para elas.

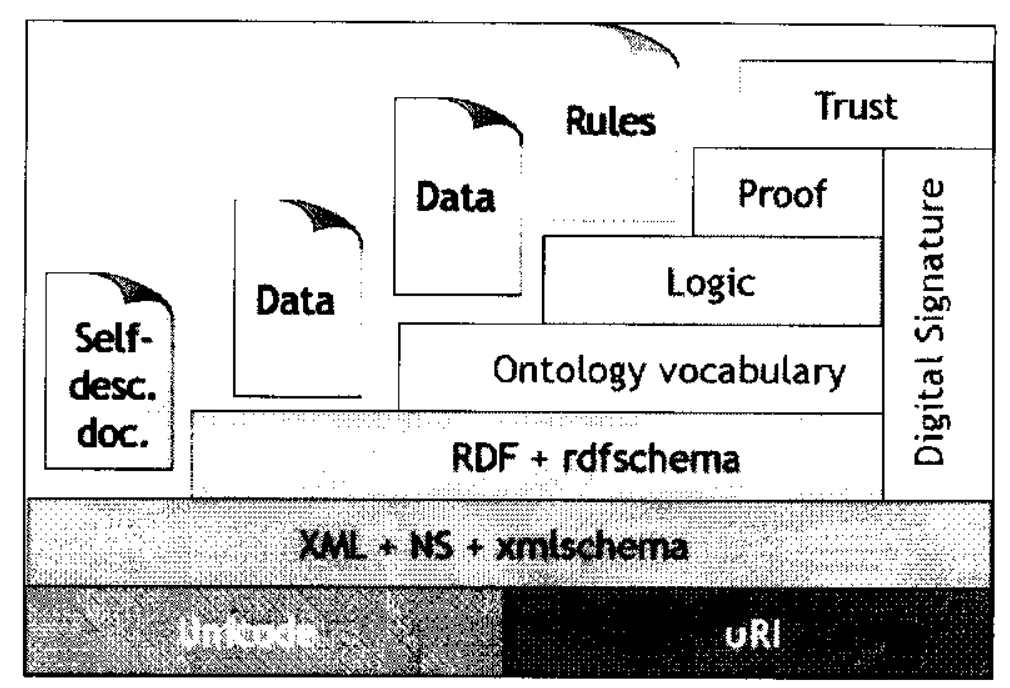

Figura 14 - Arquitctura da Web Semântica (Koivunen \& Miller 2001)

A camada Unicode/LRI traz formas de referenciar de documentos de mancira única. Já é utilizada na web atual por meio das L'RLs. A camada XMI(S) possibilita a estruturaçäo dos dados em hierarquias modeladas pelo próprio desenvolvedor. Documentos escritos em XMI. podem ter sua estrutura rigidamente estruturada por uso de DTDs ou XMI. Schema. Tal caracteristica permite que agentes computacionais separem o conteúdo de cada dado por meio das marcações (tags) associadas a ele. Por exemplo, o conteúdo da marcação <autor> é extraído separadamente da marcação $<$ titulo $>$.

Já RIF(S) serve como base para o processamento de metadados. Permite a representaçào de relações entre objetos e melhores funcionalidades para representar semântica. Documentos RDF são compostos por declaraçōes sobre os recursos (também denominados objetos), sendo que cada declaração é composta pelo objeto, uma propriedade e o valor dessa propriedade, que pode ser outro objeto. 
A camada de ontologias é a mais importante, pois é responsável por oferecer mecanismos para que os conteúdos possam ser representados com expressividade semântica. $A$ linguagem $O W L$, c utilizada para representar os conceitos presentes nos documentos $u e b$.

As demais camadas estão em desenvolvimento. A camada lógica oferecerá mecanismos para realizar inferências a partir de documentos da Web Semântica. Inferências feitas por um agente de software poderão ser aproveitadas por outros agentes. As camadas de prova e confiança oferecerão formas para que seja avaliada a confiabilidade de um agente e das conclusões feitas por ele.

\subsection{Considerações Finais}

Jiste capitulo apresentou os principais conceitos de ontologias, seus bencfícios, linguagens para representação e ferramentas para manipulação. (Ontologias têm despertado grande interesse em pesquisadores com o objetivo de represcntar informaçòes com nível scmântico.

Fim virtude das dificuldades de seleção e recuperação de informaçào em sistemas computacionais, particularmente a Internet, ontologias constituem técnica adequada $e$ imprescindivel para as necessidades de comunicação e para auxiliar o reuso automático de informaçōes (Freitas, 2003).

Porém, o uso de ontologias em sistemas computacionais é tema relativamente novo. A definição do padrão de linguagem pelo consórcio W3C ocorreu há menos de 3 meses da escrita desta dissertação. Isto demonstra que o tema ainda está emergindos e as principais vantagens do uso de ontologias estão por serem observadas nos próximos anos. 


\section{Uso de Ontologia para Classificação de Vulnerabilidades em Sistemas Computacionais}

\subsection{Considerações Iniciais}

Neste capítulo é apresentada a solução adotada com o objetivo de auxiliar a interoperabilidade semàntica entre as ferramentas de segurança. Para isso, é proposta uma ontologia para classificação das vulnerabilidades em sistemas computacionais.

Um dos problemas a serem enfrcntados para a criação de ontologias é a catalogaçào dos itens a serem inseridos. Tal problema é ainda mais crítico no caso do dominio em questão, já que vulnerabilidades são descobertas todos os dias.

Como já mencionado, o CVE apresenta catalıgação das vulnerabilidades conhecidas, com rígido controle de quais vulnerabilidades são inscridas ou retiradas desse repositório. Devido a isso, optou-se por utilizar o repositório de vulnerabilidades do projeto CVE como ponto de partida para a ontologia. Na realidade, baseando-se no fato de que o CVE tem ampla aceitação entre a comunidade de scgurança, seu uso foi fundamental para que a ontologia viesse a representar conhecimento já estabelecido no domínio em questão. Seria, portanto, inviável e desaconselhável não utilizar o projeto.

Dentro do projeto CVF, seus membros discutem de forma colaborativa as cntradas da base de vulncrabilidades. Fssas entradas foram aproveitadas para o desenvolvimento da ontologia. Além disso, como mencionado na seção 1.1, o Iaboratório Intermídia do IC.MCUSP há anos efetua pesquisas na área de Segurança Computacional e o conhecimento adquirido durante esse tempo foi aproveitado neste trabalho. Conceitos de classes, relacionamentos e instâncias inseridos na ontologia foram discutidos entre os membros do grupo para que pudessem descrever a o mais próximo possível da realidade. 
Este trabalho está inserido no mesmo contexto do trabalho de Bernardes (2002) e Martimiano (2003). Lim seu trabalho de doutorado, Bernardes propõe a modelagem da segurança computacional como um sistema de informação, utilizando tecnologias de Datu W'arehouse e Mineração de Dados para extração de conhecimento c tomada de decisão.

Já Martimiano (2003), em seu doutorado, está desenvolvendo ontologia para o domínio de incidentes de segurança e seus relacionamentos dentro da segurança da computação. Pretende se que aspectos de confidencialidade, integridade, disponibilidade, autenticação c não-repúdio estejam presentes nessa ontologia.

() trabalho aqui apresentado faz parte da ontologia proposta por Martimiano. As duas ontologias, juntas, formarão uma ontologia mais abrangente na área de scgurança da informação. As informações geradas a respeito de vulnerabilidades e incidentes de segurança serão repassadas para o sistema de informação de Bernardes processar e alimentar o Data W'arehruse.

\subsection{Metodologia Utilizada}

Para o desenvolvimento da ontologia, foram scguidos passos baseando-se na metodologia proposta por Noy e McGuinness (2001). As seguintes etapas compreenderam o desenvolvimento: determinação do domínio e escopo da ontologia, enumeração dos termos que comporão a ontologia, construção da hierarquia de classes, criação dos atributos c rélacionamentos, implementação da ontologia e instanciação das vulnerabilidades. A seguir sâo descritas as atividades efetuadas em cada etapa.

\subsubsection{Determinação do domínio e escopo da ontologia}

A determinação do domínio foi feita pela própria proposta deste trabalho. O objetivo ć o desenvolvimento de uma ontologia para mapear o domínio de vulnerabilidades em sistemas computacionais.

Pretende-se que difcrentes aplicaçōes possam referenciar uma mesma vulnerabilidade e efetuarem buscas a softwares, correções, fabricantes, formas de exploração, conseqüèncias c outras vulnerabilidades corrclatas. 


\subsubsection{Enumetação de termos importantes no domínio}

Fissa fase consistiu em criar uma lista com os termos da ontologia. Para isso, foram analisados boletins de alerta de novas vulnerabilidades e os textos presentes na base do projeto CVF. Os termos presentes na Figura 15 foram considerados pertinentes para serem inseridos na ontologia.

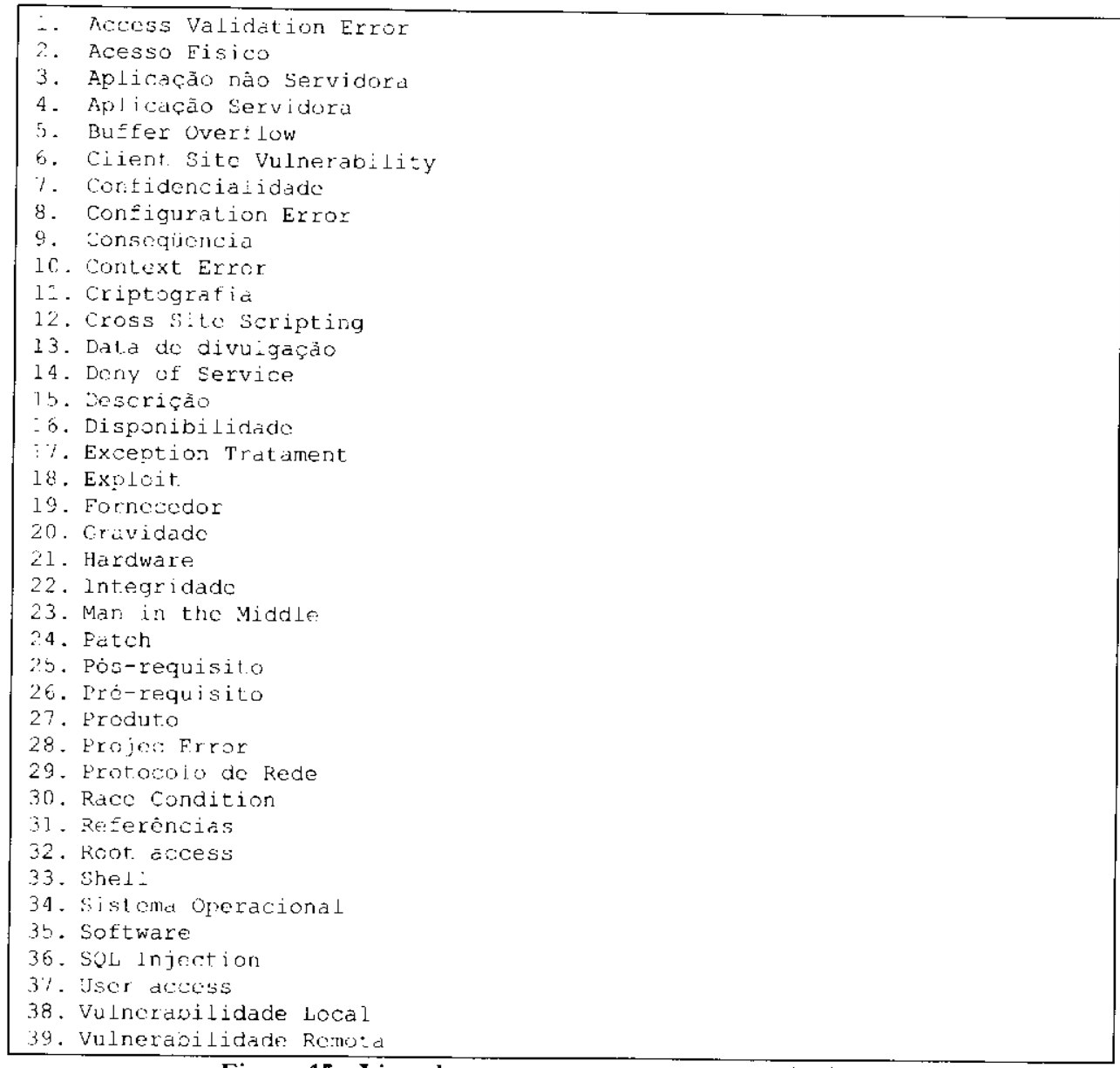

Figura 15 - Lista de termos constantes na ontologia

'Tanto os alertas analisados quanto a base CVE estâo em língua inglesa. $\Lambda$ ssim, para evitar perda de significado alguns termos foram catalogados na língua original. Traduçoess foram feitas apenas em palavras cujo termo correlato em portugués é imediato. Por exemplo, vulnerability (vulncrabilidade). 


\subsubsection{Definição da hicrarquia de classes}

Nessa etapa (apresentada na Ï̈̈gura 16) os termos resultantes da fase anterior foram colocados em hierarquias de forma que os mais genéricos foram especializados em termos mais específicos. Para isso, foi utilizada combinação a estratégia middle-up (Lschold \& Gruninger, 1996). Isto ć, os principais conceitos foram definidos primeiro e foram refinados e/ou c generalizados para a definiçào das classes mais específicas e das mais abstratas.

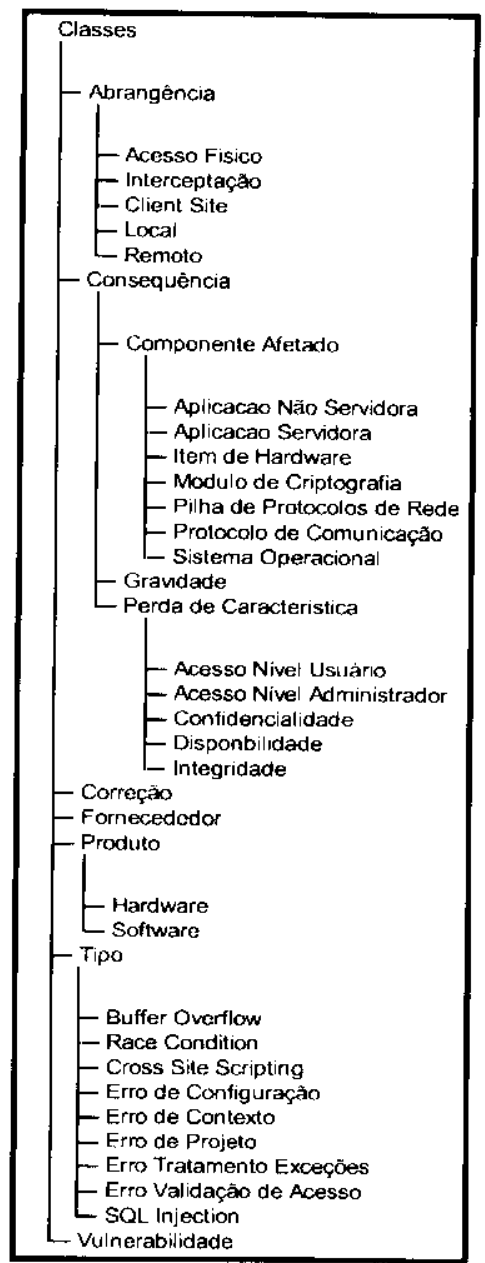

Figura 16 - Hierarquia de termos para formação de classes e subclasses

Como será visto na seção 5.3, algumas subclasses foram transformadas em instâncias porque dentro delas não havia conceitos a serem transmitidos para niveis inferiores. 


\subsubsection{Criação dos atributos e relacionamentos}

Cada classe apresenta variáveis que armazenam valores descritivos de suas características. Fissas variáveis são conhecidas como atributos. Por exemplo, a classe Vulnerabilidade tem o atributo Descrição.

Alguns atributos têm como possíveis valotes outras classes. Por exemplo, a classe Produto possui o atributo possuiFornecedor, cujo valores possiveis são instâncias da classe Fabricante. Esses atributos que unem duas classes são conhecidos como relacionamentos.

Nessa etapa do desenvolvimento foram definidos os atributos e os relacionamentos. A partir desse ponto, a ontologia já possui seu modelo conceitual e os conceitos de classes, relacionamcntos, atributos e instâncias definidos.

O modelo conceitual da ontologia, bem como a descrição de suas classes, e relações, atributos e instâncias são apresentados na Seção 5.3.

\subsubsection{Implementação da ontologia}

Lissa etapa consistiu em partir do modelo conceitual e codificá-lo em linguagrem com capacidade de representaçào semântica. Para isso, utilizou-se a linguagem OWI.

A escolha da linguagem levou em conta of fato de que o consorcio W3C recomenda a OWI como linguagem para representação de ontologias e conteúdos da Web Semântica. Para auxílio na implementação foi utilizada a ferramenta Protégé. (Vide Capítulo 4 para maiores detalhes sobre (JWI. c Protégé).

Os detalhes sobre a implementação da ontologia estão presentes na Seção 5.5 .

\subsubsection{Instanciação das vulnerabilidades}

Para que fosse possivel a validação da ontologia, cntradas da base CVt: foram cadastradas, classificando nas respectivas classes as vulnerabilidades, fornecedores, produtos, componentes afetados, correções, descrições, pré-requisitos, etc. 
A ferramenta de ICAT $^{31}$ também foi utilizada. 'Tal ferramenta of crece interface de busca às vulnerabilidades presentes na base $\mathrm{CVE}$, com informaçòes a respeito de atributos como correçócs, softwares e referências a respcito das vulnerabilidades. Dessa maneira, a ferramenta ICAT auxiliou no processo de pesquisa por características de cada vulnerabilidade a ser cadastrada.

Atualmente, a base do projeto CVI conta com 6459 vulnerabilidades. Fiscolheu-se cadastrar as vulnerabilidades indexadas pelo projeto ICAT durante o mês de março de 2003. Isto correspondeu a 117 entradas. O Anexo I traz o extrato utilizado como fonte das vulnerabilidades.

\subsection{Modelo Conceitual da Ontologia Proposta}

Essa scção apresenta a ontologia proposta para classificação de vulnerabiliclades. Sào descritas suas classes, subclasses, relações e instância pré-definidas. Cada classe representa um conceito existente no domínio em questão e cada relação represcnta ligação semântica entre conccitos.

Para a ampliação da ontologia, cada um dos conceitos pode ser iterativamente refinado em subclasses hipônimas, ou seja, subclasses que representam particularidades de significado dentro do conceito mais genérico. Posteriormente, cada uma dessas subclasses hipônimas podem receber novos relacionamentos, aumentando, assim, a riqueza da representação semântica.

Um excmplo de relação hiponímia ocorre com o conceito Produto, pois pode ser subdividido em Software e Hardware. Software, por sua vez, pode ser subdividido em Sistemas Opcracionais, Servidores, Gcrenciadores de Janelas, etc. No exemplo citado, Software está cm rclação de hiponímia com Produto.

Já a relação de hiperonímia é oposta à hiponímia, uma vez que parte do significado mais específico para o genérico. Assim, no exemplo mencionado Software está em relação de hiperonímia com Sistemas Operacionais.

i: http://icat.nist.gov 
Algumas das classes representam conceitos que no futuro podem surgir em outras ontologias. Fissas classes poderão ser ligadas por meio da relação de sinonímia. Entende-se por sinonimia a relação que une dois conceitos equivalentes. Por exemplo, a classe Software poderia ligar-se com uma classe equivalente em uma ontologia que descreva o processo de desenvolvimento de software. Assim, a ontologia de vulncrabilidades agtegaria os conceitos scmânticos presentes na ontologia de processo de desenvolvimento de software, da mesma forma que essa última também agregaria os conceitos presentes na primeira.

A Figura 17 apresenta o modelo conceitual da ontologia de vulnerabilidades. As classes são representadas por retângulos, cnquanto que as relações são representadas pelas setas. Pode-se perceber que algumas setas (relações) são do tipo isa. Essas relações são do tipo superclasse-subclasse, isto é, represcntam classes que são subclasses daquclas para onde a relação aponta. Fisse tipo de relação é também conhccida como pai-filho.

Alguns dos conceitos mencionados na seçào anterior foram modelados como instâncias e não como subclasses. Isto ocorreu porque esses conceitos năo guardavam informações que devessem ser transmitidas para descendentes (Noy et al., 2001). Ou seja, esses conceitos representavam o último nivel de especializaçâo. 


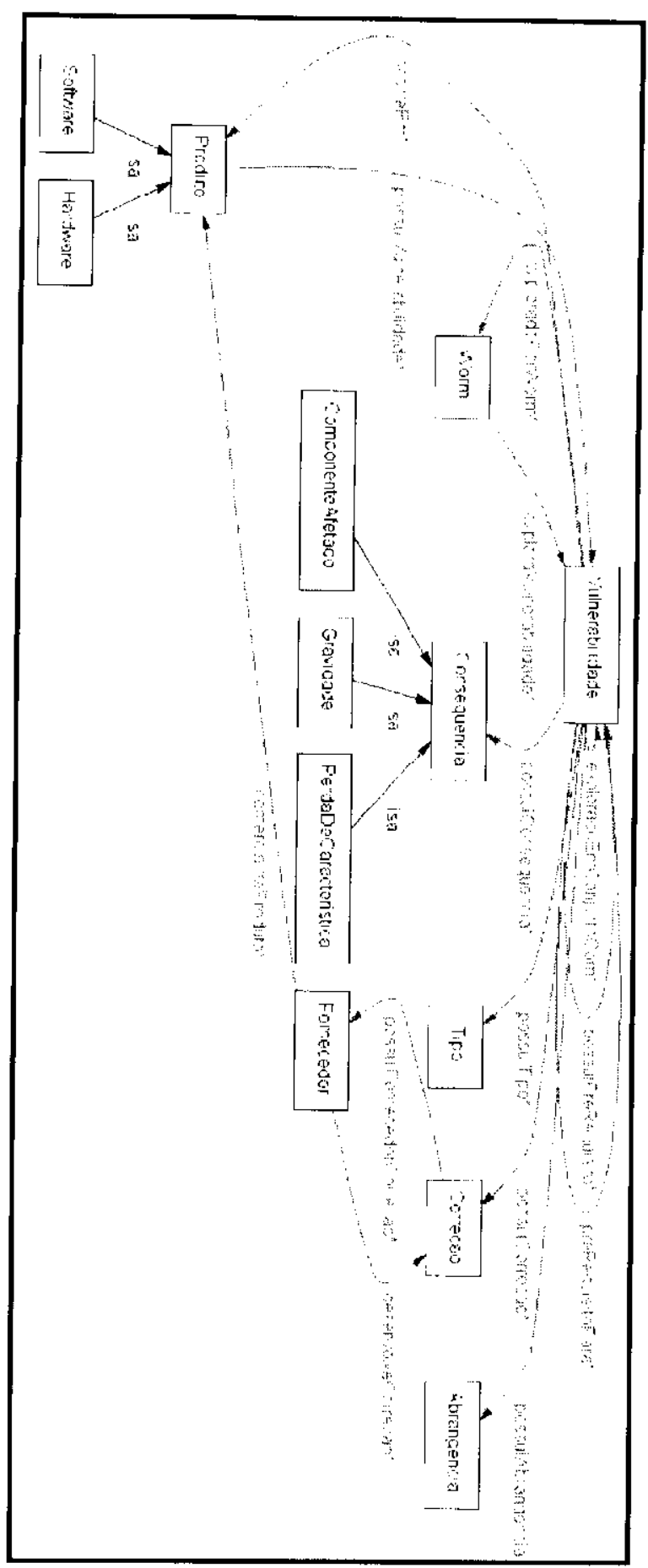

Figura 17 - Modelo conceitual da ontologia desenvolvida

()s conceitos modelados como instâncias não estão representados na Fïgura 17. As figuras a seguir apresentam esses conceitos e as classes em que foram inseridos. 


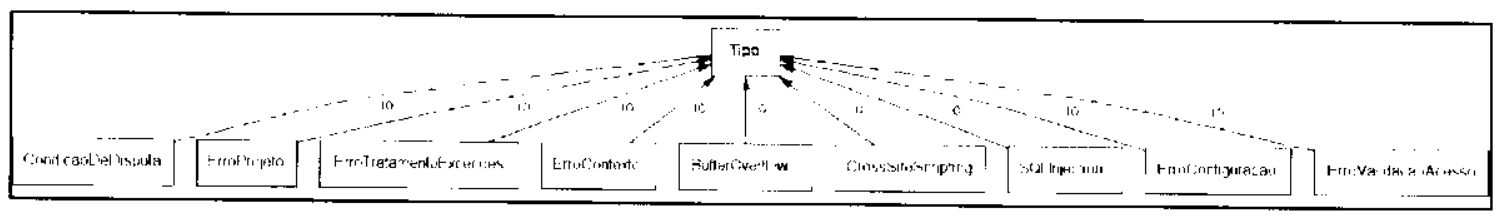

Figura 18 - Instâncias da classe Tipo

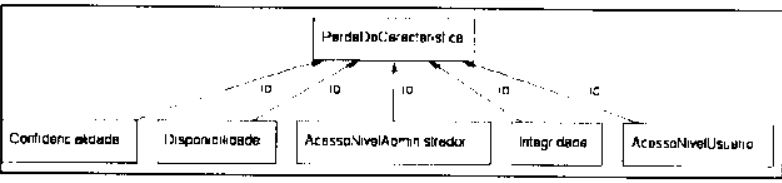

Figura 19 -Instâncias da classe PerdaDeCaracteristica

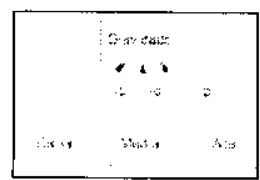

Figura 20 - Instâncias da classe Gravidade

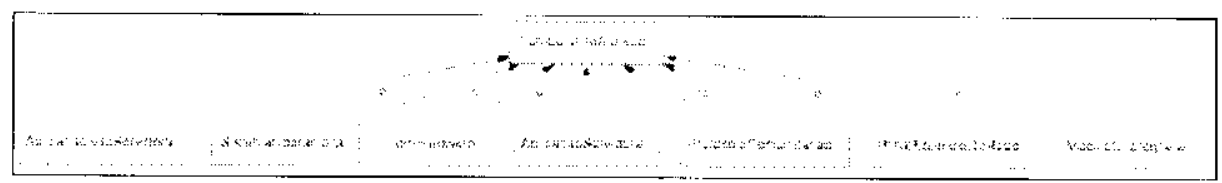

Figura 21 - Instâncias da classe ComponenteAfetado

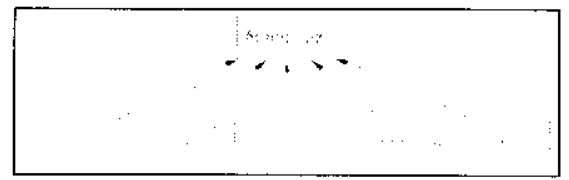

Figura 22 - Instâncias da classe Abrangencia

A próxima seção faz a descrição das classes, relações, atributos e instâncias mostradas.

\subsection{Descrição das Classes e Relações da Ontologia}

Essa seção apresenta a descrição das classes, relações e atributos da ontologia. Lintende-se por relações as propriedades que têm como possívcis valores instâncias de outras classes c atributos são as propricdades cujos valores possíveis são números, datas ou strings.

No caso de classes com instàncias cadastradas então as instâncias são também descritas a seguir. 


\subsubsection{Classe Vulnerabilidade}

Nessa classe são armazenadas as vulnerabilidades cadastradas. A partir dela partem as relações que informam qual o tipo de vulncrabilidade em questão, sua abrangência (local ou remota), suas conseqüências, o software a que está atribuída, correções e relacionamentos com outras vulnerabilidades.

A classe Vulnerabilidade possui atributos que armazenam o nome da vulncrabilidade, breve descriçào e referèncias que podem scr, por exemplo, links para páginas com descriçôcs mais detalhadas.

\section{Atributos da classe Vulnerabilidade}

referencia

Armazena links rclacionados à vulnerabilidade.Tais links podem apontar para páginas com descrição mais detalhada da vulnerabilidade, noticias, exploits, e outras informações em geral.

\section{descricao}

Armazena breve texto que descreve a vulnerabilidade. () texto é retirado da base do projeto CVE.

\section{dataDivulgacao}

Armazena a data em que a vulnerabilidade foi divulgada.

\section{Relacionamentos da classe Vulnerabilidade}

\section{ocorreEm}

Relaciona a vulnerabilidade ao produto em que ocorre. (Os possiveis valores para essa rclação são as instâncias da classe Produto ou de alyuma de suas subclasses.

Essa propriedade é inversa à propriedade possuiVulnerabilidade.

possuiTipo

Relaciona a vulnerabilidade ao seu tipo, que pode ser qualquer instância da classe Tipo.

possuiCorrecao 
Relaciona a vulnerabilidade às suas correções. Tais correções são armazenadas na classe Correção.

possuiAbrangencia

Indica qual a abrangência de exploração da vulnerabilidade. $A$ indicação é feita com instâncias da classe Abrangência.

\section{possuiConsequencia}

Indica quais as conseqüências da exploração da vulnerabilidade. Seus valores podem ser as instâncias de qualquer subclasse da classe Consequencia.

preRequisitoPara

Indica para quais vulnerabilidades a exploração dessa é pré-requisito.

Essa propriedade é inversa à propriedade possuiPreRequisito.

possuiPreRequisito

Indica quais vulnerabilidades devem ser exploradas para que a exploração dessa seja possível.

Essa propriedade é inversa à propriedade preRequisitoPara.

exploradoEmConjuntoCom

Indica quais vulnerabilidades comumente são exploradas em conjunto com a atual. Por exemplo, vulnerabilidades que são exploradas por um mesmo worm.

\subsubsection{Classe Fornecedor}

Fissa classe armazena dados referentes às cmpresas ou organizaçŏes desenvolvedoras de softwares e correções. Entre as informaçōes armazenadas estão: nome do fabricante, cndereço de contato, site e os produtos que desenvolve. $\Lambda$ classe Fornecedor está relacionada à classe Produto que, por sua vez, está relacionada à classe Vulnerabilidade. Por meio dessas relações é possivel identificar vulnerabilidades em softwares de um mesmo fabricante.

\section{Atributos da classe Fornecedor}

contato_email 
Essa propriedade armazena enderç̧o(s) de e-mail para contato com o fornecedor.

contato_fone

Essa propriedade armazena telefone(s) para contato com o fornecedor.

contato_website

Fissa propriedade armazena o endereço do site do fornecedor.

\section{Relacionamentos da classe Fornecedor}

comercializaProduto

Relaciona o fornecedor aos produtos que comercializa ou distribui.

Essa propriedade é inversa à propriedade possuiFornecedor.

\section{desenvolveCorrecao}

Relaciona o fornecedor às correções de vulnerabilidades que desenvolveu.

Tissa propriedade é inversa à propriedade possuiFornecedorCorrecao.

\subsubsection{Classe Produto}

Tissa classe armazena informaçòes a respeito dos produtos que apresentam vulnerabilidades cadastradas. Possui duas subclasses: Software c Hardware.

\section{Atributos da classe Produto}

versao

Armazena a versão correspondente a cada produto catalogado. nomeOriginal

Armazena o nome com o qual o produto é referenciado pelo fabricante.

\section{Relacionamentos da classe Produto}

\section{possuiFornecedor}

Essa relação interliga cada produto com instâncias da classe Fornecedor. 
Essa relação é inversa à relação comercializaProduto.

possuiVulnerabilidade

Interliga cada produto a instâncias da classe Vulnerablidade.

Essa relação é inversa à relação ocorreEm.

\section{Subclasses da classe Produto}

Software

\section{Hardware}

\subsubsection{Classe Software}

Essa classe, subclasse da classe Produto, armazena informações a respeito dos softwares que possam apresentar eventuais falhas. N'cla são encaixados sistemas operacionais, programas servidores, bibliotecas e demais softwares que possam apresentar vulnerabilidades. Como é uma subclasse da classe Produto, a classe Software herda scus atributos e relacionamentos.

\subsubsection{Classe Hardware}

Iissa classe, subclasse da classe Produto, armazena os itens de hardware que poderào scr associados a vulnerabilidades.

\subsubsection{Classe Correcao}

Essa classe armazena informações sobre correçōes (patches) das vulnerabilidades cadastradas.

\section{Atributos da classe Correcao}

url

Endereço wel que leva atć a correção da vulnerabilidade.

\section{Relacionamentos da classe Correcao}

\section{PossuiFornecedorCorrecao}

Essa propriedade relaciona cada Correcao com uma instância da classe Fornecedor, indicando a empresa ou entidade que disponibilizou a correção. 
Essa propriedade é inversa à propriedade desenvolveCorrecao.

\subsubsection{Classe Abrangencia}

Essa classe armazena informações sobre como a vulnerabilidade pode ser explorada e quais as condições neccssárias para que isso ocorra. Esssa classe apresenta as seguintes instâncias cadastradas:

\section{Instâncias da classe Abrangência}

\section{AcessoFisico}

O acesso físico é caracterizado quando o invasor tem oportunidade de estar no mesmo ambiente que a máquina, sendo capaz de interagir fisicamente com ela.

\section{Interceptacao}

A interceptação é caracterizada quando invasor está localizado em determinado ponto da conexão em que pode interceptar c/ou controlar a troca de informação entre a vítima e o servidor acessado. Também é conhecido como man in the middle.

\section{LadoCliente}

Vulnerabilidades com essa abrangência ocorrem em produtos utilizados pelo usuário, que sofre a invasào ao conectar-se cm servidor remoto.

\section{Local}

A exploração da vulnerabilidade pode ser feita localmente, isto é, o invasor precisa necessariamente possuir conta de acesso à máquina.

\section{Remoto}

A exploração da vulnerabilidade podc ser feita remotamente, isto é, pode ser feita por meio da rede, sem que o invasor tenha previamente conta de acesso à máquina.

\subsubsection{Classe Tipo}

Essa classe armazena os diversos tipos possiveis de vulncrabilidades. 


\section{Instâncias da classe Tipo}

\section{BufferOverflow}

Vulncrabilidades que ocorrem devido à tentativa de armazenar em um buffer quantidades maiores de dados do que foi projetado para suportar. Geralmente permite a execução de códigos arbitrários.

\section{CondicaoDisputa}

Vulnerabilidades desse tipo ocorrem devido à falta de atomicidade durante execução de código de verificação de segurança.

\section{CrossSiteScripting}

Ocorre quando aplicaçòes não fazem tratamento em dados enviados pelo usuário (invasor) e esses dados são repassados para outros usuários (vítimas). (icralmente estão presentes em aplicações avel).

\section{ErroConfiguracao}

Vulnerabilidades decorrentes a parâmetros de configuraçào que podem ser alterados pelos usuários

\section{ErroProjeto}

Vulnerabilidades causadas não por falha na implementação do sistema mas sim em seu design.

\section{ErroTratamentoExcecoes}

Vulnerabilidade que ocorrem devido à forma como o sistema lida com as exceções.

\section{ErroValidacaoAcesso}

Vulnerabilidade decorrente à falhas no mecanismo de controle de acesso.

\section{SQLInjection}

Ocorre quando os dados recebidos pela aplicação são repassados para consultas em bancos de dados sem a devida verificaçào. Lisses dados podem ser formatados de forma a manipular a consulta ao banco de dados, efetuando operações como: inserir, apagar ou modificar entradas. 


\subsubsection{Classe Consequencia}

Essa classe armazena informações das possíveis conseqüências da exploração de uma vulnerabilidade. É especializada nas subclasses abaixo.

\section{Subclasses da classe Consequencia}

\section{PerdaDeCaracteristica}

\section{Gravidade}

\section{ComponenteAfetado}

\subsubsection{Classe PerdaDeCaracteristica}

Jissa classe armazena informações referentes às características perdidas quando ocorre a exploração da vulnerabilidade.

\section{Instâncias da classe PerdaDeCaracterística}

\section{Confidencialidade}

A exploração da vulnerabilidade pode causar a divulgação de informações confidenciais.

\section{Disponibilidade}

A exploraçào da vulnerabilidade causa prejuizo à disponibilidade $\mathrm{d}$ o sistema

\section{Integridade}

A cxploração da vulnerabilidade causa a alteração não autorizada de informações

\section{AcessoNivelUsuario}

A exploração da vulnerabilidade permite que o invasor consiga acesso ao sistema com privilégio de usuário comum.

\section{AcessoNivelAdministrador}

$\Lambda$ exploração da vulnerabilidade permite que o invasor consiga acesso com privilégio de administrador 


\subsubsection{Classe Gravidade}

Fissa classe armazena informações referentes à gravidade da vulncrabilidade. As instâncias são extraídas do projeto ICAT e utiliza-se, portanto, os mesmos conceitos para gravidade Alta, Baixa, e Média.

\section{Instâncias da classe Gravidade}

Alta

São consideradas de gravidade alta as vulnerabilidades cuja exploração permita que o invasor tenha controle total sobre o sistema ou que execute códigos arbitrário, seja com nível de usuário ou de administrador.

Também são de gravidade alta as vulnerabilidades expressivas o suficiente para que haja boletins CERT a respeito das mesmas.

\section{Baixa}

Vulnerabilidades de gravidade baixa não acarretam maiores danos ao sistema a não ser por fornecer ao invasor informações que possam ser utilizadas para explorar outras vulnerabilidades.

\section{Média}

São consideradas de gravidade média as vulnerabilidades que não estejam classificadas como gravidadc Alta nem como Baixa.

\subsubsection{Classe ComponenteAfetado}

Essa classe armazena dados dos possiveis componentes do sistema afetados $\mathrm{em}$ decorrência da exploração de uma vulnerabilidade.

\section{Instâncias da classe ComponenteAfetado}

\section{AplicacaoNaoServidora}

Vulnerabilidades que ocorrem em aplicaçòes que não são servidoras de conexöes de rede.

\section{AplicacaoServidora}

Vunerabilidades que ocorrem $\mathrm{cm}$ aplicações servidoras de conexĩes.

\section{ItemHardwate}


Vulnerabilidades presentes em itens de Hardware. Fste é o caso, por excmplo, dos roteadores.

\section{ModuloCriptografia}

Vulnerabilidades que ocorrem em módulos de criptografia do sistema

\section{PilhaProtocoloRede}

Vulnerabilidades que ocorrem na implementação ou projeto da pilha de protocolos de rede.

\section{ProtocoloComunicacao}

Vulnerabilidades que ocorrem na implementação ou projeto de algum outro protocolo de comunicação.

\section{SistemaOperacional}

Vulnerabilidades que ocorrem no sistema operacional.

\subsection{Implementação}

Esssa seção traz a implementação da ontologia. Como mencionado, utilizou-se a linguagem OWL para representação das informaçōes e a ferramenta Protégé para auxilio na edição.

Os cabeçalhos da ontologia são mostrados na Figura 23. Nessa figura pode-se perceber a importação das definiçĩes das linguagens RDF, RDF Schema e OWL. Também é definido o namespace base da ontologia: "http://intermidia.icmc.usp.br/brandao/vulontology". Logo em seguida, a Iïgura 24 mostra a definição da classe Vulnerabilidade.

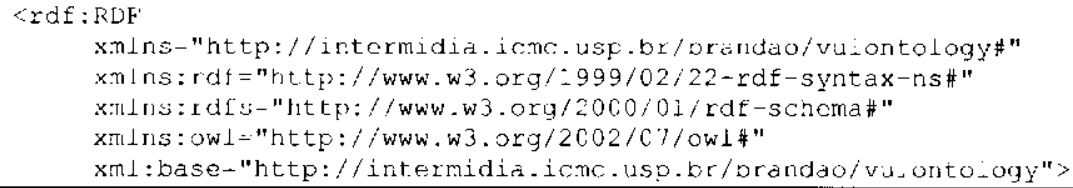

Figura 23 - Cabeçalhos da ontologia implementada

Durante a codificação da ontologia, os termos principais foram colocados em língua portuguesa e foram adicionadas as traduções para a língua inglesa. As marcações < rdfs:label> são utilizadas para isso. Portanto, ao referenciar determinado termo dentro da ontologia, podese utilizar o termo em português ou inglês. A Figura 24 mostra exemplo em que na definiçào da classe Vulnerabilidade é adicionada a tradução Vulnerability. 
<uW $\perp: C L a s s$ rdf: ID="Vu-ncrabilidade">

crdfs:comment>Essa alasse armazena as vulnerabilidades cadestradas na entologiae/rdts: coment>

$\left\langle\right.$ rdfs: $\perp_{\text {abel }} \mathrm{xm}-:$ : ang="pt">Vulneraoi_idade</rdfs:labe:>

<rdfs:label xmi:lang "on"svulnerabi-ity</rdfs:label> $\langle/$ ow $\perp$ : C ass $>$

Figura 24 - Exemplo de implementação: a classe Vulnerabilidade

A demais classes e atributos são definidas de maneira similar c a partir de então, vulnerabilidades, softwarcs, correçòes, fornecedores e outros dados podem ser inseridos. $A$ Figura 25 traz um exemplo de vulnerabilidade catalogada na ontologia.

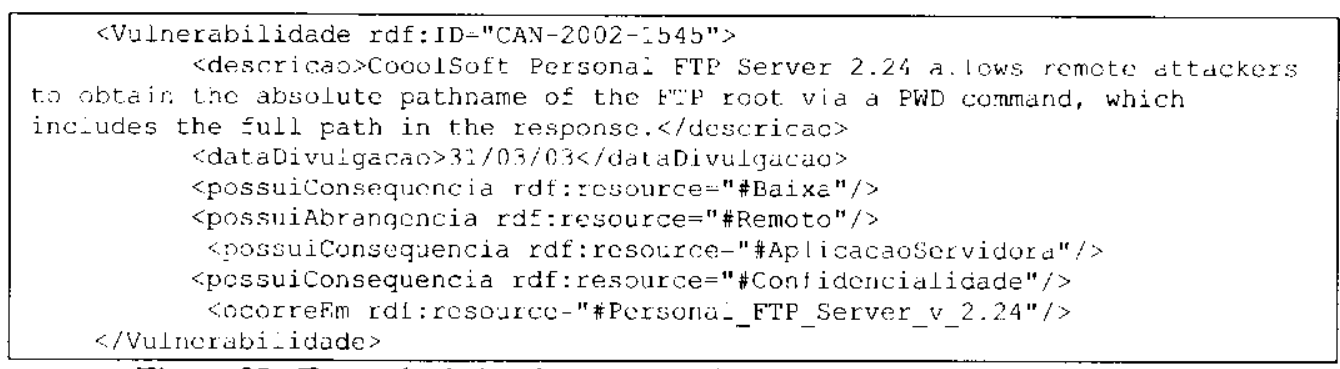

Figura 25 - Exemplo de implementação: instância da classe Vulnerabilidade

O Anexo II traz o código completo da ontologia implementada em linguagem (OWI, sem as vulnerabilidade instanciadas. As instancias das 117 vulnerabilidades, dos produtos, correções e das demais entradas da ontologia estão disponíveis para cópia em: http://cuba.intermidia.icmc.usp.br/gsi/vulontology.php

\subsection{Testes efetuados no sistema implementado}

Essa seção apresenta os testes efetuados na ontologia de maneira a validar os conceitos representados por suas classes e relações. Esses testes constituem de "perguntas" cfetuadas para a ontologia com as vulnerabilidades cadastradas.

Conforme já mencionado na Seção 5.2, após o desenvolvimento da ontologia foram cadastradas 117 vulnerabilidades presentes no projeto CVI: Portanto, os testes efetuados tiveram efeito sobre essas vulncrabilidades.

Os testes a seguir foram executados dentro da ferramenta Protégé, utilizando a interface de consultas RDQI. Os resultados são instâncias que indicam vulnerabilidades, produtos, correções, entre outros conceitos presentes na ontologia desenvolvida. 
Uma das grandes vantagens do uso de ontologias é a possibilidade de que novas ontologias podem ser agregadas à original, aumentando a riqueza semântica do sistema. Portanto, as consultas aqui mostradas poderiam ser expandidas, conforme novas ontologias forem sendo desenvolvidas em linguagem OWL, e agregadas à ontologia de vulnerabilidades.

\subsubsection{Teste 1: Busca por correções de uma vulnerabilidade}

Este teste consistiu em, dada uma vulnerabilidade, buscar por suas possiveis correções. Para isso, partiu-se de uma instância da classe Vulnerabilidade e utilizando a propriedade possuiCorrecao chegou-se a instancia(s) da classe Correcao.

A Figura 26 mostra a consulta RDQL utilizada para buscar por correçóes da vulnerabilidade CVE-2002-0387. () resultado da execução da consulta é a listagem de instâncias da classe Correcao que satisfazcm a relação mencionada.

SELECT ?C

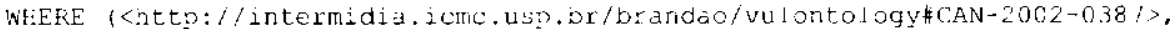

$\langle$ ht to://intermidia.icme.usp.or/brandao/vulontology\#possuicorrccaos, ?c)

Figura 26 - Consulta RDQL para busca por correçōes da vulnerabilidade CAN-2002-0387

A execução dessa consulta resultou nas seguintes instâncias presentes na Tabela 2. Esssass instâncias guardam correçōes para a vulnerabilidade em questão.

CAN-2002-0387-patch1

CAN-2002-0387-patch2

Tabela 2 - Resultado da busca por correções de uma vulnerabilidade CAN-2002-0387

\subsubsection{Teste 2: Busca por relaçōes entre vulnerabilidades c worms}

W'orms são programas que partem de um servidor infectado c lançam ataques a servidores remotos, explorando conjuntos de vulnerabilidades. Quando um desses servidores remotos é comprometido então o worm ali se copia c o utiliza como ponto de partida para novos ataques. Trata-se de um dos principais fatores de exploração de vulnerabilidades. Os exemplos dessa seção mostram que é possível utilizar a ontologia de vulnerabilidades para relacionar worms às falhas que exploram e suas possiveis correções. Para isso, foi adicionada uma nova classe na ontologia: classe Worm. 
Essa classe foi criada apenas a título de ilustração para este cxemplo e originalmente não fazia parte da ontologia. Fila abriga instâncias que representam os worms. A classe possui dois atributos: referencia e descricao, que armazenam, respectivamente, URIS de referência ao ưorm e uma breve descrição de seu funcionamento. Também foi criada a relação) exploraVulnerabilidade, que indica quais vulnerabilidades são cxploradas por cada instancia da classe Worm. Finalmente, para execução deste teste, foram cadastrados os wom.s BLASTT:R, CODERED, NIMDA e SI.AMMER e as vulnerabilidades que eles exploram.

Após os dados terem sido cadastrados, a consulta presente na Figura 27 póde ser utilizada para buscar por vulnerabilidades exploradas pelo worm CODERFD. Como resultado, obteve-se as vulnerabilidades presentes na Tabela 3.

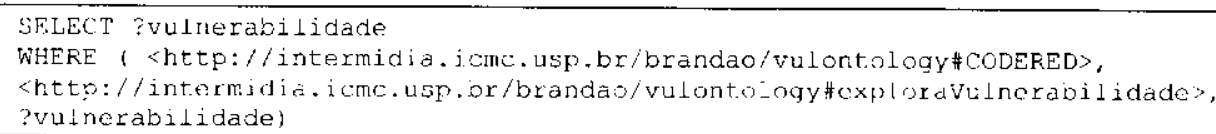

Figuta 27 - Consulta RDQL para busca de vulnetabilidades exploradas pelo worm CODERED

\begin{tabular}{|l|}
\hline ?vulnerabilidade \\
\hline CVE-2001-0500 \\
\hline CVE-2001-0506 \\
\hline
\end{tabular}

Tabela 3 - Resultado da busca de vulnerabilidades exploradas pelo worm CODERED

Consulta similar foi executada afim de que a partir da vulncrabilidade possa-se localizar os norms que a exploram. $\Lambda$ lïgura 28 mostra a consulta para buscar por norms que exploram a vulnerabilidade (VEi-2001-0333. No caso, obteve-se como resultado o worm NIMDA.

<htto://intermidia.icme.lisp.br/brandao/vuionto-ogy\#exploravulnerabilidade>,

<ht.t.p://intermidie. i cme. Lisp.br/brandao/vuionto-ogy \#CVE-2C0:-0333>1

Figura 28 - Consulta RDQL para busca de worms que exploram a vulnerabilidade CVE-2001-0333

\subsubsection{Teste 3: Busca por relacionamentos entre Vulnerabilidades e Produtos}

Nos testes aqui apresentados o objetivo foi identificar quais vulnerabilidades estão, presentes em determinado produto e vice-versa. No primeiro exemplo, partimos da classe Vulnerabilidade c usando a relação ocorreEm chegamos a instâncias da classe Produto. $\Lambda$ Figura 29 mostra a consulta utilizada para listar nome e versão dos produtos que são afetados pela vulnerabilidade (VH-2001-0333. Como resultado obteve-se os softwares IIS versão $4.0 \mathrm{e}$ IIS versão 5.0 (Tabela 4). 
SELECI ?nome, ?versao

WHERE (<hEtp://intermidia.icme.usp.or/brandao/vionto oqy \#CVE-200:-0.33.3>,

<http://intermidia.icmc.usp.br/orandao/vulontology\#ocorreEm>, ?produto, ,

( ?produto, <http://intermidia.icmc.usp.br/brandac/vulontoloqy\#nomeoriginal>,

?tome )

( ?produto, <http://intermidia.icmc.usp.ior/brandao/vulontology\#versao>, ?versao,

Figura 29 - Consulta RDQL para busca de nome e versão de produtos afetados pela vulnerabilidade CVE-2001-0333

\begin{tabular}{|l|l|}
\hline ?nome & ?versao \\
\hline IIS & 4.0 \\
\hline IIS & 5.0 \\
\hline
\end{tabular}

Tabela 4 - Resultado da busca de nome c versão de produtos afetados pela vulnerabilidade CVE-20010333

O exemplo a seguir mostra a busca por vulnerabilidades que ocorrem no produto IIS versão 4.0. Como resultado, obteve-se as seguintes vulnerabilidades presentes na Tabela 5.

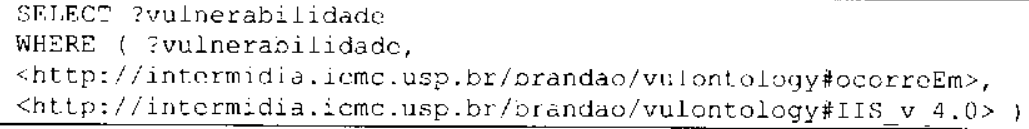

Figura 30 - Consulta RDQL para busca de vulnerabilidades que ocorrem no produto IIS 4.0

\begin{tabular}{|l|}
\hline ?vulncrabilidade \\
\hline CVE-2000-0884 \\
\hline CVE-2001-0506 \\
\hline CVE-2001-0333 \\
\hline
\end{tabular}

Tabela 5 - Resultado da busca de vulnerabilidades que ocorrem no produto IIS 4.0

Uma terceira possibilidade é partindo-se de um produto, buscar por worms que cxploram vulnerabilidades ali presentes. A consulta está mostrada na Higura 31. Como se pode observar, tem construção similar às anteriores. Neste caso, o produto consultado foi IIS versão 4.0 e como resultado da execução têm os worms CODERED e NIMDA.

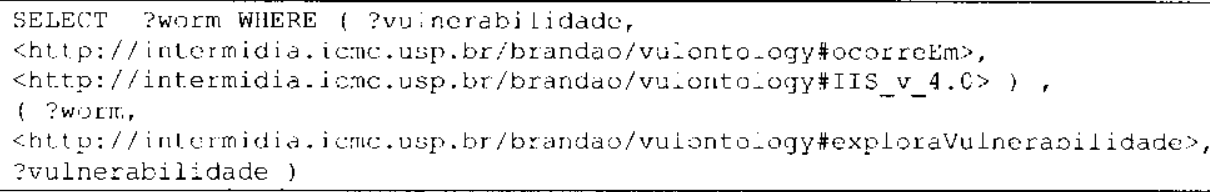

Figura 31 - Consulta RDQL para busca por worms que afetam o produto IIS 4.0 


\begin{tabular}{|l|}
\hline ?worm \\
\hline NIMDA \\
\hline CODERED \\
\hline NIMDA \\
\hline
\end{tabular}

Tabela 6 - Resultado da busca por worms que afetam determinado produto

\subsubsection{Teste 4: Busca por relacionamento entre duas ou mais Vulnerabilidades}

Nessa seção são ilustrados exemplos de uso da ontologia para correlacionar vulnerabilidades. O primeiro excmplo, ilustrado na Figura 32, indica como é possível partir de uma determinada vulnerabilidade, no caso CAN-1999-0547, c encontrar outras cuja exploração é pré-requisito para que a primeira seja explorada.

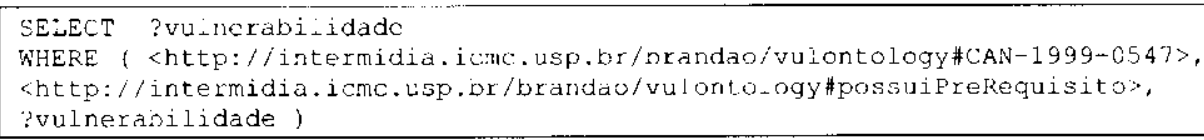

Figura 32 - Consulta RDQL para busća por pré-requisitos para a exploração da vulnerabilidade CAN1999-0547

Nesse caso, busca-se por pré-requisitos da vulnerabilidade CAN-1999-(0547. () resultado da execução dessa consulta é as vulnerabilidades CAN-1999-0631 e CAN-1999-(0554 (Tabela 7).

\begin{tabular}{|l|}
\hline ?vulnerabilidade \\
\hline CAN-1999-0631 \\
\hline CAN-1999-0554 \\
\hline
\end{tabular}

Tabela 7 - Resultado da busca por pré-requisitos da vulnerabilidade CAN-1999-0547

$\Lambda$ relação de pré-requisito no exemplo mostrado é justificada pelo fato de a vulnerabilidade consultada (CAN-1999-0547) consistir em falha de autenticação do servidor de acesso remoto S.SH que ocorre devido à presença do arquivo . rhosts na área do usuátio. Já as vulnerabilidades indicadas como pré-requisito referem-se a capacidade de o invasor utilizar o servidor NFS (network, filesystem) para a criação de arquivos arbitrários - inclusive () arquivo mencionado. Portanto, a exploração da falha do servidor NFS permite a exploração da falha do servidor SSH. Maiores detalhes sobre as vulnerabilidades CAN 1999-0547, CAN-1999. (06.31 e CAN-1999-05.54 podem ser encontradas na página do projeto CVE ${ }^{31}$.

\footnotetext{
$31 \mathrm{http:} / /$ cve.mitre.org
} 
A busca por vulnerabilidades correlacionadas pode também ser feita por meio dos morms que as exploram. O exemplo a seguir (Figura 33) busca por vulnerabilidades que são cxploradas em conjunto com a (CAN-2000-0884, utilizando-se para isso a classe Worm. $\Lambda$ ssim, têm-se como retorno as vulnerabilidades CVE-2001-0154 e CVE-2001-0333, já que essas são) exploradas pelo worm NIMDA.

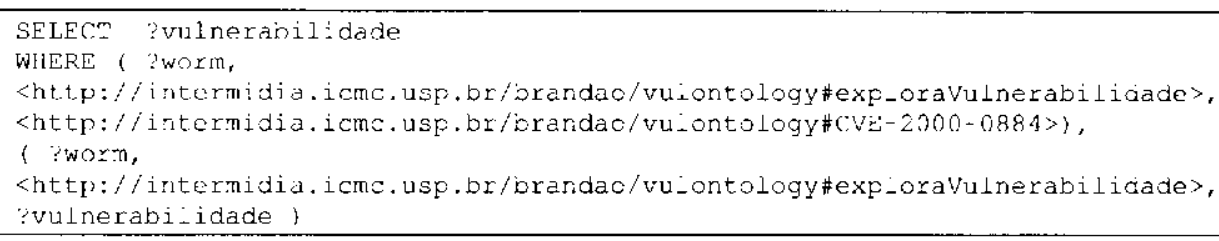

Figura 33 - Consulta RDQL para busca por vulnerabilidades que são explotadas em conjunto a CAN2000-0884

\begin{tabular}{|l|}
\hline ?vulnerabilidade \\
\hline CVE-2001-0154 \\
\hline CVE-2001-0333 \\
\hline
\end{tabular}

Tabela 8 - Resultado da busca por vulnerabilidades que são exploradas em conjunto com a CAN-20000884

\subsubsection{Teste 5: Outras Buscas por Vulnerabilidades}

Alguns outros testes foram efetuados no sistema. A Figura 34 mostra a busca por vulnerabilidades que possam ser explorada remotamente e que sejam consideradas graves. Como resultado obteve-se uma listagem mostrada na Tabela 9: 57 instâncias da classc

\section{Vulnerabilidade.}

SELECP ?vulnerailidadc

WIIFRF ( ?vulnerabilidade,

<ht p://intermidia.icmc. Lsp.or/brandao/vuLonto.ogy\#possuiconsequencia>,

<http://intermidia.icme.usp.br/brandao/vuionto-ogy \#Alta>l,

( ?vulnerabilidade,

<ht.tp://irtermidia,icnc.usp.br/brandao/vi-onto-ogy \#possuiAbrangencia>,

<http://intormidia.icnc.usp.br/brandao/vu ontoingy\#Renoto>)

Figura 34 - Consulta RDQL para busca por vulnerabilidades graves que possam ser exploradas remotamente. 


\begin{tabular}{|l|l|l|}
\hline ?vulnerabilidade & ?vulnerabilidade & ?vulnerabilidade \\
\hline CAN-2003-0139 & CAN-2003-0100 & CAN-2002-1537 \\
\hline CAN-2002-0649 & CAN-2003-0101 & CAN-2003-0131 \\
\hline CAN-2002-1552 & CAN-2002-1560 & CAN-2003-0107 \\
\hline CAN-2003-0081 & CAN-2003-0010 & CAN-2003-0077 \\
\hline CAN-2003-0151 & CVE-2001-0333 & CAN-2003-0054 \\
\hline CAN-2003-0069 & CAN-2003-0028 & CAN-2003-0055 \\
\hline CAN-2002-1337 & CAN-2003-0096 & CAN-2003-0143 \\
\hline CAN-2003-0070 & CAN-2003-0097 & CAN-2002-1553 \\
\hline CAN-2003-0150 & CAN-2003-0033 & CAN-2003-0121 \\
\hline CAN-2003-0109 & CAN-2003-0095 & CAN-2002-1546 \\
\hline CVE-2001-0500 & CAN-2003-0050 & CAN-2003-0065 \\
\hline CAN-2002-1549 & CAN-2002-1558 & CAN-2003-0066 \\
\hline CAN-2003-0146 & CAN-2002-1541 & CAN-2003-0024 \\
\hline CAN-2003-0138 & CAN-2003-0126 & CAN-2003-0140 \\
\hline CAN-2002-0842 & CAN-2003-0030 & CAN-2002-1536 \\
\hline CAN-2003-0098 & CAN-2003-0049 & CAN-2003-0067 \\
\hline CAN-2003-0063 & CAN-2003-0085 & CAN-2003-0068 \\
\hline CAN-2003-0064 & CAN-2003-0352 & CAN-2003-0080 \\
\hline CAN-2002-1510 & CAN-2003-0009 & CAN-2002-0387 \\
\hline
\end{tabular}

Tabela 9 - Resultado de busca por vulnerabilidades graves que possam ser exploradas remotamente

O último exemplo aqui mostrado ilustra a busca por vulnerabilidades de um determinado tipo cuja a exploração acarrete em determinada conseqüência. No exemplo aqui mostrado, a busca foi por vulnerabilidades do tipo Buffer(overflow e que tivessem como conscyüência a perda da disponibilidade do sistema. O resultado foi uma lista de 13 instâncias da classc Vulnerabilidade que satisfazcm a consulta.

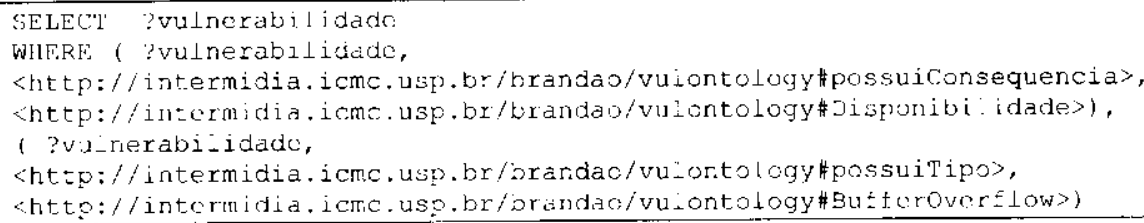

Figura 35 - Consulta RDQL para busca por vulnerabilidades do tipo BufferOverflow com conseqüência a perda de disponibilidade 


\begin{tabular}{|l|}
\hline ?vulnerabilidade \\
\hline CAN-2003-0100 \\
\hline CAN-2002-1542 \\
\hline CAN-2003-0099 \\
\hline CAN-2003-0102 \\
\hline CAN-2003-0125 \\
\hline CAN-2002-1551 \\
\hline CAN-2002-0649 \\
\hline CAN-2003-0140 \\
\hline CAN-2003-0030 \\
\hline CAN-2002-1539 \\
\hline CAN-2003-0122 \\
\hline CAN-2003-0123 \\
\hline CAN-2003-0107 \\
\hline
\end{tabular}

Tabela 10 - Resultado da busca por vulnerabilidades do tipo BufferOverflow com conseqüência a perda de disponibilidade

\subsection{Benefícios do uso de Ontologia de Alertas de Segurança}

De acordo com o já abordado na Seção 4.2, o uso de ontologias provê diversos bencfícios sendo que o maior deles está em agregar valor semântico aos dados. Isto permite inferências por parte dos agentes de software capazes de interpretar a ontologia, interligando os conceitos ali representados com outros conceitos, presentes na mesma ou em outra ontologia. Conforme essas ligações vão se multiplicando, torna-se possivel ao software conhecer melhor o real significado do conceito representado na ontologia e a inferências tornam-se mais poderosas.

Além dos benefícios já citados, alguns outros são alcançados peto uso de ontologia particularmente no domínio de Segurança da Informação. Fissa Seção visa discutir alguns cenários em que há benefício no uso de uma ontologia de vulncrabilidades.

\subsubsection{Auxílio na Análise Forense}

Os relacionamentos entre vulnerabilidades auxiliam peritos durante a análise forense. Vulnerabilidades comumente exploradas em conjunto podem receber relacionamentos que indiquem esse fato. Isso pode ser alcançado pelos relacionamentos exploradoEmConjuntoCom, preRequisitoPara e possuiPreRequisito. 
Por exemplo, se a exploração de uma vulnerabilidade A é pré-requisito para a exploração da vulnerabilidade $\mathrm{B}$ e isso está representado na ontologia, então, ao encontrar rastros da exploração de B uma ferramenta forense poderia já indicar ao perito para que procure por rastros da exploração de $A$.

Uma outra situação em que a análise forense poderia ser auxiliada pelo uso de ontologia é o quando worms estão se propagando por sistemas. Histes programas geralmente exploram diversas vulnerabilidades de uma só vez, procurando comprometer determinado servidor para a partir dele lançar ataques a outras máquinas.

'Tais vulnerabilidades podem não ter relação aparente, a não ser, é claro, por serem exploradas pelo mesmo uorm. lí o caso do worm CodeRed (CERT, 2001), que explora as vulncrabilidades CVE-2001-0500 e CVE-2001-0506. Estando cadastradas na ontologia então ao descobrir a exploração de uma dessas vulnerabilidades pode ser feita a pesquisa por quais norms a exploram e quais outras vulnerabilidades são exploradas por esses worms.

\subsubsection{Correlacionamento de alertas em tempo real}

É comum o uso de diversas ferramentas de segurança simultaneamente e essas ferramentas geram alertas em formatos proprietários. Na ocasião em que as ferramentas utilizadas para análise forem compatíveis com a ontologia, seus alertas poderão ser gerados diretamente na linguagem OWL.

Soma-se isso o fato de que novas ontologias de dominios correlatos às vulnerabilidades serão desenvolvidas e poderão ser mescladas com a ontologia apresentada neste trabalho. Por exemplo, a ontologia em desenvolvimento por Martimiano (2003) abrangerá o domínio incidentes de segurança, o qque permitirá a classificação de informaçōes como: endereço de origem e destino, portas utilizadas, horário do ataque, entre outros, além da vulncrabilidade correspondente.

Alertas gerados na linguagem de representação da ontologia podem ser incorporados por ferramentas de gerenciamento e essas, por sua vez, podem fazer o correlacionamento desses alertas por meio das relações presentes na ontologia de vulnerabilidades. 


\subsubsection{Indicar a aplicaçãa de correções (patches)}

Um dos problemas decorrentes do gerenciamento de scgurança de sistemas computacionais é o controle das aplicações de correções. Além de registrar quais correções foram aplicadas em seus bosts, o administrador deve levar em conta quais as vulnerabilidades são solucionadas por tais correções.

Além disso, algumas correções são mais confiáveis do que outras. Por exemplo, cm julho de 2002 a empresa ISS $^{32}$, especializada em Segurança da Informação, anunciou a descoberta de uma vulnerabilidade no servidor web Apache ${ }^{3.3}$ (Rash, 20(4)). Junto com o anúncio da vulncrabilidade foi uma disponibilizada correção, desenvolvida pela própria ISS, sem prévia consulta ao fabricante do software $\Lambda$ pache. Fssa correção na verdacle não solucionava a vulnerabilidade e foram grandes os problemas decorrentes do caso.

O resultado desse episódio foi a disseminação de um worm, denominado Slapper, que explora justamente tal vulnerabilidade. ( ) worm propagou-se, infectando milhares de hosts atć que uma correção oficial do servidor Apache ficasse pronta e fosse disponibilizada. Nesse meio tempo, diversas empresas disponibilizaram correções para a vulnerabilidade, o que ajudou a aumentar a confusão gerada pelo incidente.

Este incidente mostra que em alguns casos mais de uma correção está disponível para uma mesma vulnerabilidade e a escolha de qual correção aplicar ao sistema deve levar em conta fatores como, por exemplo, o histórico das correçōes disponibilizadas pelo fabricante. $\Lambda$ ontologia pode ajudar nessa tarefa, por meio das classes Correcao, Fornecedor e Vulnerabilidades, que são interligadas por meio dos relacionamentos desenvolveCorrecao, possuiCorrecao, possuiFornecedorCorrecao, possuiVulnerabilidade, ocorreEm e comercializaProduto.

\footnotetext{
$3 \mathrm{http:} / / \mathrm{www}$.internetsecuritysystems.com/

$33 \mathrm{http} / / / \mathrm{www}$ apache.org
} 


\subsubsection{Documentar o conhecimento tácito em segurança computacional}

Uma das vantagens do uso de ontologias é a estruturação formal das informações. $A$ partir do momento que as vulnerabilidades, suas características, correções e seus relacionamentos são colocados na ontologia, passa a ser possível cadastrar também parte do conhecimento que atualmente está presente apenas como conhecimento tácito nos especialistas. Entende-se por conhecimento tácito aquele que não está cxplicitado em documentos e que é adquirido por meio da prática. É o caso, por exemplo, das relaçòes possuiPreRequisito, preRequisitoPara e exploradoEmConjuntoCom, que representam ligações entre vulnerabilidades e cujos valores são observados com o passar do tempo, conforme as novas vulnerabilidades vão sendo exploradas. 


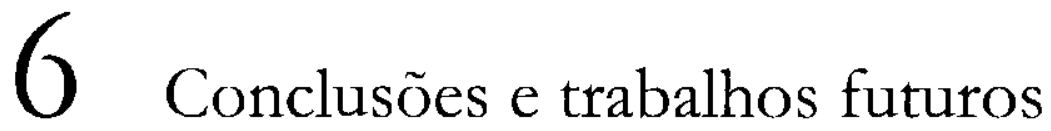

liste trabalho teve como objetivo investigar e dar os primciros passos para a utilização de ontologias para classificação de vulnerabilidades em sistemas computacionais. Fơi efetuada a modelagem da ontologia para representação dos conceitos do dominio, com a especificação de suas classes, atributos e relacionamentos.

Utilizou-se como fonte de dados o projeto CVH e 117 vulnerabilidades foram classificadas. Após a classificação foi possivel efetuar testes que comprovaram a viabilidade do uso da ontologia para facilitar o gerenciamento de segurança em sistemas computacionais.

() código e as vulnerabilidades cadastradas estão disponiveis para acesso via Internet e poderão ser utilizados por aplicações compativeis com as tecnologias da Web Semântica c que precisem de informações a respeito de vulnerabilidades de sistemas computacionais.

() trabalho contribuiu com a investigação do uso de ontologias no dominio de segurança da informação. () protótipo desenvolvido poderá agora ser utilizado em outros trabalhos, dentro ou fora do grupo de pesquisas. Na realidade, já está em andamento trabalho de doutorado que incorpora a ontologia aqui desenvolvida (Martimiano, 2003).

Também é contribuição desse trabalho as definições dos conceitos que envolvem as classes, relações e instâncias. Além disso, a investigação das vantagens do uso da ontologia de vulnerabilidades poderá auxiliar em pesquisas futuras.

\subsection{Trabalhos Futuros}

Como sugestão de trabalhos futuros com relação a essa pesquisa, tem-se:

\subsubsection{Classificar o restante das vulnerabilidades do projeto CVE}


Neste trabalho cadastrou-se 117 vulnerabilidades. A classificação teve como objetivo a comprovação da viabilidade da idćia. Porém, as demais vulnerabilidades da base CVE podem ser cadastradas. Na realidade, novas vulnerabilidades são descobertas quase que diariamente e pode-se, inclusive, desenvolver um framıework. com métodos para classificaçào de novas vulnerabilidades na ontologia.

\subsubsection{Ampliação da ontologia}

Além do trabalho de Martimiano (2003), é possível também ampliar a ontologia para abranger outros subdomínios da segurança da informação. Por cxemplo, conceitos de política de segurança, vírus, engenharia social e outros podem ser inseridos para aumentar a riqueza de representação.

\subsubsection{Integração com outras ontologias}

Com o advento da Web Semântica, é grande a tendência do desenvolvimento de novas ontologias que utilizem a linguagem (OWI. Isto permitirá a integração da ontologia de vulnerabilidades com outras ontologias.

\subsubsection{Desenvolvimento de ferramentas de segurança}

As atuais ferramentas de segurança precisam ser modificadas para que sejam capazes de entender a ontologia. Algumas ferramentas, como o sistema de detecção de intrusōes (SDI) Snort ${ }^{34}$, são extensíveis por meio do desenvolvimento de plugins.

Pode-se, portanto, desenvolver plugins para o Snort que scjam capazes de efetuar consultas RDQL similares às consultas efetuadas nos testes deste trabalho. Além de SDIs, ferramentas de análise forense computacional podem ser estendidas para utilizar a ontologia de vulnerabilidades como auxílio na busca por relações entre vulnerabilidades, correções, sistemas operacionais, etc.

\footnotetext{
34 http://www.snort.org
} 


\section{Referências Bibliográficas}

Ambrósio, D. R. (2002). Métodos Alternativos de Reconhecimento de Padrões para Sistemas de Detecção de Intrusão. Dissertação (Mestrado). ICMC/USP. São Carlos.

Axclsson, S. (2000). The base-rate fallacy and the difficulty of intrusion detection. ACM 'Transactions on Information and System Security, 3 (3).

Baalen, J. V., Fikes, R..; (1993). The Role of Reversible Grammars in Translating Between Representation Languages. Disponivel na Internet em: http://kslweb.stanford.edu/knowledge-sharing/papers/index.html. Verificado em: $01 / 03 / 2004$.

Bechhofer, S., Horrocks, 1., Goble, C., Stevens, R. (2001). Oillid: a Reason able Ontology riditor for the Semantic Web. In: Proceedings of KI2001, Joint German/Austrian conference on Artificial Intelligence, 2001. ProceedingsSeptember, Vienna. Springer-Verlag INAI Vol. 2174, pp 396-418.

Bench-Capon, T. I. M.; Visser, P. R. S. (1997) (Ontologies in Legal Information Systems: the need for explicit specifications of domain conceptualizations. In: Proceedings of the Sixth International Conference on Artificial Intelligence and Law. Mclbourne, Australia, 1997. P 132-141.

Bernardes, M.C. (2000). Avaliação do L'so de Agentes Móveis em Segurança Computacional, Dissertação (Mestrado). ICMC/USP. São Carlos.

Bernardes, M. C. (2002). Modelagem de Sistemas de Segurança Computacional como Sistemas de Informação. Qualificação de Doutorado, ICMC/USP - Sâo Carlos.

Berners-Lec, T., Hendler, L, Iassila, O. (2001); The Semantic WTEB. Scientific American 284, 5. pp 34-43.

Bernstein, T.; Bhimani, A. B.; Schultz, E.; Siegel, C. A. (1996). Internet Security for Business. Fd. John Wiley \& Sons.

Bonifácio Jr., J. M. (1998) Sistemas de Segurança Distribuído: Integração de Firewalls com Sistemas de Detecção de Intrusão. Dissertação (Mestrado). ICMC/USP. São Carlos.

Brandão, A. J. S.; Moreira, E. S. (2002) Agentes Móveis c Sistemas de Gerenciamento SNMP, Anais do II Workshop em Segurança de Sistemas Computacionais, Búzios.

Bray, T, Paoli, J., Sperberg-Mcqueen, C. M. (1998). Extensible Markup Language (XML) 1.0. W3C Recommendation. February. Disponivel na Internet em http://www.w3.org/T'R/1998/REC-xml-19980210. Verificado em: 10/08/2003.

Brickley, D., Guha, R. V. (2003). RDF Vocabulary Description I anguage 1.(l: RDI: Schema. W3C Rccommendation. Disponivel na Internet em http://www.w3.org/TR/rdf schema. Verificado em: 10/07/2003. 
Cansian, A. M. (1997). Desenvolvimento de um sistema adaptativo de detecção de intrusos em redes de computadores. Tese (Doutorado). IFSC/USP. São Carlos.

CERT $\left({ }^{(}\right)$Advisory CA-2001-19. (2001). Code Red Worm Exploiting Buffer Overflow In IIS Indexing Service DLL. July 19, 2001. Disponivel na Internet em hitp://www.cert.org/advisorics/CA-2001-19.html. Verificado em: 07/03/2004.

CI:RT ${ }^{\circledR}$ Advisory CA-2003-21. (2003). GNU Project FTP Server Compromise. August 13, 2003. Disponivel na Internet $\mathrm{em} \mathrm{http} / /$ www.cert.org/advisories/CA-200321.html. Verificado em: $24 / 08 / 2003$

Cicilini, R. (1994); Descnvolvimento de um Agente SNMP. Dissertação (Mestrado). ICMC/USP. São Carlos.

Curry, D. Debar, H. (2003). Intrusion Detection Message Exchange Format Data Model and Fxtensible Markup Language (XML) Document Type Definition. Internet draft, draft-ietf-idwg-idmefxml-10.txt. Jan.2003.

CVE. (2004). CVF Compatible Products and Services. Disponivel na Internet em: http://www.cve.mitre.org/compatible/. Verificado cm: 20/02/2004

Dean, M., Schreiber, G. Editors. (2004).OWL. Web Ontology Language Reference, W3C Recommendation, 10 February, 2004, Disponivel na Internet em: http://www.w3.org/TR/2004/REC-owl-ref-20040210/. Verificado em: $29 / 02 / 2004$.

Escamilla, T. (1998) Intrusion Detection: Network Security Beyond the Fircwall. Fd. John Wiley \& Son.

Feinstein, B. Mathews, G. White, J. (2002). The Intrusion Detection lixchange Protocol (IDXP). Internet draft, draft-ietf-idwg-beep-idxp-07.txt. October.

Fernández-Lópcy, M., Gómez-Pérez, A., Juristo, N., Pazos-Sierra, J. (1999); Building a Chemical Ontology using Methontology and the Ontology Design Environment. IERE: Intelligent Systems. January-February. pp. 37-46.

Fernández-Iópez, M. (1996). Chemicals: Ontologia de elementos químicos. Final-Year Project. Facultad de Informática de la Universidad Politécnica de Madrid.

Fonseca, F., M. Figenhofer and K. Borges (2000). Ontologias e Interoperabilidade Semântica cntre SIGs. In.: II Workshop Brasileiro em Geoinformática Geolnfo2000, São Paulo.

Freitas, F. (2003). Ontologias c a Web Semântica. In.: XXIII Congresso da Socicdade Brasileira de Computação (SBC2003). JAI: Jornada de Atuali»ação em Informática. Campinas.

I'ukuda, Y. (1995). Variations of Knowledge in Information Society. In: Third International Symposium on the Management of Industrial and Corporate Knowledge, Copiegne, France. pp. 10-26

Garfinkel, S., Spafford, (1996) G. Practical LNIX and Internet Security. 2a Lidiçäo. ()'Reilly \& Associates, Inc. 971p. 
Genesereth, M. R., Fikes, R. E. (1992). Knowledge Interchange Format. Version 3.0. Reference Manual. Computer Science Department. Stanford University. Disponível na Internet em http://ksl-web.stanford.edu/knowledgesharing/kif/. Verificado em: 06/03/2004.

Gosh, A. K. (1998). E-Commerce Security: Weak Links, Best Defences. Ld. John. Wiley \& Sons.

Gruber, T.R. (1993) A Translation Approach to Portable Ontology Specifications. Technical Report KSI. 92-71, Knowledge System Iaboratory, Stanford University.

Gruber, T. R. (1995). I'oward principles for the design of ontologies used for knowledge sharing. In: Formal Ontology in Conceptual Analysis and Knowledge Representation. Kluwer Academic Publishers.

Grüninger, M., Fox, M. S. (1995). Methodology for the Design and Evaluation of Ontologies. Procecdings of the International Joint Conference on Artificial Inteligence (IJCAI95), Workshop on Basic Ontological Issues in Knowledge Sharing, April.

Grüninger, M., Lee. , J. (2002); Ontology: Applications and Design. Communications of the ACM, February, Vol. 45, No 02. pp. 39-41.

Guarino, N., Giaretta, P. (1955). Ontologies and Knowledge Bases: Towards a Terminological Clarification. Towards Very Large Knowledge Bases. Iid. IOS Press. pp. 25-32.

Herrera, J. A. F., Martins Júnior, J., Moreira, E. S. (2002). A Model for Data Manipulation and Ontology Navigation in DEEPSIA Project. In First Seminar on Advanced Research in Electronic Busincss (FBR02). Novembro. Rio de Janciro-RJ.

Holsapple, (. W.; Joshi, K. D. (2002). A Collaborative Approach to Ontology Design. In Communications of the ACM, Volume 45, Issue 2, 2002. pp. 42-47.

Huhns, M.N.; Singh, M.P. (1997). Ontologies for Agents. IEEE Internet Computing. November-December.

ISO - International Organization for Standardization / International Eletrotechnical Committee. (1999). Information Processing Systems - Open Systems Interconnection - Basic Reference Model - Part 2: Security Architecture. International Standard 7498-2.

Koivunen, M., Miller, F. (2001). W3C Semantic Web Activity. Disponivel na Internet cm: hitp://www.w3.org/2001/12/semweb-fin/w3csw. Verificado em: $12 / 03 / 2004$.

lieira, J. I. (1995). Utilização de Audio e Video em Sistemas Gerenciadores de Redes de Computadores. Dissertação (Mestrado). ICMSC/USP-São Carlos.

Lopez, M. F., Gomez-Perez, A., Sierra, J. P., Sierra, A. P. (1999). Building a Chemical Ontology Using Methontlogy and the Ontlogy Design Environment. IEEE: Intelligent Systems, 14, P. 27-36. 
Maedche, A., Staab, S. (2003). KAON: The Karlsruhe Ontology and Semantic Web Meta Project. Künstliche Intelligenz. Special Issue on Semantic Wcb.

Mann, D., Christey, S. (1999). Towards a Common Fnumeration of Vulnerabilities. 2nd Workshop on Research with Security Vulnerability Databases, Purduc University, West Lafayette, Indiana. January.

Martimiano, L. A F. (2003). Sobre a Esstruturação de Informação em Sistemas de Segurança Computacional: o L'so de Ontologia. Qualificação de Doutorado. ICMC/USP. São Carlos.

Martin, R. A. (2001). Managing Vulnerabilities in Networked Systems. IEEE Computer Socicty Magazine, Computer, Vol. 34, No. 11.

Menzies, T. (1999). Cost-Benefits of Ontologies. Intelligence. ACM Press. New York, NY. p. 26-32.

Módulo. (2003). 9a. Pesquisa Nacional de Segurança da Informação. li-Módulo Security, novembro. Disponivel na Internet em http://www.modulo.com.br, Verificado em: 02/02/2004.

Moraes, S. (1995). Voz em Sistemas Computacionais: Projeto e Implementação de Módulos de Processamento de Voz em Gerenciamento de Redes. Dissertação (Mestrado). IC.MC/USP. Sào Carlos.

Morishita, F. '1'. (1997). Uma Avaliação Evolutiva dos Protocolos de (ierenciamento da Internet: SNMPv1, SNMPv2 e SNMPv3. São Carlos, 1997. 68p. Dissertação (Mestrado). ICMC/USP. São Carlos.

Noy, N.F. McGuinness, D. L. (2001). Ontology Development 101: A guide to create your first ontology. 20(01. Knowledge Systems Laboratory Tech Report KSL-0105. Stanford University.

Noy, N. H., Sintek M., Decket, S., Crubezy M., Fergerson, R. W., Musen, M. A. (2001). Creating Semantic Web Contents with Protégé-2000. IEFr: Intelligent Systems $16(2)$ : pp.60-71.

Oda, C. S. (1994). Desenvolvimento de um Sistema Monitor Gráfico Baseado em Protocolo de Gerenciamento SNMP. Dissertação (Mestrado). ICMC/USP. São Carlos.

Ortêncio, V.V. (2001). Introduçâo à Abordagem Capitalização de Conhecimento. Bate Byte, n. 108, Companhia de Informática do Paraná - CELFPAR, abril.

Pacheco, R.C.S., Kern, V.M. (2001). Uma Ontologia Comum para a Integraçào de Bases de Informação e Conhecimento sobre Ciência e Tecnologia. Revista Ciência da Informação, Vol.30, No 03, Set/Dez. pp. 56-63. Disponivel na Internet em http://www.ibict.br/cionline/300301/3030801.pdf. Verificado em $10 / 12 / 2003$.

Pinkston, J., Undercoffer, J., Joshi, A., Finin T. (2003). A Target-Centric Ontology for Intrusion Detection. Proceedings of the IJCA1-03 Workshop on Ontologies and Distributed Systems. Acapulco, August. 
Precec, A., Shinghal, R. (1992). Verifying Knowledge Bases by Anomaly Detcction: an experience report. In Proc. 10th Furopean Conference on $A$ rtificial Intelligence (ECAI-92), pp. 835-839, John Wiley.

Rash, W. (2004). Apache worm highlights operational flaws. ZDNet Austrália. 11/07/2002. Disponível na Internet $\mathrm{em}$ : http://www.zdnet.com.au/news/communications/0,2000061791,20266325,00.h tm. Verificado em: 20/02/2004.

Raskin, V., Hempelmann, C. F., Triezenberg, K. F., Nirenburg, S. (2001). ()ntology in Information Security: A Useful Theoretical Foundation and Methodology 'Iool. In Proceedings of the Workshop on New Security Paradigms (NSPW). September.

Reami, 1.. R. (1998). Especificaçào e Prototipagem de um Ambiente de Gerenciamento de Segurança apoiado por Agentes Móveis. Dissertação (Mestrado). ICMC/USP. São Carlos.

Rufino, N. M. (2002). Segurança Nacional - 'T'écnicas e Ferramentas de Ataques e Defesa de Redes de Computadores. Ed. Novatec.

Seaborne, A. (2004). RDQI. - A Query Language for RDF. W3C. Member Submission. 9 January, 2004. Disponivel na Internet em: http://www.w3.org/Submission/2004/SUBM-RDQL-20040109/. Verificado em: $01 / 03 / 2004$.

Smith, M., Welty, C., McGuinness, D. (2003). Web Ontology Language (OWL) Guide Version 1.0 W3C Recommendation. Disponivel na Internet em: http://www.w3.org/TR/200.3/WD-owl-guide-20030210/ - Verificado em: $24 / 08 / 2003$.

Soares, L. I: G., Lemos, G., Colcher, S. (1995). Redes de Computadores: das I.ANs, MANs e WANs às redes ATM. 2a. cd. Rio de Janeiro: Campus, 1995. $704 \mathrm{p}$.

Sowa, J. F., KR Ontology. (2002). Disponivel na Internet $\mathrm{cm}$ http://users.bestweb.net/ sowa/ontology/. Verificado cm: 16/01/2004.

Stein, L.D. (1998). Web Security $-\Lambda$ Step-by-Step Reference Guide. Ed. Addison Wesley Longman.

Sure, Y., Eirdmann, M., Angele, J., Staab, S., Studer, R., Wenke D. (2002). Ontolidit: Collaborative Ontology Development for the Semantic Web Proceedings of the first International Semantic Web Conference 2002 (ISWC 2002), June. Sardinia, Italia.

Thompson, II. S., Beech, D., Maloney, M., Mendelsohn, N. (2001). X.MI, Schema Part 1: Structures W/3C Recommendation 2 May. Disponivel na Internet em http://www.w3.org/TR/2001/RГC-xmlschema-1-20010502/. Verificado em: $10 / 08 / 2003$

Uschold, M., King, M. (1995). Towards a Methodology for Building Ontologies. Workshop on Basic Ontological Issues in Knowledge Sharing, IJCAI'95.

Uschold, M, Gruninger, M. (1996). Ontologies: Principles, Methods and Applications. Knowledge Iingineering Revicw. Vol. 11, №2. June. 
Valente, A.; Russ, 'I'; McGregor, R.; Swartout, W. (1999). Building and (Re) Lsing an ()ntology of Air Campaign Planning. IEkE Intelligent Systems \& their applications. pp. $27-36$

Zuñiga, G. L. (2001). Ontology: Its Transformation from Philosophy to Information Systems. Proceedings of the 2nd International Conference on Formal Ontology in Information Systems (FOIS). October. pp. 187-197. 


\section{Anexo I - Extrato da Base CVE}

\begin{tabular}{|c|c|}
\hline Nome & Descriçäo \\
\hline CAN-2002-0387 & $\begin{array}{l}\text { Buffer cverflow in gxrisapi6.d. i NGAFT olugin of the connector Module for sun } \\
\text { ONE Application Server before } 6.5 \text { al.ows remoto attackors ro nxecute } \\
\text { arbitrary code via a long HTTP request URL. }\end{array}$ \\
\hline CAN-2002-0842 & 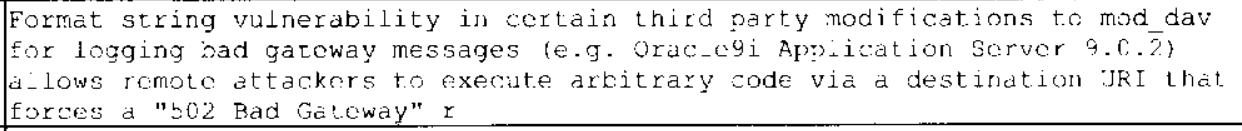 \\
\hline CAN-2CO2-133? & $\begin{array}{l}\text { Buffer over llow in sendmail } 3.79 \text { to } 8.22 .7 \text { al-ows remotc attackersi to } \\
\text { exceute arbitrary code via a certain formatted address fields, related to } \\
\text { sender and recipient header comments as processed by the crackaddr function } \\
\text { of hoaders.c. }\end{array}$ \\
\hline $\mathrm{CAN}-2002-1472$ & $\begin{array}{l}\text {-inxll.so in } x \text { frees6 a lows ocal uscrs to gain root privileges via a } \\
\text { modified LD PRELCA: environment variable that points to a malicious module. }\end{array}$ \\
\hline CAN-2002 15C9 & $\begin{array}{l}\text { A patch Eor shadow-utils } 20000902-7 \text { causes the useradd command to create a } \\
\text { mail spoo- files with read/write privileges of the new user's group (mode } \\
660), \text { which aliows other users in the sume group to read or modify the now } \\
\text { uscr's incoming enail. }\end{array}$ \\
\hline CAN-2002-1b10 & $\begin{array}{l}\text { xdm, with the authcomplain variabie sct to also, aldows aroitrary attackers } \\
\text { to connct to the } x \text { server if the } x \text { dm duth directory does not exist.. }\end{array}$ \\
\hline $\mathrm{CAN}-2002-151=$ & $\begin{array}{l}\text { The vncserver wrapper for vric vetore } 3.3 .3 \times 2-21 \text { uses the rand) function } \\
\text { insted of arand }) \text {, which causes vncserver to gcnerd:o weak cookins. }\end{array}$ \\
\hline $\mathrm{CAN}-20 \mathrm{C} 2-1529$ & $\begin{array}{l}\text { Cross-site scripting (XSS) vulrerability in msgError.asp for che } \\
\text { administrativo wob interface (STEMWADM for SurtContro: superScout Emait } \\
\text { Filter a-lows remote attackers to insert aroitrary script or ITML via tho } \\
\text { Reason paramete. }\end{array}$ \\
\hline$\overline{C A N}-2002-: 530$ & $\begin{array}{l}\text { The administrative wob interface (STEMWADM) for SurfContro S Superscout Email } \\
\text { Filter a-lows users to obtain usernames and plaintext pdsswords via a } \\
\text { request to the userlist.asp program, which includes the passwords in a user } \\
\text { cditing form. }\end{array}$ \\
\hline$C A N-2002-: 531$ & 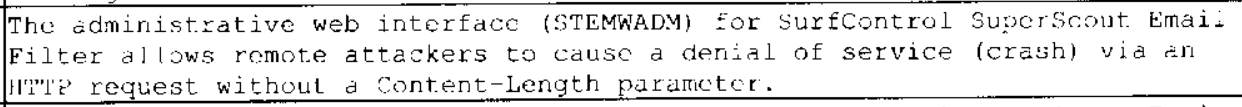 \\
\hline $\mathrm{CAN}-2 \mathrm{C} 02-1532$ & 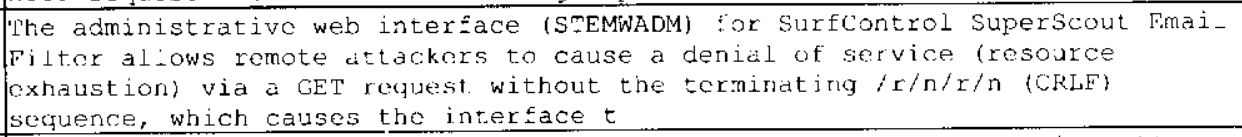 \\
\hline CAN-2002-1533 & $\begin{array}{l}\text { Cross-sjte scripting (XSS) vulnerability in Jetty JSP servlet ongine allows } \\
\text { remote attackers to insert arbitrary ITML or seript via an HTm request to a } \\
\text {-jsp file whose name contains the mallicious script and some concoded linefeed } \\
\text { characters (o,0a). }\end{array}$ \\
\hline CAN-2002-.534 & $\begin{array}{l}\text { Macromedia Flash F ayer allows remote attackers to read aroitrary files via } \\
\text { XML script in } a \text {. Swf fidc that is hosited on a remote SMR share. }\end{array}$ \\
\hline CAN-2C02-: 335 & 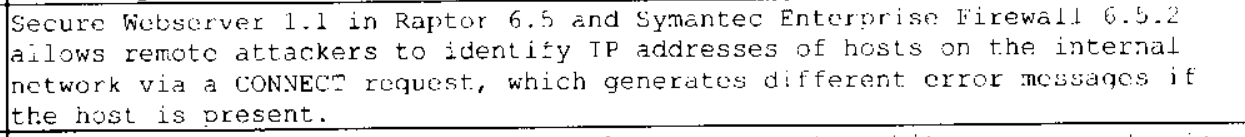 \\
\hline CAN-2002-1536 & 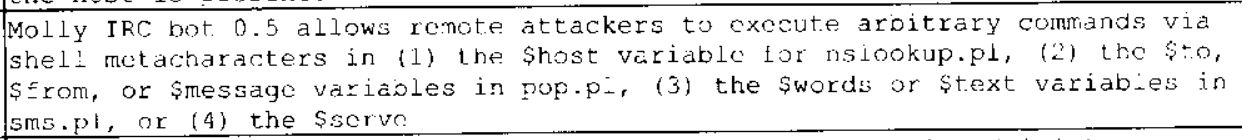 \\
\hline CAN-20C2-153i & $\begin{array}{l}\text { admin ug auth.pho in phoBB } 2 . C .0 \text { allows loca- users to gain administrator } \\
\text { privileges by directly ca:ing admin ug_euth.php with modifod form fields } \\
\text { such as "u". }\end{array}$ \\
\hline 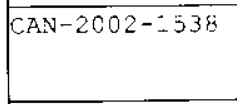 & $\begin{array}{l}\text { Acuma Acusend 4, and possibiy earlier versions, allows remote autherticated } \\
\text { users to read the reports of othor users by inferring lone fli. URL, whose } \\
\text { name is easily predictable. }\end{array}$ \\
\hline $\mathrm{CAN}-20$ & $\begin{array}{l}\text { Buffer overt ow in MDaemon pop server } 6.0 .7 \text { and earier aliows romote } \\
\text { authenticated users to cause a dentid, of service vid long (1) DELE or (2) } \\
\text { lidol arguments. }\end{array}$ \\
\hline
\end{tabular}




\begin{tabular}{|c|c|}
\hline CAN-2002-:540 & 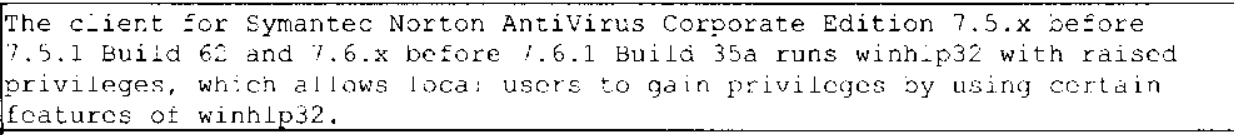 \\
\hline$[\mathrm{CAN}-2002-154]$ & $\begin{array}{l}\text { BadBlue } 1.7 \text { al ows remole at teckers to pyoss password protoct ions for } \\
\text { directorjes and tiles via an Hmo roquest containing an extra } / \text { (stash). }\end{array}$ \\
\hline $\mathrm{CAN}-2002-1542$ & $\begin{array}{l}\text { So-arwinds TFTP server } 5.0 .55 \text { and earlier aliows remote attackers to cause } a \\
\text { denial of service (crash) via a -arge ubp datagram, possibly triggnring a } \\
\text { bufter overflow. }\end{array}$ \\
\hline CAN-2002-1543 & $\begin{array}{l}\text { Bufter overtlow in trok on NotBSD l.b through } 1.5 .3 \text { al.ows loca- users to } \\
\text { gain privileges vie long keyooard irput. }\end{array}$ \\
\hline $\mathrm{CAN}-2022-1544$ & 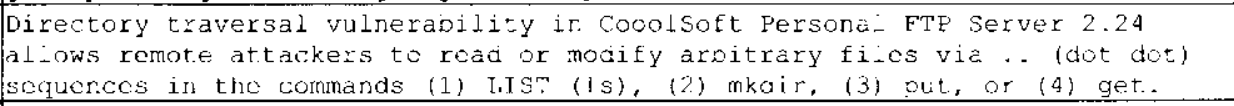 \\
\hline$(\mathrm{AN}-2002-1545$ & $\begin{array}{l}\text { Cooolsoft Personal l'l' Server } 2.24 \text { aliows remote attackers to obtain the } \\
\text { absolute pathname of tho FTP root via a PWD commind, which includes the fuil } \\
\text { path in the response. }\end{array}$ \\
\hline $\mathrm{CAN}-2002-1546$ & $\begin{array}{l}\text { BRS Webweaver web server } 1.01 \text { allows remote attackers to bypass password } \\
\text { protections for files and directories via an HaTp request containing a "/./" } \\
\text { scouence. }\end{array}$ \\
\hline CAN-2002-154i & 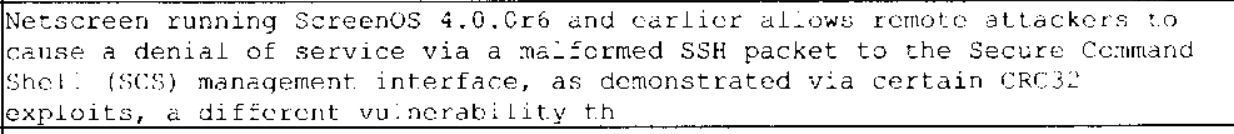 \\
\hline $\mathrm{CAN}-200 ?-1 \mathrm{~b} 48$ & $\begin{array}{l}\text { Uniknown vilnorability in autofs, when using execucáble maps, allows } \\
\text { attackers to cxocule arbitrary commends as root, possibly retated to } \\
\text { improper "string hand ing." }\end{array}$ \\
\hline $\mathrm{CAN}-2002-1549$ & $\begin{array}{l}\text { Buffer overflow in Light HTPd (inttpd) } 0.1 \text { aliows remote attackers to } \\
\text { execute arbitrary code via a long HTM GEm request. }\end{array}$ \\
\hline $\mathrm{CAN}-20 \mathrm{C} 2-1.55 \mathrm{C}$ & $\begin{array}{l}\text { dump_smutil.sh in IBM AIX a llows local users to perform unauthorized file } \\
\text { operations via a symlink attack on tcmporary filos. }\end{array}$ \\
\hline CAN-2002-1551 & $\begin{array}{l}\text { Buffer overflow in nslookup in IBM AIX may al-ow attackers to causo a denia. } \\
\text { ot service or execute arbitrary code. }\end{array}$ \\
\hline $\mathrm{CAN}-2002-1552$ & 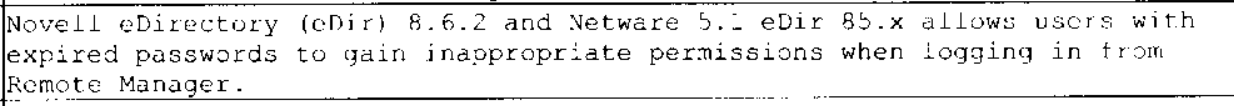 \\
\hline CA.V-2002-:לb3 & 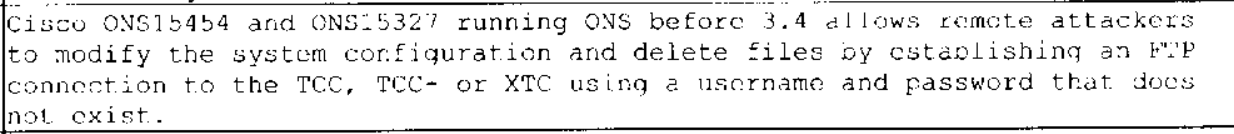 \\
\hline CAN- & 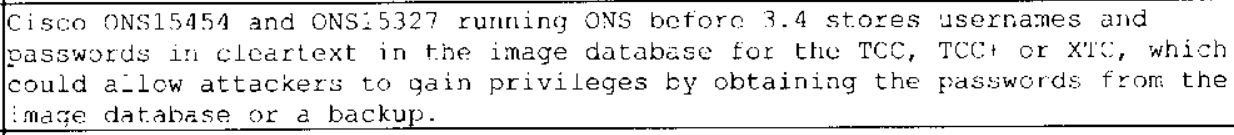 \\
\hline CAN-2002-1bb! & $\begin{array}{l}\text { Cisco ONS- } 454 \text { and ONS1532. running ONS before } 3.4 \text { uses a "public" sNMP } \\
\text { community string that cannol be changed, which aliows remote attackors to } \\
\text { ontain scnsitive information. }\end{array}$ \\
\hline $\mathrm{CAN}-2002-1556$ & 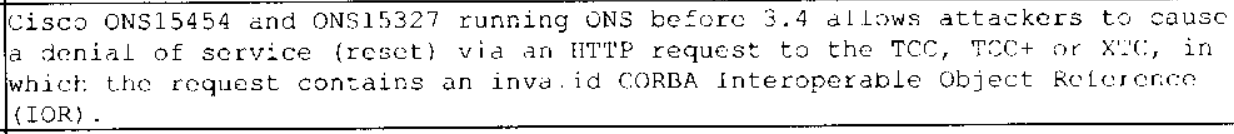 \\
\hline$\overline{c 2}-155 \%$ & 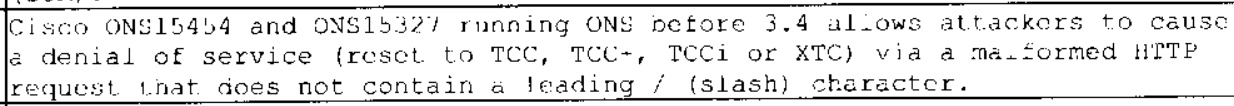 \\
\hline $\mathrm{CAN}-3002-528$ & 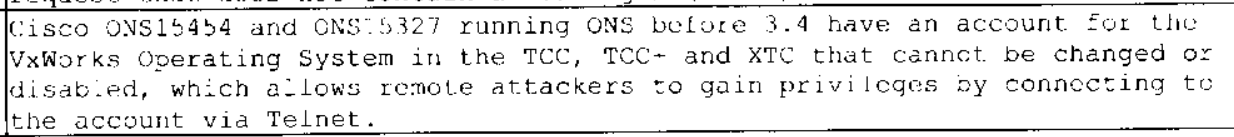 \\
\hline $102-1559$ & $\begin{array}{l}\text { Directory traversal vulncrabiitty in ion-p.exc laka ion-p) allows remoto } \\
\text { attackers to read arbitrary fices via (1) } 6: \text { (drive -ettor) or (2) . (dot- } \\
\text { dot) sequences in the page parameter. }\end{array}$ \\
\hline CAN-2002-1560 & $\begin{array}{l}\text { index pho in gBook } .4 \text { a.ows remote attackers to bypass authentication and } \\
\text { gain diministrative privi oges by sctting tho ogin parametcr to true. }\end{array}$ \\
\hline$\overline{C A N}-2003-0009$ & $\begin{array}{l}\text { Cross-site scripting (XSS) vulnerability in He-p and support conter for } \\
\text { Microsoft windows Mo al:ows remote attackers to execute aroitrary soript ir } \\
\text { the local computer security context vid an hop:// JRL with the maliciods } \\
\text { script in the topic parameter. }\end{array}$ \\
\hline $\mathrm{CAN}$ & Integer overflow in JsArraytunctionheapsurt : ureticn used by windows sor ipt \\
\hline
\end{tabular}




\begin{tabular}{|c|c|}
\hline & $\begin{array}{l}\text { Engine for uScript (JScript.d-L) on various windows operating system allows } \\
\text { romote attackors to execute arbitrary code via a malicious wen page or HML } \\
\text { e-mail that uses a large ar }\end{array}$ \\
\hline $\mathrm{CAN}-2 \mathrm{CO} 3-\mathrm{CO}=1$ & $\begin{array}{l}\text { Jnkrown vulnerabiaity ia the DNS intrusion detection applicalion filter for } \\
\text { Microsott Internet Sechrity and Acceleration (ISA) Server } 2000 \text { al-ows remoto } \\
\text { attackers to calise a deniai of service (blocked traffic to DNS servers) via } \\
\text { a cortain type of incoming }\end{array}$ \\
\hline CAN-2C03-0020 & $\begin{array}{l}\text { Apache docs not filter termina- escape sequences from its error logs, which } \\
\text { could make it easier for attackers to insert those scquencos into terminal } \\
\text { emulators containing vulncrabiitics reiated to escapo sequences. }\end{array}$ \\
\hline $\mathrm{CAN}-2003-0021$ & 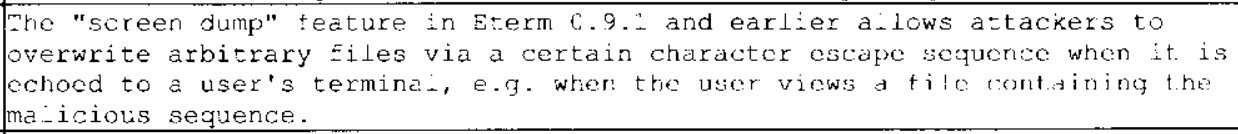 \\
\hline$\therefore A N-2003-0022$ & $\begin{array}{l}\text { Whe "screen dump" feature in rxvt } 2 . \% \text { ailows attackers to overwite } \\
\text { arbitrary tilcs via a certain character escape sequence when it is echocd to } \\
\text { a uscr's tominal, o.g. when the user views a file concaining the malicious } \\
\text { sequence. }\end{array}$ \\
\hline CAN-2003-0023 & $\begin{array}{l}\text { Tho monuBar tcaturc in rxvt } 2.7 .8 \text { allows attackers to modify menu options } \\
\text { and execute arbitrary commands via a cortain character escape sequence that } \\
\text { inserts the commands into the meru. }\end{array}$ \\
\hline $\mathrm{CAN}-$ & $\begin{array}{l}\text { Ihe menubar Eeature in aterm } 0.42 \text { a } 1 \text { Lws attackers to modify menu options } \\
\text { and cxccuto arbitrary comands via a certain character escape sequenco that } \\
\text { inserts the commandis into the menu. }\end{array}$ \\
\hline $\mathrm{CAN}-$ & $\begin{array}{l}\text { Integer overElow in the xdrmem getbytes() function, and possibly other } \\
\text { Eunctions, of XDR (cxtcrnal dal.d representation) Librarios derived trom } \\
\text { SunkPC, inc-uding -ionst, libc, and glibc, al-ows remote attackers to } \\
\text { execute aroitrary code via certain integcr }\end{array}$ \\
\hline CAN-200 & 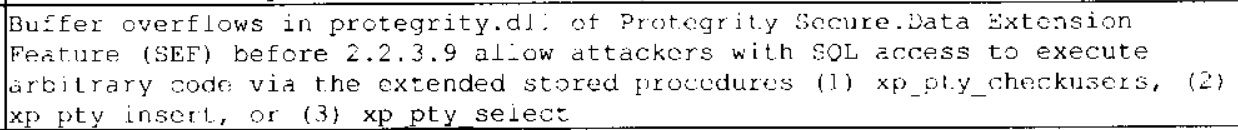 \\
\hline CAN & 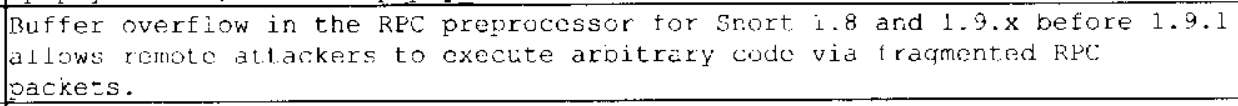 \\
\hline $\mathrm{CAN}-2 \mathrm{CO}$ & $\begin{array}{l}\text { AFE in Mac os } x \text { be:ore }: 2.2 .4 \text { allows adrinistrators to log in as other uscrs } \\
\text { by using the administrator password. }\end{array}$ \\
\hline $\mathrm{CAN}$ & $\begin{array}{l}\text { parse } x m 1 . c g i \text { in Applo Darwin Streaming Administration Server } 4.1 .2 \text { and } \\
\text { QuickTime Streamirg Scrver } 4.1 .1 \text { allows remote attackors to oxecute } \\
\text { arbitrary code vid shell motacharacters. }\end{array}$ \\
\hline $\mathrm{CAN}-$ & 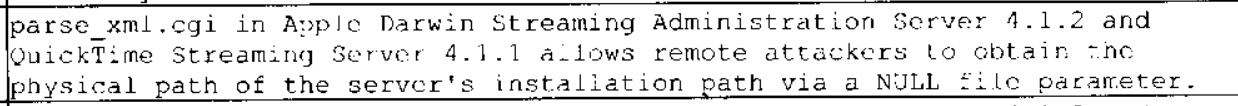 \\
\hline CAN-20.3 3 & $\begin{array}{l}\text { parse xm.,cgi in Applo Darwin Streaming Administration Server } 4.1 .2 \text { and } \\
\text { cuickTime Streaming Sorver } 4.2 .1 \text { allows romole attackers to ist arbitrary } \\
\text { directories. }\end{array}$ \\
\hline$\therefore \mathrm{AN}-2003$ & 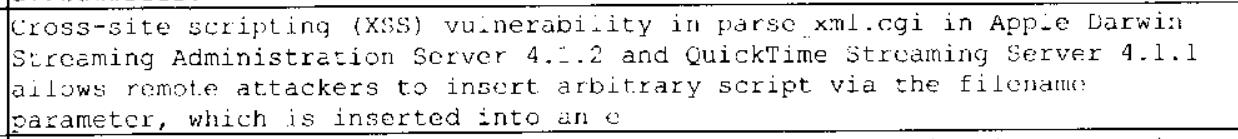 \\
\hline$\overline{\cos 4}$ & 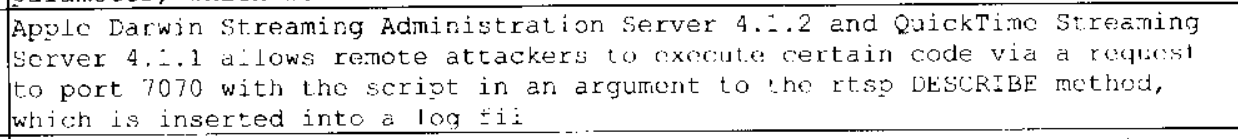 \\
\hline CAN -2 & 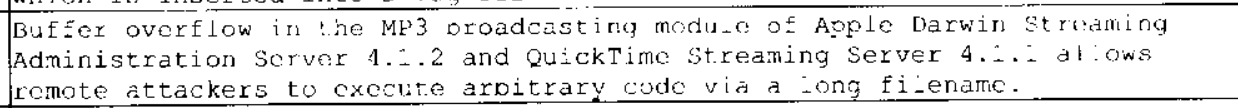 \\
\hline CAN-2O & 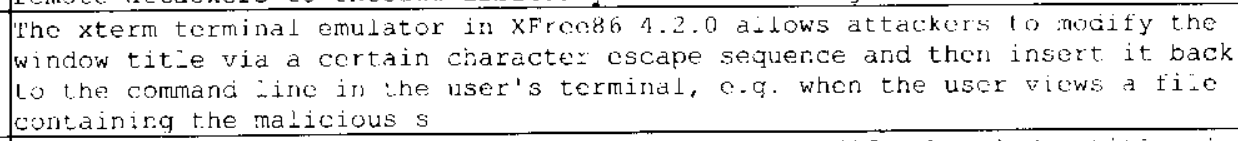 \\
\hline 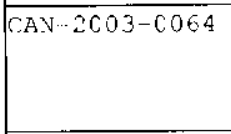 & 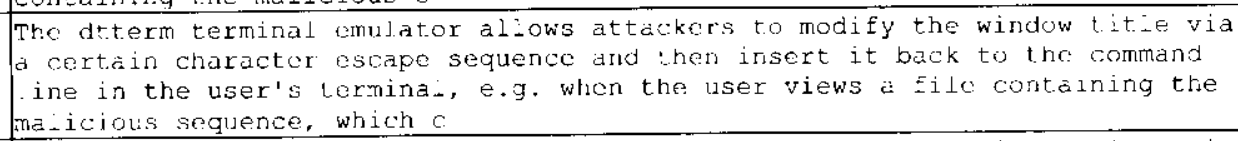 \\
\hline $\mathrm{CAN}-2003-0063$ & 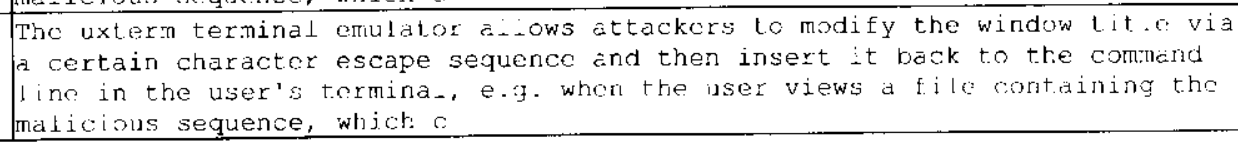 \\
\hline
\end{tabular}




\begin{tabular}{|c|c|}
\hline CAN-2C03-C066 & 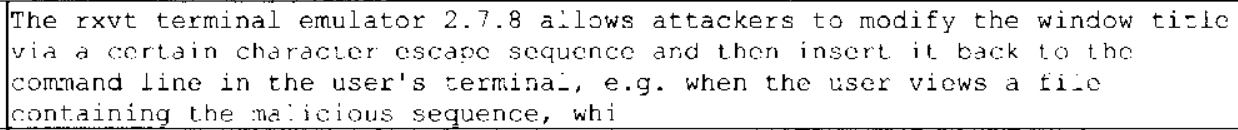 \\
\hline CAN-2003-006\% & 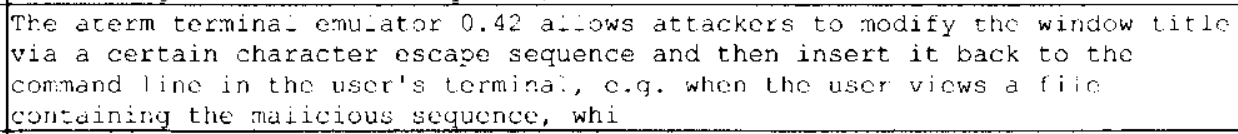 \\
\hline $\mathrm{CAN}-2 \mathrm{CO} 3-\mathrm{CO} 68$ & 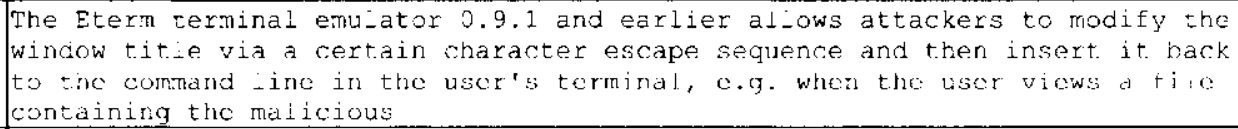 \\
\hline $\mathrm{CAN}-2003-0069$ & 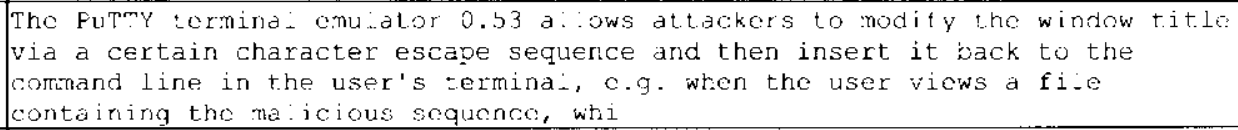 \\
\hline-6070 & $\begin{array}{l}\text { The gnome-termina- termina- emulator allows attackers to modify the window } \\
\text { t.it.le vid a certain character escape sequence and ther insert it back to the } \\
\text { command line in the cser's terminai, e.g. when the user views a fi-e } \\
\text { containing the maicious sequenco, }\end{array}$ \\
\hline $203-0071$ & $\begin{array}{l}\text { The DEC JDK processing feature in the xterm terminal emulator in xFree } 86 \\
4.2 .0 \text { a. lows attackers to cause a denial of service via a certain character } \\
\text { escape sequence that causes the torninal to enter a tight loop. }\end{array}$ \\
\hline $103-0017$ & 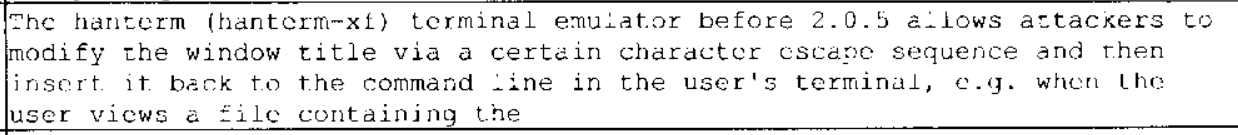 \\
\hline $\mathrm{CAN}$ & 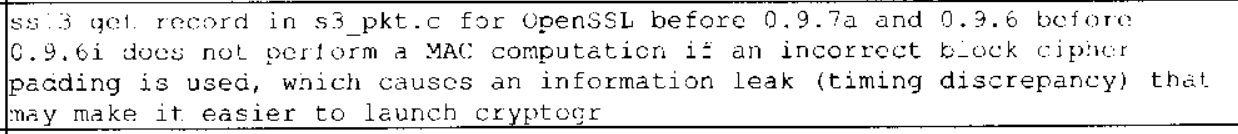 \\
\hline CAN- & $\begin{array}{l}\text { The DEC UDK processing feature in the hanterm (hanterm-xf) terminal emiutar } \\
2 . \mathrm{C} \text { allows attackers to cause a denial of service via a certain character } \\
\text { cocepe sequence that causes the termina. to chtcr a tight loop. }\end{array}$ \\
\hline CAN- & $\begin{array}{l}\text { The iptables ruleset in Gnome-lokkit in Red Hat Linux } 8.0 \text { does not incluae } \\
\text { any ruics in the Forward chain, which could al-ow attackers to bypass } \\
\text { intended decoss restrictions if packet forwardig is erladed. }\end{array}$ \\
\hline $\mathrm{CAN}-$ & 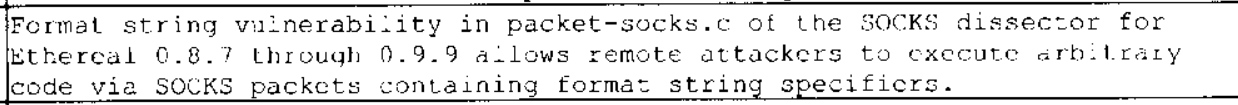 \\
\hline CAN-- & $\begin{array}{l}\text { Buffer overflow ia the sMB/CIFS packet fragment re-assombly code for sMB } \\
\text { daemon (smod) in Saming betore } 2.2 .8 \text { allows remote attacks to execute } \\
\text { arbitrary code. }\end{array}$ \\
\hline CA.Y- & $\begin{array}{l}\text { The code for writing reg fizes in samba before } 2.2 .8 \text { aliows cocal users to } \\
\text { overwrite aroitrary fices via a race condition involving chown. }\end{array}$ \\
\hline$-\cos 7$ & $\begin{array}{l}\text { Buffer ovorflow in libim ibrary (ibIM.d) for National Language support } \\
\text { (NLS) on AIX } 4.3 \text { through } 5.2 \text { al ows loca- users to gain privileges via } \\
\text { scvoral possible attack vectors, including a cong -im argumont to aixterm. }\end{array}$ \\
\hline CAN- & 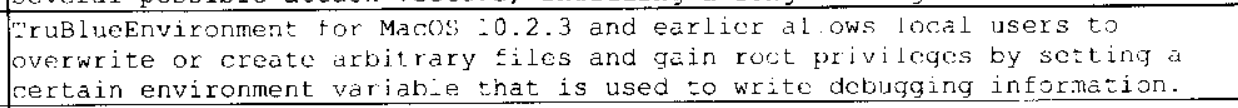 \\
\hline-0093 & 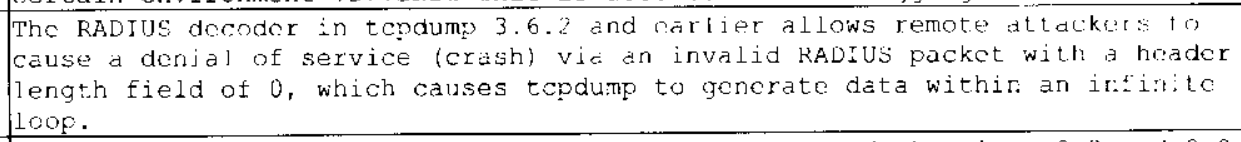 \\
\hline$\overline{C A N}$ & $\begin{array}{l}\text { A patch for mcookie in the utiz-linux package for Mandrake Linux } 8.2 \text { and } 9.0 \\
\text { uscs / dev/urandom instead of /dcv/random, which causes mookin to use an } \\
\text { entropy sourco that is more predictable than expected, which may nake it. } \\
\text { casier for certain types of atta }\end{array}$ \\
\hline CAN $-2003-C 09 b$ & 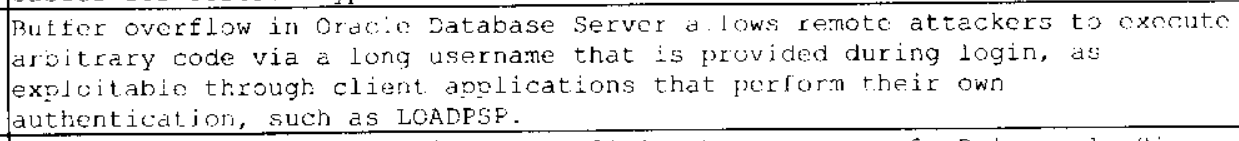 \\
\hline 0096 & 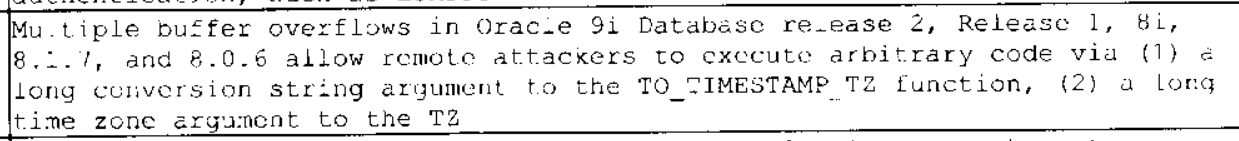 \\
\hline $\mathrm{CA}$ & 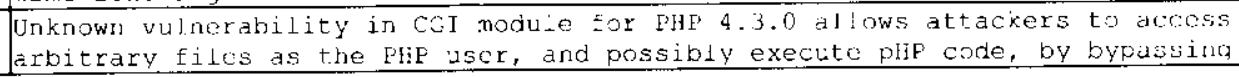 \\
\hline
\end{tabular}




\begin{tabular}{|c|c|}
\hline & $\begin{array}{l}\text { the CGl force redirect settings logi.force redirect or --enable-force-cqi- } \\
\text { rodiroct). }\end{array}$ \\
\hline $\mathrm{CAN}-2 \mathrm{CO} 3-\mathrm{CO} 9 \mathrm{~B}$ & $\begin{array}{l}\text { Inknown vulnerabi:ity in apcupsd betoro } 3.8 .6 \text {, and } 3.10 . x \text { before } 3.1 C .5 \text {, } \\
\text { al lows remote attackers to gain root privi-eges, possibly via format strings } \\
\text { ir. a request to a slave server. }\end{array}$ \\
\hline $\mathrm{CAN}-2 \mathrm{C} 03-\mathrm{CO} 099$ & 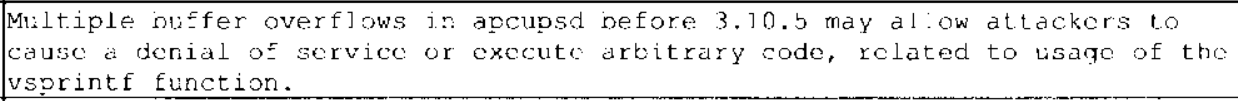 \\
\hline $\mathrm{CAN}-2 \mathrm{CO} 3-\mathrm{C} 100$ & $\begin{array}{l}\text { Cisco Ios } 11.2 . x \text { to } 12.0 . x \text { adows remote attackers to cause a derial of } \\
\text { service and possibly execute commands via a large number of usl'e neighbor } \\
\text { announcements. }\end{array}$ \\
\hline CAN-2C03-C101 & $\begin{array}{l}\text { miniserv.pl in (1) webmin before } 1.070 \text { and (2) Jsermin before } 1 . \text { coc does not } \\
\text { oroperty handle metacharacters such as line feeds and carriage returns } \\
\text { (CRLF) in Base-64 encoded strings during Basic atthentication, which dlows } \\
\text { remote attackers to spoof a ses }\end{array}$ \\
\hline $\mathrm{CAN} \cdot 2 \mathrm{CO} 3 \cdots \mathrm{ClO} 2$ & 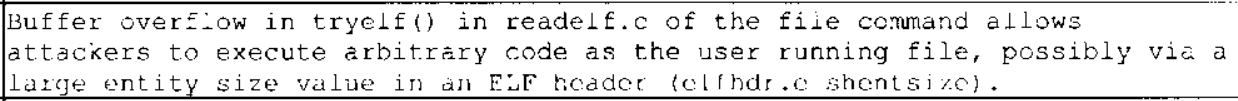 \\
\hline $\mathrm{CAN}-2 \mathrm{CO}$ & $\begin{array}{l}\text { Format string vulnerability in Nokia } 621 \mathrm{C} \text { handsct aliows romote attackcrs to } \\
\text { cause a donial o } 2 \text { service (crash, lockup, or restart) via a Multi-Part vcard } \\
\text { with fields containing a large number of format string soccificrs. }\end{array}$ \\
\hline $\mathrm{CAN}-2 \mathrm{CC}$ & 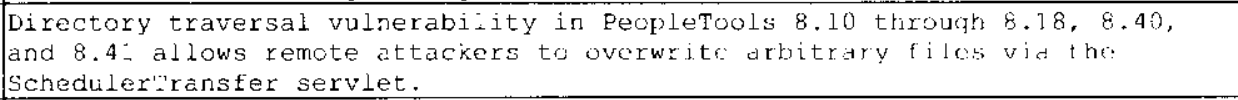 \\
\hline CAN- & 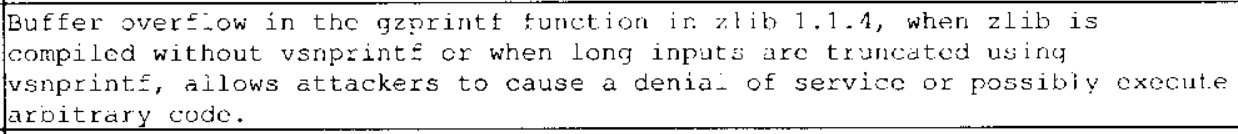 \\
\hline $\mathrm{CAN}-20$ & 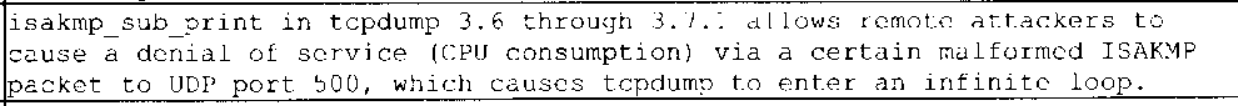 \\
\hline $0=09$ & 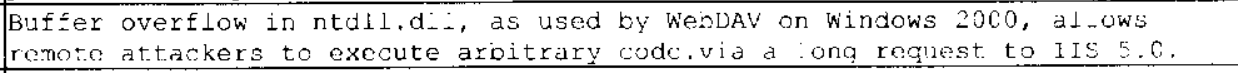 \\
\hline-0.20 & 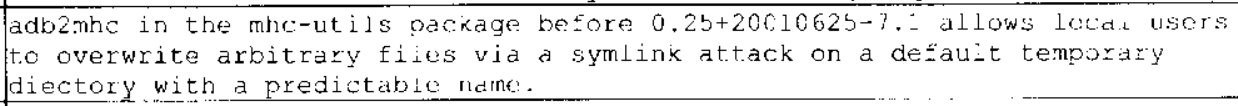 \\
\hline $\mathrm{CAN}$ & 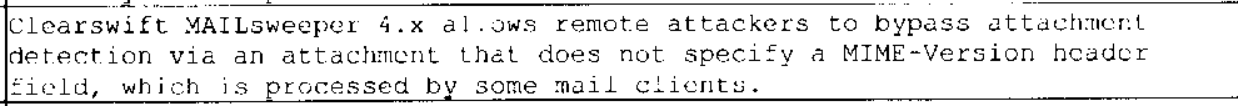 \\
\hline CAN & $\begin{array}{l}\text { Buffer overflow in Notcs sorver before Lotus Notes R4, R5 beforc b.0.1:, and } \\
\text { eariy R6 a:lows remote attackors to execute arbitrary code via a long } \\
\text { distinguishod name (DN) during NotesRPC authontication and an outer ficld } \\
\text { length that is oss than that of } t\end{array}$ \\
\hline 123 & 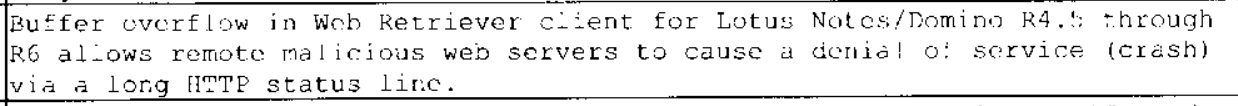 \\
\hline $0.3-0124$ & $\begin{array}{l}\text { man before l.bl a.lows attackers to executo drbitrary code via d malformed } \\
\text { man tile with improper quotes, which causes the my xsprintf Eunction lo } \\
\text { retim a string with the value "unsafe," which is then exccuted as a program } \\
\text { vid d system call. }\end{array}$ \\
\hline 12.5 & $\begin{array}{l}\text { Buffer overflow in the wen interface for soHo Routefinder } 550 \text { berore } \\
\text { firmware } 4.63 \text { allows romole attackers to cause a denia. ot sorvice (roboot) } \\
\text { and execute arbitrary code via a long GET /OPTIONS value. }\end{array}$ \\
\hline 26 & $\begin{array}{l}\text { The weh interface for soHo Routefinder } 550 \text { firmware } 4.63 \text { and earlier, and } \\
\text { pussibiy later versions, has d defaut "admin" docount with a blark } \\
\text { password, which could a-low attackers or the LAN side to conduct } \\
\text { uneuthorized activities. }\end{array}$ \\
\hline C.AN- & 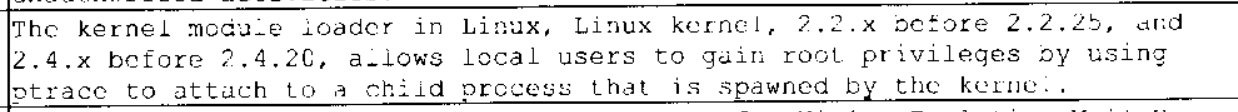 \\
\hline CAN- & 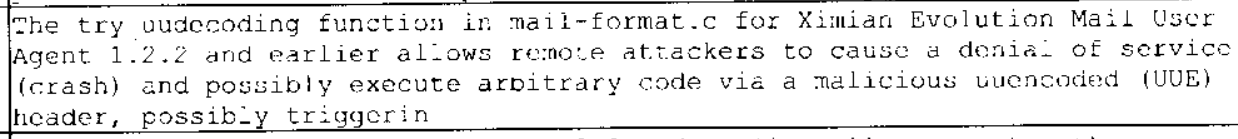 \\
\hline $\mathrm{CAN}-2003-0: 29$ & $\begin{array}{l}\text { Ximian Evolution Mail Jser Agent } 2.2 .2 \text { and earlier a lows remote attacers } \\
\text { to cause a denial of service (memory consumption) via a mai- message that is } \\
\text { uuencoded multific times. }\end{array}$ \\
\hline 30: & The hand o image sunction in maid-format. for formian Evolution Mail Jusr \\
\hline
\end{tabular}




\begin{tabular}{|c|c|}
\hline & $\begin{array}{l}\text { Agent } 3.2 .2 \text { and carlicr does not properly escape HML characters, which } \\
\text { al-ows remote attackers inject droitrary data and HTML via a MIME Content-TI) } \\
\text { header in a MLME-encoded inage. }\end{array}$ \\
\hline CAN-2003-0131 & 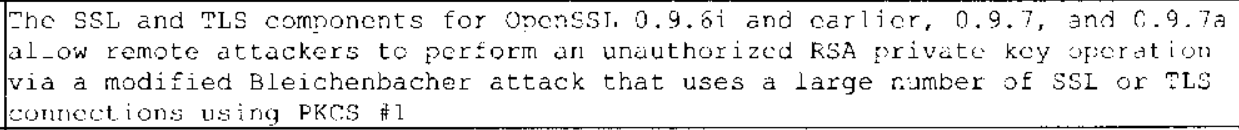 \\
\hline$\therefore A N-2003-0137$ & $\begin{array}{l}\text { SNMF daemon in the DX2CO based network element for Nokia Serving CPRS } \\
\text { support node (SGSN) allows remote attackers to read SNMP options viā } \\
\text { arbitrary community strings. }\end{array}$ \\
\hline CAN-2003-0.38 & $\begin{array}{l}\text { Version } 4 \text { of the Kerberos protoco- (krb4) aldows an attacker to impersonate } \\
\text { any principal in a realm va a chosen-plaintext attack. }\end{array}$ \\
\hline CAN-200.3-0.39 & $\begin{array}{l}\text { Certain weaknesses in the implementation of version } 4 \text { of the kerberos } \\
\text { protocol (krb4) in the krbs distribltion, when triple-DEs keys are used to } \\
\text { key krod sarvices, aliow an attacker to create kro4 tickets for unauthorized } \\
\text { principals using a cut-and-paste }\end{array}$ \\
\hline $\mathrm{CAN}-2003-0.40$ & 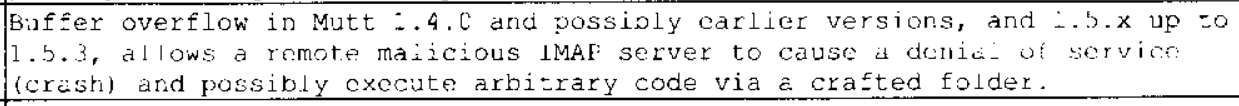 \\
\hline CAN-2003-0.43 & 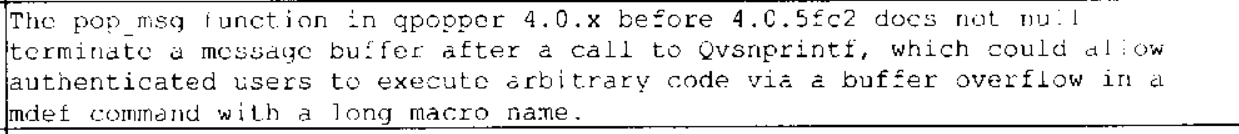 \\
\hline CAN-20C3-0144 & $\begin{array}{l}\text { Buffer overtlow in the eprm command in the lprold parkage on suse i.l } \\
\text { through } 7.3 \text {, and possibiy other distributions, allows oca: uscrs to gair. } \\
\text { root privileges. }\end{array}$ \\
\hline CAN-2003-0145 & $\begin{array}{l}\text { Unknown vulnerability in tcpdump before } 3.7 .2 \text { related to an inability to } \\
\text { "Handle unknown RADIJs attributes properly," ailows remote attackers to } \\
\text { cause a denia- of service (infinite oop), a difterent vulnerability than } \\
\text { CAN-2003-0093. }\end{array}$ \\
\hline CA.N & 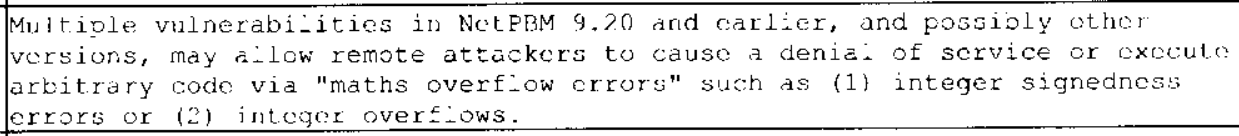 \\
\hline $\mathrm{CAN}-2 \mathrm{CO} 3-\mathrm{Cl} 47$ & $\begin{array}{l}\text { OpcnSSL does not use RSA b:inding by dofaut, which allows local and remete } \\
\text { attackers to ont.rin the scrver's private kcy by determining factors using } \\
\text { timing differences on (1) the number of extra reductions during Montgonery } \\
\text { reduction, and (2) the use of }\end{array}$ \\
\hline CAN-200.3-0.50 & 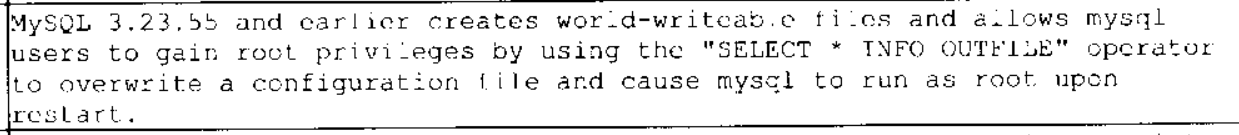 \\
\hline CAN-20C3-315i & 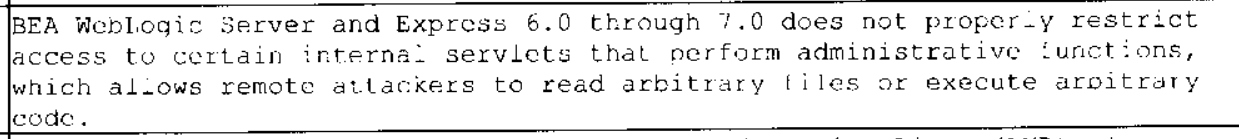 \\
\hline CAN-2003-0156 & $\begin{array}{l}\text { Diroctory traversid vilnerability in Cross-Referencing Linux (LXR) al ows } \\
\text { remote attackers to read arbitrary files via } . \text { (dot dot) sequences in tho } v \\
\text { parameter. }\end{array}$ \\
\hline
\end{tabular}




\section{Anexo II - Código OWL da ontologia implementada}

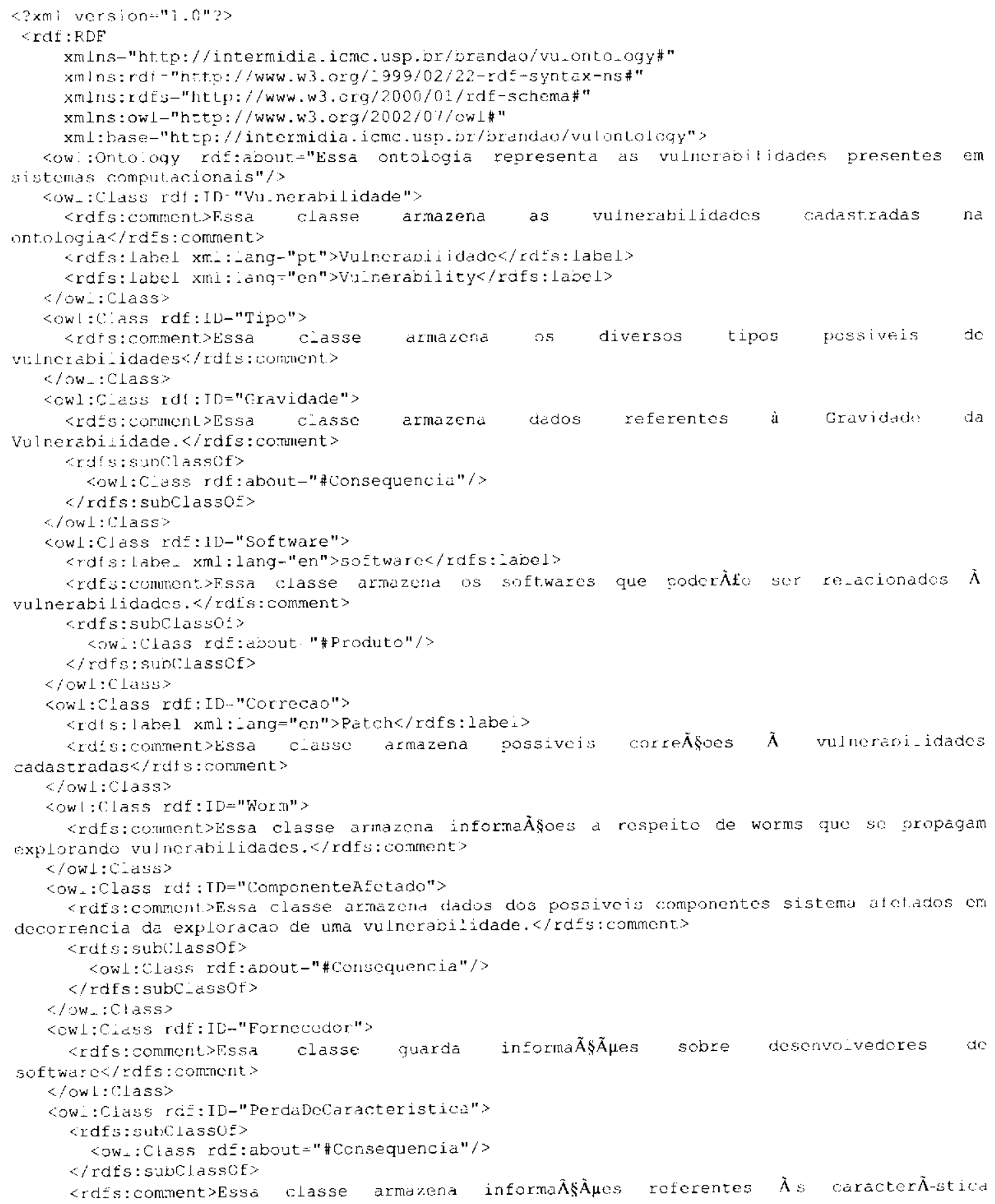




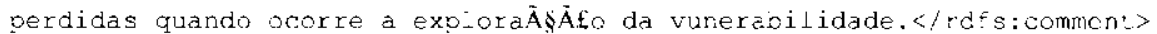

<low: : : a ass

Low 1 :Cases rdf:Is-"Hardware">

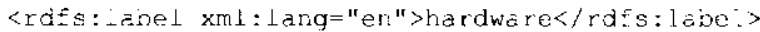

<ris:comment>Essa classe armazena os $\tilde{\Lambda}$-tens de hardwarc que poder $\tilde{A}$ e scr associados $\hat{\Lambda}$ vilnorabi idados.</rdfs:comment>

$\langle r d \in s: s u i c l a s s o f\rangle$

〈owl: Class rdf: about-"\#Produto"/>

$\langle/$ rdfs:subC-assOf $>$

$<$ low: : CLass

Cow:C_ess rdf:ID-"Prodito">

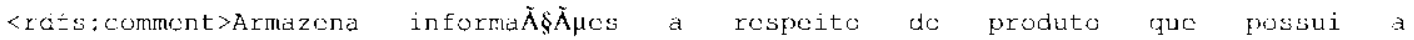

vilnerabi:idadec/rdfs:comment;

<rdfs: Labe $\perp \mathrm{xm} \perp:$ lang-"en">Product</rdfs: Labe_>

$\langle$ /OW : CLass>

<owl:C-ass rdf:ID-"Abrangencia">

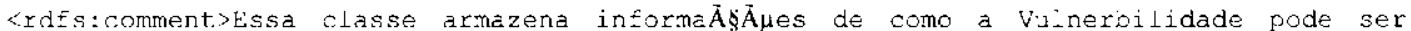

exporada. irdts:comment $>$

$\langle$ /OW : Class $>$

〈owl:C-ass rdf:iD-"Consequencia">

<rdis: label xml : lang "cn">Consequences/rdfs:-abel>

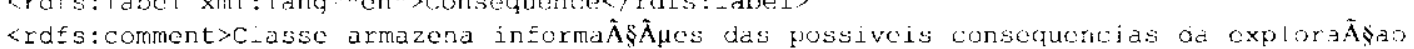

de uma vilnerabi-idade. Ámo especializada em algumas subciases.〈/rdfs:comment>

<low: : Class>

<owl:objectProperty rdf:ID="possuizipo">

“rdfs:domain rdf: resource-"\#uinerabiiidade"/>

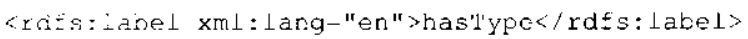

$\langle$ rdis: range rdt: resource="\#ipo"/>

$\left\langle/ O W_{\perp}\right.$ : ObjoctPrciperty $\rangle$

<cwl:CbjectProperty rdf: iD-"comcrcial i zâFroduto">

<rdfs:range rdf:resolirce-"\#Produto"/>

<rdfs:domain rdf:resource-"\#Frnecedor"/>

〈ow : inverseot>

<ow 1 : Object Property rdt:about_"\#possui Eornecedor"/>

$</ O w 1$ : inverseuf $>$

$\langle/$ ow l :Opject.Property>

<ow 1:Objoct froperty rdt: ID-"possuiAbrangencia">

<rdfs:range rdf : resource " \#Abrangencia"/>

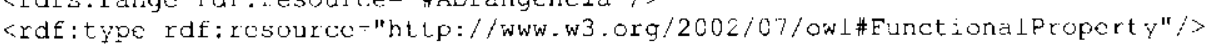

<rdfs:domain rdf:resource-"\#Vulnerabi:idade" />

$\langle$ owl: Oojociproperty>

<ow: :objectproperty $x$ df: ID="cxpioradoforworm">

<rdfs:domain rdf: resource-" \#VuLnerabi_idade"/>

<rdfs:range rdf:resource-"\#Worm"/>

$\left\langle W_{-}\right.$: inversoof $>$

¿owi:objectepropert.y rdf:about-"\#exploravulneravil idade"/>

$</$ owl: inverscof $>$

<dfs:comment>Rodaciona a Vunerabiaidade aus worms que cla oxpiora</rdzs:comment>

$</$ ow : objectproperty>

< ow $1: 00$ ject Property rdf: ID="desenvolvecorrecao">

<owi: inversect>

<owl: Oujechproperty rdË:about="\#possui Fornecedorcorrecac" $\mid>$

<low: inversco:s

<rdfs:domain rdt: resource-"\#liornecedor"/>

<rdfs:range rdf:resource="\#Correcao"/>

</OWL:Object Property>

〈ow: ObjectFroperty rdf:ID-"possuiconscquencia">

〈rdfs: domain rdf: resource="\#Vulnerabilidade"/>

<rdfs:range rdf: rcuourco" \#consequencia"/>

$</ O w 1$ : Objoct:Property $>$

<ow: : ObjectProperty raf: ID="possuiPreRequisito">

sowl : inverseot>

<ow : objectPropcrty rdt:about-"\#preRequisitopara"/>

$\langle/$ ow : : inversouf $>$

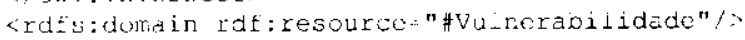

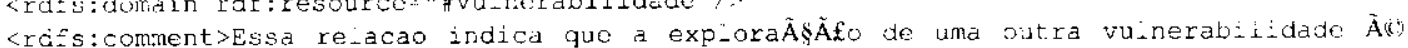

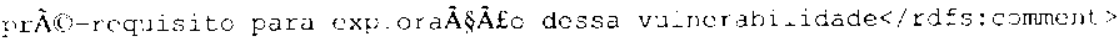

</ow1: objectproperty $>$

<Owl: Object.Froperty rdf: $D=$ "possui Fornecedor">

<owl: inversoot raf: resolurce="\#comorriaizzal'rodito"/s

<rdis:dchatin rdfiregource="\#produto"/> 
$</$ ow l : OD jectFroperty $>$

Low! : Objoct.fropert.y rif: ID "ocorretm">

«rdfs:domain rd: : resource="\#vulnerabi_idadc"/>

〈ow: inverseof>

<ow: : Ob ject.Froperty rdf:abolt.-"\#pessuivuinerabiliaade"/>

«ow

<rdfs: range rdf: resource-"\#Produt.s"/>

</ow 1 : objectiroperty

<ow : Objectfroperty rdf: ID-"possuivulnerabi:idade">

$\langle$ rdfs:domain rdf: rescurce=" \#roduto"/>

vul nerbi l idades</rdfs:comment;

<owl : inverseof rdf:resource-"\#ocorreEm"/>

<rdfs:range rdf:rosource..."\#vulnerabilidade"/>

$\langle/$ ow: ObjectProperty $\rangle$

<owl ovject Property rdl : TD-"possuitornccedorcorrecao">

$<$ rdfstrange rdf:resource="\#Fornocodor" $/>$

cowl: inversedf rdf:resource="\#desenvo:vccorrecao"/;

irdes:comment>Relaciona cutr a empresa ou entidade que disponibilizm

cozreñ $\hat{\Lambda}$ to</rdfs:comment>

<rdfs:-abel xnl: Lang-"cn">hasvencor</rdfs: label>

<rdfs:domair rdf: resourco=" \#Curecao"/>

$</$ ow $1: 0 \mathrm{O} \div$ octProperty $\rangle$

sowl:object Frowerty rdi: ID" "possuicorrecao">

<rdfs:range rdf:rescurce="\#Correcao"/>

<rdfs:domein rdf:resource-"\#uLnerabilidade"/>

〈low : ODjectproperty>

<ow 1 :objectProperty rd:: ID= "vreRequisitopara">

<rdfs:rarige rdf:resource-"\#佂nerabi_idade"/>

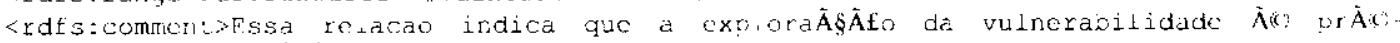

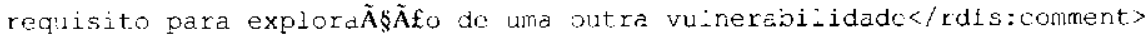

<ow-: inverseof rdE: rcsource "\#oosstiprekequisito"/>

<rdfs:domain rdf:resource="\#VuLnerabilidade"/>

¿lowl:objectProperty

<ow : Oojectiroperty rdt: ID-" oxpLoravu-nerabi-idade">

$<$ rdfs:range ruf: rcsource="\#vulnerabilidado" $/>$

$\langle$ rdEs:domain rdf: resolirce. "\#Wrm"/>

〈rdis:comment>kelaciona o worm $\tilde{A}$ vu_nerabilidade que elo expiora. $<$ rdfs:commont>

<owl:inverseof rdf:resource="\#exploradoPorworm"/>

$\langle/ O w \perp: 0 b$ iect Proper ly.

<ow 1 : DatatypeProperty rd: ID="contato_emai:">

<rdfs:range rdf:resourcc="http://www.w3.org/2c0:/XMLSchora\#string"/>

$\langle$ rdt : domain rdf: rosource="\#Forncecdor" $/>$

$<$ /owl: DatatypeProperty>

Low: : Dätatypeproperty rdI: ID-"zeferencia">

<rdts:domain>

$\langle 0$ i:Class

<owl:urionof rdf:parsepype="Colicotion">

<owl:Class rof:about-"\#VuLnerabilidede"/>

<ow l: (:lass rdE:about=" \#Worm"/>

〈low: : unionof>

$\left\langle/ O W_{-}:\right.$: $Q$ Lass

$\ll$ rdfs:domain>

<xdfs:range rdf:roscurce-"nttp://www.w3.org/2001/XMLSchemisit.eing"/:

<rdfs:labe: xmL: I arg="en">reEerencc</rdfs: Label>

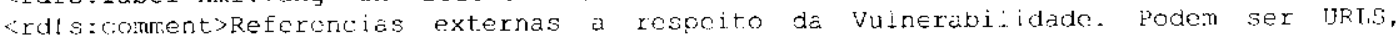
rumero de bo-otins CERT, entre outros. $</$ rdes:comment.>

</ow l: DatatypeProperty>

<ow i Datatypeproperty rde: ID="nomeoriginal">

$<$ rdfs:range rdf:resource-"http://www.w3.org/2001/XMI.schema\#string"/>

〈rdfs:comment>Guarda o nome do produto (sem a concatenacao con a verseo)</rdfs:commenty

$\langle$ rdEs: dona in rdf: resource=" \#roduto"/>

<low 1 : DatatypeProperty>

<ow : DatatypcProporty odr:ID "website"

<rdts:range rdf:resource-"h11.p://www.w3.org/2001/XMLschemil string"/>

<rdfs: domain rdf: rcsource="\#Forneccdor" $/>$

$\langle/$ / $1:$ Dal at ypefroperty

Low : Datatypo'roperty rdt: ID=" "descricap">

$\langle\mathrm{ris}$ : domain>

rowl:cisas

<owl:uniondf rdi:parselype="Coliection"> 


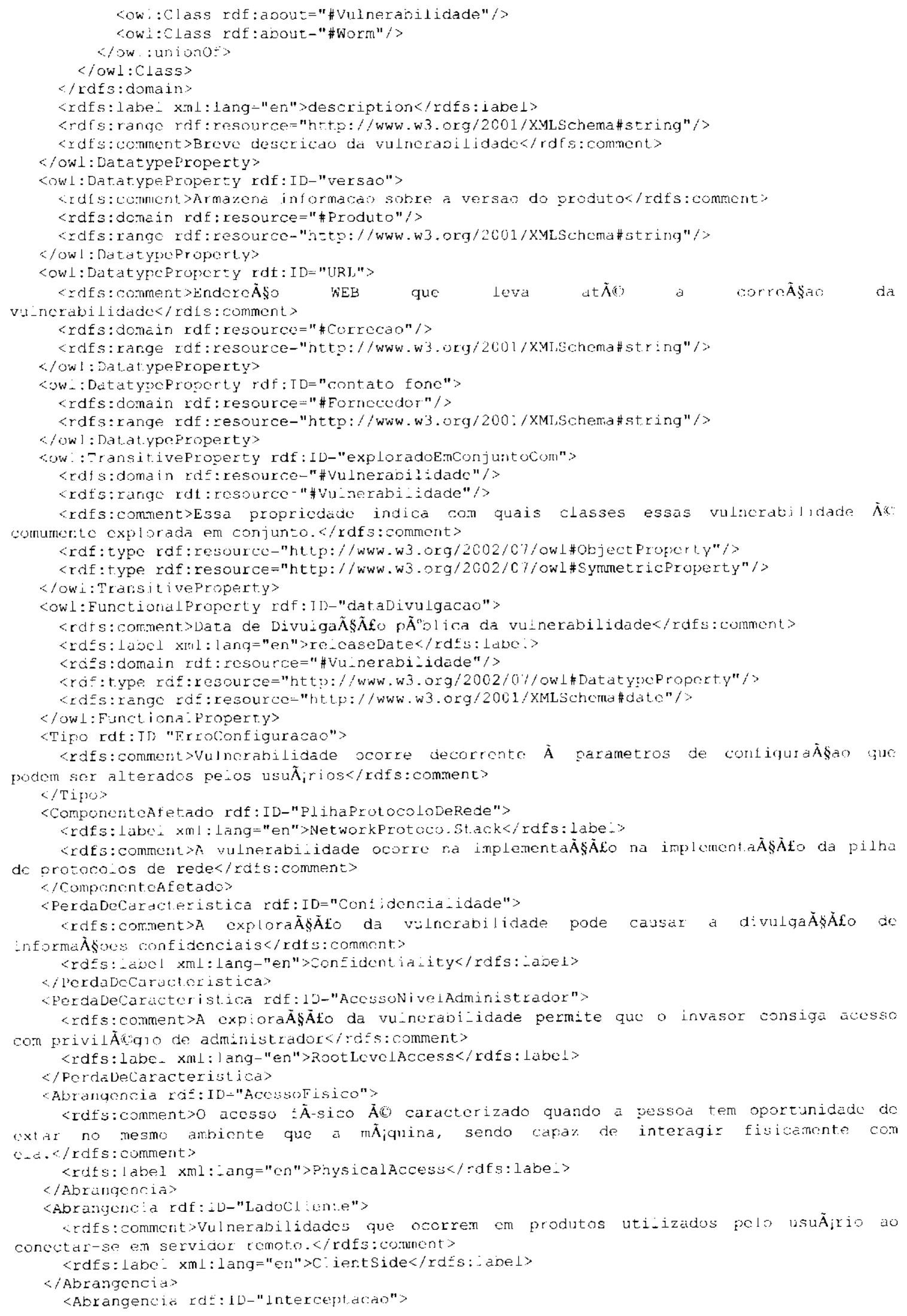




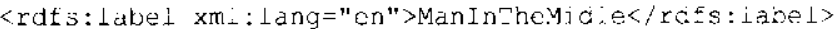

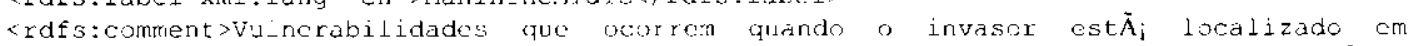
detcrminado ponto da conexÃfo em que pode interceptar e controlar a troca do informañşa entre a vÃ-tima e o servidor acossaco.<irdfs:coment>

«/Abrangercià

〈Ảrangencia rdf: ID-"Loca:">

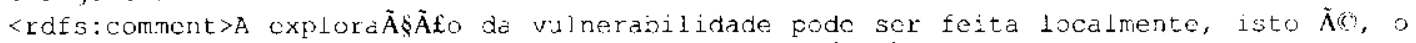
invasor precisa necessariamente possuir conta de dccsso $\tilde{A}$ nÁ jquina.</rdfs:comment»

$\langle$ rdfs: labcl xm. : lang-"en">Loca:</rdEs:labe:>

$</$ Abrangencias

<ComponenteAfetado rdf:ID-"Itemiardwarc")

$\langle r d f s:-a b e \perp$ xml : lar:g-"cn">Hardware</rdEs:labe:>

crdfs:comment>A vulnerabii.idade ocorre em in À-tem de fardware</ralsicomrent>

$\langle/$ ComponenteAfetacio $\rangle$

<Comporontenfetado rdf: ID-"ModuloCriptogra:ia"?

<rdfs:comment>A vutnorabilicade ocorre em mÁduio de criptourafia</rdfs:comment»

$<$ rdfs: abe: xml: lang-"en">EncryptionModu $e</$ rdfs: 1 abel>

$<$ Compononichint.ado?

CGravidade rdf:ID="Alta"

<rdfs: Labe: $x \mathrm{x} \perp$ : Lang="en">High</rdfs:label>

〈Gravidado>

SMino rdt:ID-"ErrolratamentoExcecoes">

<rdfs:comment>VuLncrailidado que ocorrem devido $\tilde{\Lambda}$ tormä como o sistema 1 ida com us

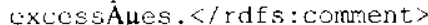

<rdfs: iabel xm-: ang="en">ExceptionalConditionError</rdfs: iabel>

$</ \mathrm{T}$ ino $\rangle$

$<$ Tipo rdf: ID-"Erroirojeto">

<rdf : label xmL: iang-"en">DesignFrror</rdfs: :abe:>

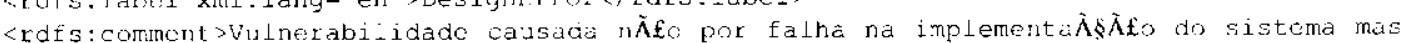
sim em seu design. </rdts:comment;

$\langle/$ Tipo>

$\langle$ Tipo rdf: T D-"Bufferoverf Low" $>$

<CompononteAfetado rdf:ID="Sistcmaoperaciona $\perp ">$

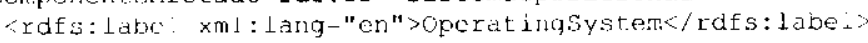

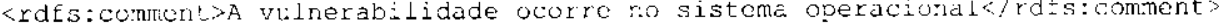

ComponenteA Éetado>

ComponenteAfetado raf: ID-"ADl icacoservidora">

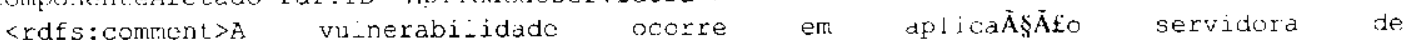

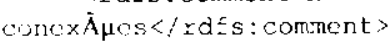

$<$ rdfs: $\perp$ abcl $x m \perp$ : ang-"en" >ServerAplication</rdfs: $\perp$ due $:$

$<$ ComponenteAfetado>

COravidade rdf:ID-"Media" >

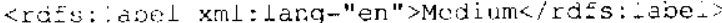

$<$ Gravidade

Tipo rdf:ID-"Condicaovedisputa">

<rdfs:comment>Vilnorabilidades desse tipo ocorrem devido $\hat{A}$ falta de atumiciciade

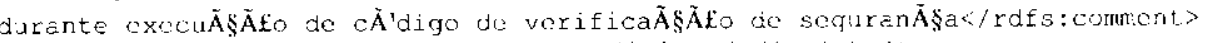

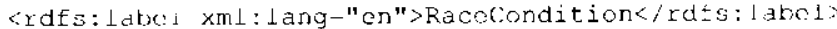

$</$ Tipo>

:l'ipo ras:tD."Frrocontexto":

<rdfs:comment>Vunerabiidade que ocorre devido $\tilde{A}$ determinado estado ospecial do

sisteria $\langle/$ rdfs: comment $>$

<rd:s: Labe 1 xmL:Lang. "en">EnviromentFrror</rdfs: Label>

$\langle/$ Tipo>

Componenloftetado rdf:ID-"Ap-icacaonaoservidora">

<rdfs:coment>ViLnerabilidado ocorre em aplicaÃs̆âfo nÃfo servidora de

conex ̃̃Hes</rdfs: comment>

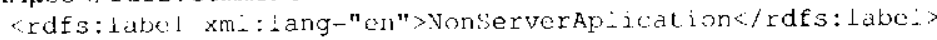

$<$ Comporentertetado>

<erdibocaracteristica rdf: ID-"Intogridade">

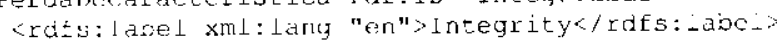

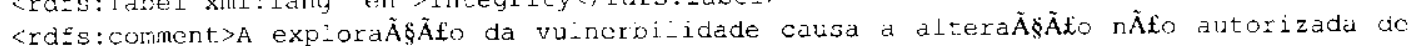

informa $\bar{A} s \hat{A} \mu e s</$ rdt $s:$ commenty

$<$ PerdaDecaracteristicas

<ComponenteAfetado rdf: I $\mathrm{D}=$ "Protocolocomidnicacao">

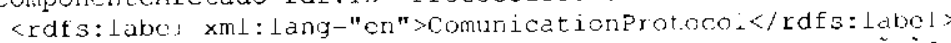

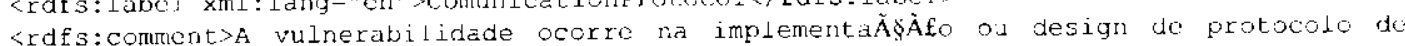

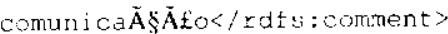

$\varangle /$ Componenteafetado $>$ 
〈PerdaDecaracteristica rdś:ID="Disponioi:idade">

〈rdfulabel $\mathrm{xm}:$ : lang-"en">Availabi-ity</rdfs: ianel>

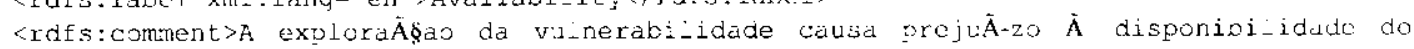
sistema</rdf $a$ : comment?

$</$ PerdaDecaracteristica>

<PerdaDeCaracteristica rdf: ID-"Acessonive:Usuario">

$<$ rdfs: label $\mathrm{kml}$ : lang="en" >UsortevelAccess</xdfs: label>

« rdfs:coment>A expioraÃßÃfo da vulnercilidade permite que o invasor consiga acosso do sistema com privil⿵人ogio de usǘrio comum.</rdfsicomment>

¿/PordaDecaracteristica>

$\langle$ Tipo rdi : in="Crossitescripting"/>

<Abrangencià rdf:ID-"Remoto">

<rdfs: iabe- xml: lang="en">Remote<irdfs:-abe>

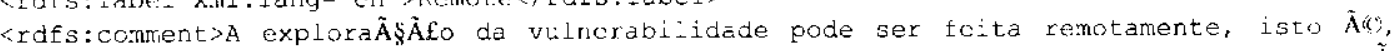

pode ser feita por micio dä rede, ser. que o irvasor tenha conta de acessc ã

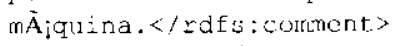

〈Abrangencia $>$

〈Tipo rdf:ID. "FrrovialidacaoAccsso">

$<$ rdfs: label xril: an:" on">AccessvaidationError</rdfs: _abol>

<rdfs:comment>inerabi-idade decorrente $\tilde{A}$ falnas no mecanismo de controle de dessbou/rdFs:comment>

$\langle/$ Tipo>

$<$ Tipo rdf:: i-"SQLInjection"/>

<Cravidade rdf: IL-"Baixa">

<rdfs: iabe: $\mathrm{xnl}$ : lang-"en">Low</rdfs: label>

$\langle/$ Gravidade $>$

$\langle/$ rdf : RLE $>$ 